\title{
Modularização da Coleta de Lixo na Máquina Virtual de Pesquisa Jikes.
}

\author{
Rosianni de Oliveira Cruz
}

DISSERTAÇÃO DE MESTRADO APRESENTADA AO INSTITUר $\cup$ DE MATEMÁTICA E ESTATÍSTICA DA UNIVERSIDADE DE SÃO PAULO

Curso: Mestrado em Ciência da Computação Área de Concentração: Linguagens de Programação

Orientador: Prof. Dr. Alan Mitchell Dủrham

São Paulo, Agosto de 2004 


\section{Resumo}

Este trabalho apresenta o projeto e a implementação de uma interface genérica de coleta de lixo no sistema de execução de uma linguagem de programação para avaliação de desempenho. A interface genérica de coleta de lixo proposta é composta por duas interfaces: a interface do gerenciador de memória e a interface da linguagem de programação. A primeira interface permite ao sistema de execução da linguagem de programação interagir com o gerenciador de memória de maneira independente do algoritmo de coleta de lixo utilizado. Já a segunda, é necessária para que o coletor de lixo delegue à linguagem de programação a implementação de rotinas que envolvem o conhecimento prévio do formato das objetos na memória.

Com uma interface genérica de coleta de lixo, vários algoritmos de liberação automática de memória podem ser facilmente acoplados ao sistema de execução de uma linguagem de programação. Além disso, alterações de um algoritmo de coleta de lixo não seriam necessárias para que diferentes sistemas de execução de linguagens de programação o utilizassem. Desta forma, uma interface genérica disponibiliza uma independência entre o coletor de lixo e a linguagem de programação. 


\section{Sumário}

1 Introdução $\quad 7$

2 Coleta de Lixo 11

2.1 Termos e Definições . . . . . . . . . . . . . . . . . . . . . . 11

2.2 Tipos de Algoritmos de Coleta de Lixo . . . . . . . . . . . . . . . . . . . 14

2.3 Algoritmos de Coleta de Lixo . . . . . . . . . . . . . . . . . . . . . . . 19

2.3.1 Contagem de referência . . . . . . . . . . . . . . . . . . . 19

2.3.2 Marcar-e-Varrer . . . . . . . . . . . . . . . . . . . . 21

2.3.3 Marcar-e-Compactar . . . . . . . . . . . . . . . . . . 22

2.3.4 Semi-espaço não incremental . . . . . . . . . . . . . . . . . . . . 24

2.3.5 Semi-espaço Incremental de Baker . . . . . . . . . . . . . . . . . . . 27

2.3.6 Gerações de semi-espaços . . . . . . . . . . . . . . . . . . . . 30

3 Interface Genérica de Coleta de Lixo 33

3.1 Interação entre a Linguagem de Programação e o Coletor de Lixo . . . . . . . . 34

3.2 Trabalhos relacionados . . . . . . . . . . . . . . . . . . 38

3.2 .1 Abordagens completas . . . . . . . . . . . . . . . . 38

3.2 .2 Abordagens Parciais . . . . . . . . . . . . . . . . . . . 44

4 Implementação $\quad 47$

4.1 Jikes RVM . . . . . . . . . . . . . . . . . . . . . . . . . . 48

4.1 .1 Jikes RVM escrita em Java . . . . . . . . . . . . . . . . . . . 48

4.1 .2 Compiladores . . . . . . . . . . . . . . . . . 50

4.1 .3 Modelo dos Objetos . . . . . . . . . . . . . . . 51 
4.1 .4 Pilhas de Execução . . . . . . . . . . . . . . . . . . . . . . 53

4.1.5 Gerenciamento de Memória . . . . . . . . . . . . . . . . 55

4.2 Situações não previstas nas interfaces estudadas . . . . . . . . . . . . 58

4.2 .1 Formato de uma referência para um objeto na heap . . . . . . . . . . 58

4.2 .2 Modelos de objetos distintos na heap . . . . . . . . . . . . . . . . 59

4.2 .3 Objetos copiados mudam de tamanho . . . . . . . . . . . . . . . 59

4.2 .4 Objetos com finalização . . . . . . . . . . . . . . . . 60

4.2.5 Chamadas da biblioteca padrão Java para o gerenciador de memória. . 60

4.2.6 Forte ligação entre o Gerenciador de Memória e os outros subsistemas da Jikes RVM . . . . . . . . . . . . . . . . . . . . . 6 60

4.3 Definição da Interface Genérica . . . . . . . . . . . . . . . . . . . . 61

4.3.1 Interface da Linguagem de Programação . . . . . . . . . . . . . . . . 62

4.3.2 Interface do Gerenciador de Memória . . . . . . . . . . . . . . . . 65

4.4 Implementação da Interface Genérica na Jikes RVM . . . . . . . . . . . . . . 69

4.4 .1 Construção da imagem de boot . . . . . . . . . . . . . . . . 71

4.4 .2 Início da execução da máquina virtual . . . . . . . . . . . . . . 71

4.4 .3 Barreira de leitura e de escrita . . . . . . . . . . . . . . 72

4.4.4 Alocação de objetos na heap . . . . . . . . . . . . . . . . . . 72

4.4.5 Execução do coletor de lixo . . . . . . . . . . . . . . . . . 73

4.4.6 Tratamento de objetos que possuem o método finalize . . . . . . . . 75

4.4 .7 Liberação de objetos . . . . . . . . . . . . . . . . . . . . . . . 76

4.4 .8 Informações sobre o gerenciamento de memória . . . . . . . . . . . . 77

4.4.9 Espaços de memória associadas a cada processador . . . . . . . . . . 77

4.4 .10 Final da execução da máquina virtual . . . . . . . . . . . . . . . . 77

4.5 Implementação dos coletores de lixo . . . . . . . . . . . . . . . . . . . 78

5 Avaliação de Resultados $\quad 85$

5.0 .1 Análise do código . . . . . . . . . . . . . . . . 85

5.0 .2 Análise de desempenho . . . . . . . . . . . . . 86

$\begin{array}{llr}6 & \text { Conclusão } & 89\end{array}$ 


\section{Capítulo 1}

\section{Introdução}

O gerenciamento manual de memória exige do programador o controle rigoroso sobre o código de sua aplicação para evitar desperdício ou liberação indevida de memória. Se a memória não é liberada, uma aplicação pode deixar de executar por falta de memória. Já a liberação indevida de memória pode provocar erros de execução inesperados e difíceis de serem detectados. Sistemas maiores e mais complexos são mais sujeitos a erros de execução relacionados à manipulação incorreta da memória pelo programador.

Vários algoritmos de coleta de lixo foram propostos para simplificar a construção de sistemas. Algoritmos de coleta de lixo são responsáveis pela liberação do espaço de memória que não é mais referenciado por uma aplicação, sem a ação explícita do programador. Entretanto, para o programador se beneficiar da coleta de lixo é necessário que ela integre o sistema de execução da linguagem de programação.

A implementação de um coletor de lixo é dependente da implementação da linguagem de programação. Para implementar o coletor é necessário disponibilizar informações, como por exemplo, o formato da pilha de execução da linguagem de programação. Além disso, para a inclusão do coletor de lixo, alterações na implementação da linguagem de programação podem ser indispensáveis, se antes não era necessário conhecer as referências contidas na pilha de execução, com o coletor, a implementação da linguagem deve preocupar-se em encontrá-las, por exemplo.

Para pesquisas sobre o desempenho de diferentes implementações de coletores de lixo, um sistema de execução de linguagem de programação que permitisse executar diferentes 
coletores de lixo sem a necessidade de que o pesquisador conhecesse a implementação dessa linguagem seria muito proveitoso. Entretanto, um dos problemas da experimentação de coletores de lixo é que a maioria dos sistemas de execução das linguagem de programação não foram projetados para executar diferentes algoritmos de coleta de lixo.

Tanto para facilitar as pesquisas em coleta de lixo como a adição de um coletor em um sistema de execução de uma linguagem de programação, uma interface genérica de coleta de lixo poderia ser utilizada. Através da interface genérica de coleta de lixo, vários algoritmos de coleta de lixo podem ser inseridos no sistema de execução da linguagem de programação sem que seja necessário conhecer a implementação dessa linguagem. Outra vantagem dessa interface é que a mesma implementação de um algoritmo de coleta de lixo pode ser utilizada em diferentes sistemas de execução de linguagens de programação. Para que essas vantagens sejam possíveis, tanto o coletor de lixo como a linguagem de programação devem implementar uma das interfaces que compõem essa interface genérica: a interface do gerenciador de memória e a interface da linguagem de programação. A primeira interface é implementada pelo gerenciador de memória e utilizada pelo sistema de execução da linguagem de programação. A segunda interface é implementada pelo desenvolvedor da linguagem de programação e utilizada pelo coletor de lixo. Através da interface da linguagem de programação, o implementador do coletor delega à linguagem de programação a implementação das rotinas específicas ao ambiente de execução da linguagem. Com a interface do gerenciador de memória, a linguagem de programação utiliza um conjunto de rotinas padrão para interação com o coletor de lixo.

Este trabalho apresenta o projeto e a implementação de uma interface genérica de coleta de lixo no sistema de execução de uma linguagem de programação para avaliação de desempenho. A interface genérica de coleta de lixo apresentada por Durham [Dur97] é a base de nosso trabalho. O artigo de Uchiyama et al [YUS] também descreve uma interface genérica muito semelhante com a proposta por Durham. Algumas das rotinas de Uchiyama et al não existentes na interface de Durham foram incluídas em nossa interface genérica.

A Máquina Virtual de Pesquisa Jikes [RVM], conhecida como Jikes RVM, foi escolhida para a implementação de nossa interface genérica. O Jikes RVM é propício para nossa implementação, pois: seu código fonte escrito principalmente em java é aberto; foi implementada por uma empresa de respaldo, a IBM; foi construída com o propósito de ser útil a pesquisas 
principalmente em gerenciamento de memória.

Este trabalho está organizado da seguinte forma: o capítulo dois descreve alguns algoritmos de coleta de lixo e apresenta alguns termos e definições necessários à compreensão dos mesmos; o capítulo três discorre sobre a interação existente entre o sistema de execução da linguagem de programação e o coletor de lixo, além de abordar trabalhos relacionados à independência entre essas partes através de uma interface genérica de coleta de lixo; o capítulo quatro descreve a máquina virtual Jikes RVM e relata situações não previstas nas interfaces anteriores, em seguida, apresenta a n̂̀ossa interface genérica de coleta de lixo e sua implementação na Jikes RVM; o capítulo cinco mostra os resultados dos testes realizados para avaliar o desempenho da Jikes RVM e do gerenciamento de memória com a inclusão de nossa interface e o último capítulo é a conclusão de nosso trabalho. 


\section{Capítulo 2}

\section{Coleta de Lixo}

A liberação automática de memória, também conhecida como coleta de lixo, é responsável pela liberação de memória dinamicamente alocada que não é mais referenciada por uma aplicação, sem a participação direta do programador. Assim, não é necessário que o programador insira códigos que requeiram a liberação de uma área de memória, como a rotina free de C.

Neste capítulo apresentaremos alguns termos e definições necessários a compreensão de coleta de lixo. Além disso, mostraremos algumas classificações de algoritmos de coleta de lixo. No final, discorreremos sobre alguns algoritmos de coleta de lixo e seus detalhes de funcionamento.

\subsection{Termos e Definições}

A região da memória onde os dados são alocados dinamicamente é chamada de heap. O gerenciamento de memória da heap pode ser manual ou automático. O primeiro é realizado explicitamente como parte do programa em execução. O último é realizado como parte do sistema em execução da linguagem de programação.

As estruturas alocadas na heap chamaremos de células ${ }^{1}$. Uma célula contém campos que armazenam dados definidos pelo programador e pelo sistema em execução da linguagem. O formato da célula engloba a disposição desses campos e é definido pelo implementador da

\footnotetext{
${ }^{1} \mathrm{O}$ termo célula é utilizado no artigo de [AR98]. Em linguagens orientadas a objetos, uma célula é um objeto.
} 
linguagem.

Uma célula é formada por um ou mais blocos de memória. Cada bloco é uma parte contígua da heap. Na heap podemos identificar os blocos retidos e os blocos livres. Os blocos retidos são os blocos que não podem ser utilizados para atender as requisições de alocação porque já estão alocados formando uma célula. Já os blocos livres são os blocos da heap que não estão correntemente alocados. Quando blocos retidos tornam-se blocos livres após a liberação de memória automática, dizemos que as células foram liberadas pelo coletor e recuperadas para serem reutilizadas em novas alocações de memória.

Distinguimos referências de ponteiros como apresentado no trabalho de Durham[Dur97]. Um ponteiro representa um endereço de memória qualquer. Já uma referência é um manipulador inicial para uma instância de um tipo de dado. Uma referência pode conter um ponteiro para a palavra inicial dessa instância na heap. Outra possibilidade é a referência conter a própria instância do tipo de dado, como por exemplo, pequenos inteiros que possam ser representados no campo destinado à referência. Estas referências são chamadas de referências imediatas. Ponteiros são utilizados para designar os blocos constituintes de uma célula. Veja a figura 2.1, extraída do livro [GJ87], ilustra a representação de uma string de tamanho variável na qual uma referência contém um ponteiro para a palavra inicial deste tipo de dado e outros ponteiros para partes constituintes da string localizados em blocos distintos.

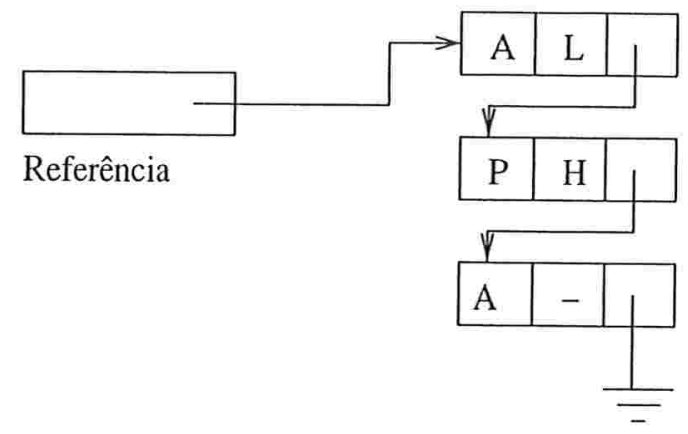

Figura 2.1: Representação de uma string de tamanho variável

A raiz é o conjunto de referências para células na heap que podem ser utilizadas pela aplicação, como os contidos em registradores, pilhas de execução e variáveis globais ${ }^{2}$.

\footnotetext{
${ }^{2}$ Observe que podem existir entre os elementos da raiz, alguns que não são mais necessários para aplicação,
} 
Uma célula que é alcançada a partir da raiz é considerada viva, as outras são lixo. Ou seja, uma célula é viva se for referenciada diretamente pela raiz ou por uma célula viva. Quando há alguma referência para uma célula, esta célula é chamada de célula alvo dessa referência. Podemos visualizar a heap como um grafo direcionado, onde células e referências são respectivamente nós e arestas. Este grafo é chamado de grafo de alcançabilidade da heap. Quando se percorre esse grafo a partir de uma célula lixo e consegue-se encontrar um caminho de volta para essa célula, encontramos um ciclo de lixo composto pelas células desse caminho.

Durante a execução de um programa, se considerarmos a liberação automática e a alocação de memória na heap, podemos definir três agentes: o alocador, o coletor e o modificador. O alocador e o coletor de lixo gerenciam a heap: o alocador fornece blocos de memória para a aplicação e o coletor libera células não mais utilizadas pela aplicação. Chamamos a aplicação do usuário de modificador por alterar o grafo de alcançabilidade da heap através de operações como atribuição e remoção de referências.

O alocador é responsável por gerenciar os blocos livres da heap, que inicialmente foram recebidos do Sistema Operacional, da seguinte forma:

- identificando todos os blocos livres da heap;

- atendendo as requisições de alocação de memória do modificador quando possível, escolhendo blocos entre o conjunto de blocos livres da heap;

- reintegrando blocos retidos que foram liberados ao conjunto de blocos livres da heap;

- chamando o coletor de lixo quando necessário.

Existem vários algoritmos de alocação de memória na heap[WJNB95]. O alocador pode, por exemplo, alocar objetos contíguos na heap apenas incrementando um ponteiro para a próxima região livre. Neste caso, a heap é formada por um grande bloco livre e as alocações são realizadas incrementando-se um ponteiro dentro desse bloco. Esse ponteiro é um divisor entres os blocos retidos e os blocos livres da heap: a região da heap localizada antes do ponteiro contém os blocos retidos e a região posterior, o bloco livre. Chamaremos essa técnica de alocação de ponteiro de incremento ${ }^{3}$. Outra técnica de alocação utiliza listas para

como por exemplo, valores obsoletos em registradores e variáveis locais que já foram utilizadas pela última vez, porém não é possível determinar no caso geral quais são eles.

${ }^{3} \mathrm{O}$ termo em inglês para a técnica de alocação contígua é bump pointer. 
encadear blocos livres. Existem muitas políticas de alocação que utilizam lista de blocos livres. A mais simples utiliza o algoritmo de primeiro encaixe. Neste algoritmo, a requisição de um bloco de memória é satisfeita, percorrendo-se a lista livre até que um bloco de tamanho maior ou igual ao do bloco requisitado seja encontrado. O alocador pode, ainda, gerenciar um conjunto de listas livres. Cada lista desse conjunto é dividida em blocos de tamanhos iguais, sendo que as listas diferem entre si pelo tamanho de seus blocos. Quando um tamanho de memória é requisitado, a lista que possuir blocos de menor tamanho, mas maior ou igual aỏ tamanho requisitado é utilizada para alocação. Chamaremos essa técnica de alocação de listas separadas, para maiores detalhes sobre essas técnicas de alocação de memória veja o artigo de Wilson et al [WJNB95].

O coletor ou coletor de lixo detecta e remove células lixo. Algumas células lixo podem ser consideradas pelo coletor como vivas e por isso são chamadas de falsas vivas. O que não pode ocorrer é o coletor considerar uma célula viva como lixo pois poderia provocar resultados inesperados ao modificador. O coletor executa quando o alocador não consegue atender uma requisição de alocação ou quando a quantidade de espaço disponível para alocações é menor que um limite mínimo pré-determinado. Quando uma execução do algoritmo de coleta de lixo é realizada, dizemos que ocorreu um ciclo de coleta de lixo. Uma célula sobreviveu a um ciclo de coleta de lixo quando não foi liberada pelo coletor. O coletor pode liberar células em qualquer ordem. Isto forma "buracos" entre os blocos retidos, ou seja, blocos retidos são intercalados com blocos livres. Esses "buracos" podem ser muito pequenos para satisfazer futuras requisições de alocação gerando o problema chamado de fragmentação, no artigo de Ullman et al [GGU72] há uma análise mais detalhada da relação entre algoritmos de alocação de memória e fragmentação.

\subsection{Tipos de Algoritmos de Coleta de Lixo}

Um algoritmo de coleta de lixo deve implementar a distinção entre células lixo e células vivas, assim como a liberação dessas células lixo. A liberação de células lixo pode ocorrer indiretamente, como é o caso dos algoritmos que apenas compactam as células vivas em uma área contígua da memória. Os algoritmos de coleta de lixo podem ser classificados pelas características a seguir: 
- Quantidade de lixo coletado em um ciclo de coleta:

Um coletor de lixo é dito completo quando todas as células que deixaram de ser alcançadas a partir da raiz antes do término do ciclo de coleta de lixo são liberadas ainda nesse ciclo. Caso contrário, o coletor é dito parcial.

- Possibilidade de mover células:

Um coletor de lixo é dito de cópia quando copia células consideradas vivas de uma região da heap para outra. Caso contrário é dito sem cópia.

- Identificação das referências:

Um coletor de lixo é dito conservador quando considera como referência tudo na heap que tem o formato de uma referência, ou seja, qualquer padrão de bits alinhados apropriadamente que poderiam indicar o endereço de uma célula na heap [Wil94]. Neste caso, outros tipos de dados poderiam ser confundidos com referências. Dados considerados incorretamente pelo coletor como referências são chamados de falsas referências. Se células lixo forem apontadas por falsas referências, elas podem não ser liberadas pelo coletor. Um coletor conservador não pode ser utilizado em coletas de lixo que movem células. Isso porque uma falsa referência poderia causar a tentativa de movimento de sua suposta célula alvo. Além disso, as referências para uma célula movida devem ser atualizadas para indicar sua nova localização, portanto, falsas referências para uma célula movida teriam seus dados alterados indevidamente. Já um coletor é dito exato quando distingue de forma correta uma referência de uma não referência. Existe ainda o coletor dito semi-conservador. Esse coletor realiza os dois tipos de identificação de referências já descritos, como por exemplo, uma identificação "exata" de referências na heap e uma identificação "conservadora" na pilha de execução [Bar88]. Neste caso apenas as células que foram identificadas de forma conservadora não podem ser movidas.

Em sistemas exatos ou semi-conservadores, o interpretador ou compilador geralmente coopera com o coletor fornecendo as referências na pilha e nos registradores. O artigo de Wilson [Wil94] descreve duas estratégias para que essas informações sejam passadas ao coletor: em pontos seguros e em qualquer ponto. Para a estratégia em qualquer ponto, o compilador assegura que o modificador pode ser interrompido em qualquer ponto 
de sua execução. Já na estratégia em pontos seguros, o compilador assegura que se o modificador for interrompido em apenas alguns pontos de sua execução, o coletor terá informações suficientes para executar corretamente. A vantagem dessa estratégia é que o compilador possui mais flexibilidade, possibilitando otimizações complexas nos pontos inseguros. Uma desvantagem desta estratégia é que se o modificador for composto por várias threads e se uma dessas threads requerer a execução da coleta de lixo, todas as threads deverão alcançar pontos seguros para que a coleta de lixo possa ser realizada e as threads possam continuar sùa execução normal[BOP03].

- Divisão da heap em gerações:

Um coletor de lixo é dito de geração quando particiona a heap em regiões, chamadas de gerações. Um coletor que não é dividido em gerações é dito sem geração. Geralmente é associado a cada célula uma idade, correspondendo ao número de vezes que a célula sobreviveu a um ciclo de coleta de lixo. Cada geração contém células de uma faixa de idade pré-determinada. As gerações são ordenadas de acordo com essa faixa de idade de forma crescente. Uma geração pode conter células referenciadas por outras gerações. Essas referências são chamadas de referências intergerações. A raiz de uma geração deve conter também as referências intergerações para suas células. Um critério heurístico utilizado para coleta de gerações é realizar com mais freqüência coleta de lixo nas gerações mais novas, pois células mais novas, normalmente, tornam-se lixo mais rapidamente que células mais velhas.

- Período de execução de coletor e do modificador:

Um coletor é dito paralelo quando o algoritmo de coleta de lixo, se beneficiando da existência de mais de um processador, executa de modo paralelo. Caso contrário, o coletor é dito não paralelo.

Um coletor de lixo é dito não incremental quando pára a execução do modificador durante o ciclo de coleta de lixo ${ }^{4}$. Já um coletor dito incremental intercala sua execução com a do modificador durante o ciclo de coleta de lixo.

O coletor de lixo incremental geralmente é entendido através de uma abstração, cha-

\footnotetext{
${ }^{4} \mathrm{O}$ termo não incremental foi utilizado neste trabalho, ao invés do termo em inglês stop-the-world.
} 
mada de marcação tricolor que descreveremos a seguir. Inicialmente, todas as células são brancas, sendo que a raiz é considerada de cor cinza. Durante o ciclo de coleta, uma célula visitada pelo coletor torna-se cinza ou preta. Se a célula é preta, indica que a célula já foi totalmente percorrida pelo coletor, ou seja, todos os seus descendentes diretos já foram visitados, caso contrário a célula seria cinza. Desta forma, as células cinzas são utilizadas pelo coletor para determinar quais células brancas ainda serão visitadas. Quando não há mais células cinzas, todas as células que permaneceram brancas são consideradas lixo. Cuidado deve ser tomado para que o coletor de lixo incremental não considere uma célula viva como lixo. Isto porque enquanto o ciclo de coleta está ocorrendo, o modificador pode alterar o grafo de células alcançáveis resultando na referência de uma célula branca por uma célula preta e na quebra de todos os caminhos que levavam células cinzas a esta célula branca. Neste caso, a célula branca seria alcançada apenas da célula preta e como tal não seria mais percorrida pelo coletor. Observe que se apenas uma dessas duas condições fosse evitada, células vivas não seriam consideradas como lixo. A figura 2.2 ilustra uma célula viva sendo considerada lixo pelo coletor ao executar intercalado com o modificador. Ela ilustra o caso onde, durante um ciclo de coleta, o modificador altera o grafo de referências fazendo com que uma célula preta que referencia outra célula preta (a) troque esta referência para uma referência a uma célula branca (b) e uma célula cinza que referencia essa célula branca deixa de referenciá-la (c). O coletor considera que todas as células referenciadas a partir de uma célula preta já foram marcadas e como só há caminho para essa célula através da célula preta, a célula branca não será mais marcada e, portanto, será coletada.

Barreiras de leitura ou barreiras de escrita podem ser utilizadas para que um coletor incremental execute corretamente. A barreira de leitura detecta quando o modificador tenta acessar uma referência em uma célula. Já a barreira de escrita detecta quando o modificador atribui uma referência para um campo de uma célula. Veja a figura 2.3.

As barreiras possibilitam a sincronização entre o coletor e o modificador. Assim, antes que o modificador acesse uma célula através de uma referência ou altere a célula referenciada por outra célula, o coletor pode executar alguma ação. O artigo de Pirinen [Pir98] descreve algumas das ações tomadas pelo coletor quando uma dessas barreiras é acionada. 


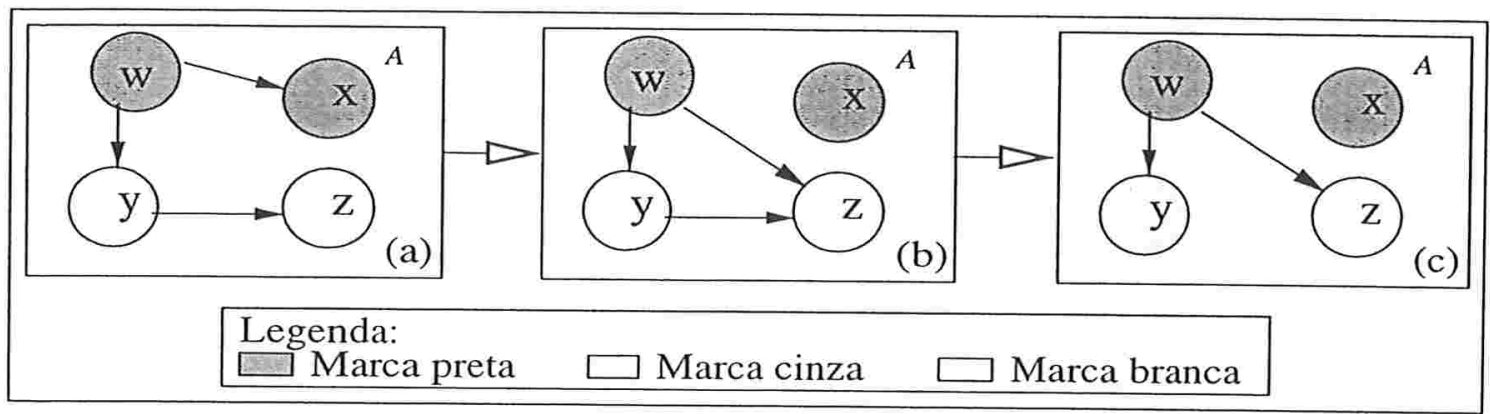

Figura 2.2: O grafo ilustra as células $x, y, w$ e $z$ de uma aplicação $A$, em três momentos de sua execução: (a), (b), e (c), nesta ordem. As setas indicam as referências existentes entre as células. Para a célula $z$, existem apenas as referências indicadas na figura. Em (a), apenas o coletor de lixo executa. Em $(b)$ e (c), apenas o modificador executa. Quando o ciclo de coleta continuar, a célula $z$ será considerada, incorretamente, como lixo pelo coletor.

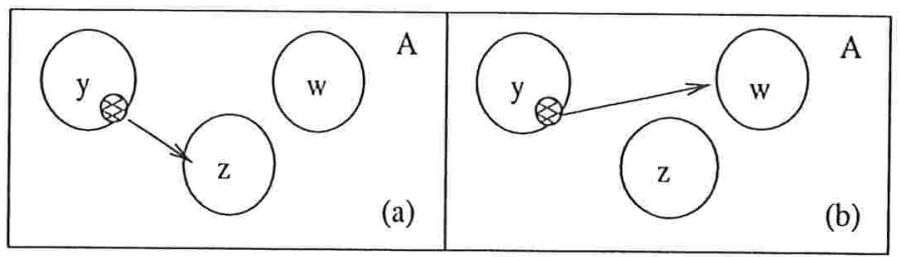

Figura 2.3: O grafo ilustra as células $y, w$ e $z$ de uma aplicação $A$ em dois momentos de sua execução: (a) e (b), nesta ordem. As setas no grafo indicam as referências existentes entre as células. Existe uma barreira na célula $y$. Se essa barreira fosse de escrita, ela seria acionada antes da célula $y$ referenciar a célula $w$ em (b). Se, entretanto, essa barreira fosse de leitura, ela seria acionada caso o modificador tentasse acessar a célula $z$ através da célula $y$ em $(a)$.

Em algoritmos incrementais de cópia, além de evitarmos que células vivas sejam consideradas lixo por mudanças no grafo de alcançabilidade realizadas pelo modificador, precisamos informar ao modificador das mudanças realizadas pelo coletor. Quando o coletor move uma célula, o modificador pode tentar acessá-la através de uma referência que não foi atualizada para designar sua nova localização. Caso o modificador não saiba como proceder para obter a nova localização da célula, a aplicação executará de forma incorreta. Uma maneira de evitarmos este erro é usando barreira de leitura. Assim, quando o modificador tentar acessar uma célula movida, o coletor é chamado para indicar a nova localização da célula.

Se coletores sem cópia são utilizados em um algoritmo incremental, é preferível a utilização apenas de barreiras de escrita, pois barreiras de leitura sem o apoio do hardware apresentam baixo desempenho. 


\subsection{Algoritmos de Coleta de Lixo}

Nesta seção descreveremos os algoritmos clássicos de coleta de lixo com o objetivo de identificar algumas rotinas necessárias à construção de uma interface genérica de coleta de lixo. Desta forma perceberemos interações entre o coletor e o modificador, assim como possíveis dependências entre um algoritmo de coleta de lixo e a implementação de uma linguagem de programação ou o compilador desta linguagem.

Inicialmente descreveremos os algoritmos "contagem de referência", "marcar-e-varrer", "marcar-e-compactar" e "semi-espaço", presentes em quase todos os tutoriais sobre coleta de lixo. Depois descreveremos os algoritmos "cópia incremental de Backer" e "gerações de semi-espaço" com o intuito de mostrar algoritmos de coleta de lixo do tipo incremental e de gerações, além do uso de barreiras de leitura e escrita. A não ser que indicado em contrário, as descrições deste capítulo são baseadas na descrição de Wilson[Wil94].

\subsubsection{Contagem de referência}

O algoritmo contagem de referências associa um contador de referências a cada célula.

\section{- Descrição do algoritmo:}

1. Quando uma célula é criada seu contador é igual a 0.

2. Quando uma referência é atribuída a um campo de uma célula, o contador de sua célula alvo é incrementado.

3. Quando uma referência é removida, o contador de sua célula alvo é decrementado. Uma referência é removida quando é substituída por outra referência ou por uma indicação de referência inexistente. No primeiro caso, além do contador da célula alvo da referência removida ser decrementado, o da nova referência é incrementado, conforme descrito no passo 2.

4. Quando o contador de uma célula for igual a zero, ela pode ser liberada. Quando isto ocorre, todos as células que são referenciadas por ela decrementam seus contadores de referências. Desta maneira a liberação de uma célula pode levar a liberação de muitas outras em um efeito cascata. 
Os passos 1, 2 e 3 realizam a detecção de lixo e o passo 4, a liberação dos mesmos. A manipulação do contador de referências deve ser uma operação atômica, caso contrário células vivas podem ser incorretamente liberadas. A detecção e a liberação de lixo são intercalados entre si e com o modificador. A barreira de escrita é utilizada para realizar a atualização do contador.

- Algumas vantagens:

- Simples de implementar.

- Quando uma célula é considerada lixo, ou seja, quando seu contador é igual a 0 , ela pode ser liberada imediatamente. Desta forma poderá ser reutilizada pela aplicação mais rapidamente.

- Esse coletor de lixo incremental pode ser facilmente redefinido para aplicações de tempo-real. Para isto, o efeito cascata, onde a liberação de uma célula lixo pode levar a muitas outras, deve ser evitado. Nesse caso, a liberação de lixo deve ser adiada até que sua execução seja apropriada. Pode-se por exemplo, manter uma fila de espera de liberações a serem realizadas.

\section{- Algumas desvantagens:}

- Não coleta ciclos de lixo. Imagine uma aplicação $A$ qualquer que em certo instante contém apenas três células $x, y$ e $z$, e apenas quatro referências. Sendo que a raiz possui uma referência para $x, x$ possui um referência para $y, y$ possui uma referência para $z$ e $z$ possui uma referência para $y$. Como essas referências são as únicas do cenário, os contadores das células $x, y$, e $z$ conterão $1,2,1$, respectivamente. Se $x$ deixa de referenciar $y$, o contador de $y$ conterá 1 . Neste caso, $y$ e $z$ não serão mais alcançados pela raiz e seus contadores serão iguais a 1. Portanto, o coletor de lixo não conseguirá liberar o ciclo de lixo formado por $y$ e $z$. A figura 2.4 ilustra esse cenário.

- A ocorrência do efeito cascata prejudica o desempenho do modificador, pois este poderá esperar um tempo indeterminado para continuar sua execução.

- Os contadores de referência devem ser atualizados a cada operação com referências realizada pelo modificador. A aplicação é constantemente intercalada com a 


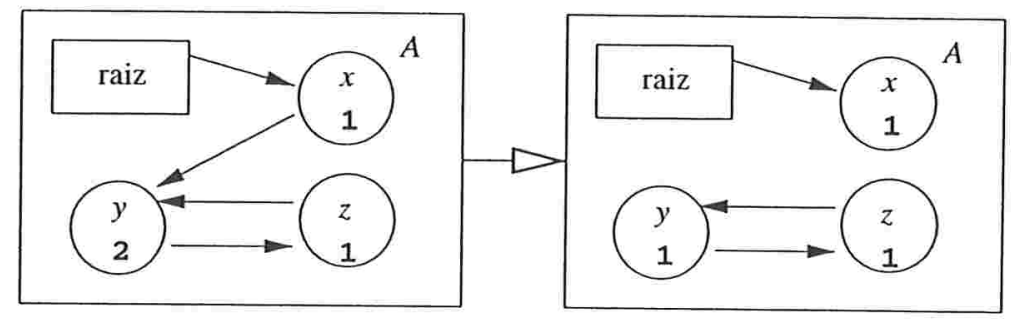

Figura 2.4: Ciclo de Lixo

coleta de lixo, pois geralmente operações com referências são freqüentes em uma aplicação. Mesmo quando há memória suficiente para uma aplicação executar, o tempo de execução dessa aplicação é acrescido com o tempo despendido para a execução da coleta de lixo.

\subsubsection{Marcar-e-Varrer}

O algoritmo marcar-e-varrer é dividido em duas fases: fase de marcação, onde é realizado a deteç̧ão do lixo e a fase de varredura, onde ocorre a liberação do lixo. A cada célula é associado uma marca, um bit 0 ou 1, onde será indicado se uma célula foi alcançada ou não pela raiz. Células com a marca igual a 1 são ditas marcadas.

Abaixo descreveremos um algoritmo de marcar-e-varrer não incremental.

- Descrição do algoritmo

1. Na fase de marcação, as células são percorridas a partir da raiz seguindo-se as referências. Cada célula encontrada é marcada.

2. Depois, ocorre a fase de varredura: toda a heap é percorrida e as células não marcados são liberadas e o bit de marca das células marcadas retornam a 0.

A fase de marcação pode ser realizada através de uma pilha temporária. Inicialmente a pilha conterá apenas as referências que compõem a raiz. Depois ocorrerão sucessivas retiradas das referências do topo pilha. Se a célula alvo da referência retirada não estiver marcada, ela o será e suas referências serão inseridas na pilha. Quando a pilha estiver vazia não há mais células a serem marcadas. A desvantagem desta estratégia é o espaço de memória requerido pelo coletor para armazenar a pilha. 
- Algumas vantagens:

- Ciclos de lixo são coletados;

- A coleta de lixo pode ser realizada apenas quando for necessário para a aplicação mais memória.

- Algumas desvantagens:

- O custo da coleta de lixo é proporcional ao tamanho da heap, pois toda a heap deve ser varrida na segunda fase do algoritmo.

- Fragmentação da heap não é tratada.

- Esse algoritmo deve ser capaz de identificar os objetos na heap durante a fase de varredura. O coletor precisa conhecer o início e o fim de cada bloco que compõe uma célula na heap. Essas informações nem sempre podem ser obtidas através da primeira palavra de cada bloco.

\subsubsection{Marcar-e-Compactar}

O algoritmo marcar-e-compactar é dividido em duas fases: fase de marcação, onde é realizado a deteç̧ão do lixo e a fase de compactação, onde as células vivas são movidas para uma parte contígua da heap. Um bit de marca e um ponteiro é associado a cada célula. $\mathrm{O}$ bit de marca indica se uma célula foi alcançada ou não pela raiz na fase de marcação. Já o ponteiro indica a nova localização da célula durante a fase de compactação.

\section{- Descrição do algoritmo}

1. Na fase de marcação, as células são percorridas a partir da raiz seguindo-se as referências. Cada célula encontrada é marcada.

2. Depois, ocorre a fase de compactação. Para compactar é necessário copiar as células vivas de forma contígua na heap e atualizar as referências para designarem a nova localização das células.

A figura 2.5 ilustra o algoritmo marcar-e-compactar. 


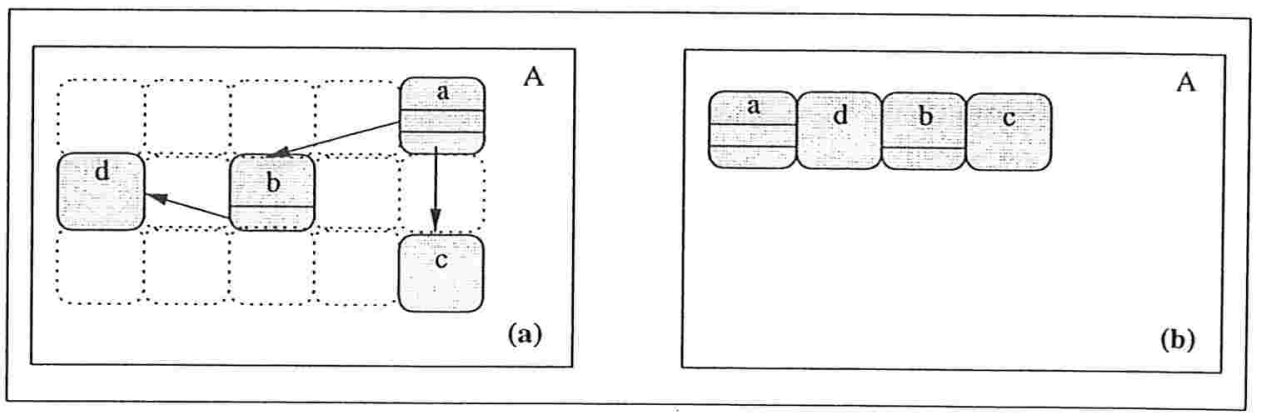

:Figura 2.5: A figura ilustra as células $a, b, c$ e $d$ de uma aplicação $A$, em dois momentos da execução do algoritmo marcar-e-compactar: (a) e (b), nesta ordem de execução. O momento (a) ocorre após o término da fase de marcação e o momento (b) ocorre no final da fase de compactação. As setas na figura indicam as referências existentes entre as células.

A fase de marcação deste algoritmo e do algoritmo marcar-e-varrer são similares. A diferença entre eles está na segunda fase. No livro de Tremblay et al [TS85] um algoritmo da fase de compactação é apresentado. Esse algoritmo percorre a heap três vezes: primeiro para calcular o endereço para o qual cada célula marcada será movida, segundo para atualizar o valor das referências contidas em células marcada, pois devem designar a futura localização das células alvo e, por último, para mover as células marcadas.

\section{- Algumas vantagens:}

- Compacta a heap, eliminando a fragmentação.

- A alocação de memória é simples. É necessário apenas incrementar um ponteiro da heap de forma linear.

- Ciclos de lixo são coletados.

\section{- Algumas desvantagens:}

- O custo da coleta de lixo é proporcional ao tamanho da heap, pois toda a heap deve ser varrida na segunda fase do algoritmo. Além disso, a heap é percorrida mais de uma vez nessa fase.

- Esse algoritmo deve ser capaz de identificar os objetos na heap durante a fase de compactação. 


\subsubsection{Semi-espaço não incremental}

O algoritmo de semi-espaço que descreveremos usa a implementação sugerida por Cheney [Che70] para a cópia das células. A heap é dividida em duas partes contíguas, chamadas de semi-espaços: o semi-espaço origem e o semi-espaço destino. Durante a execução normal do programa apenas um dos semi-espaços está sendo utilizado pelo modificador. Este semiespaço é chamado de semi-espaço corrente.

O coletor de semi-espaço inicia sua execução quando uma requisição de alocação não pode ser satisfeita no semi-espaço corrente. Neste caso, o modificador pára de executar até que o ciclo de coleta termine.

A figura 2.6 ilustra o algoritmo de semi-espaço não incremental.

\section{- Descrição do algoritmo:}

1. No semi-espaço corrente, ou seja no semi-espaço origem, percorre-se todas as células alcançadas a partir da raiz e a medida que elas são encontradas são copiadas para o semi-espaço destino em posições contíguas. Esta cópia é realizada através do ponteiro exame e do ponteiro livre. O ponteiro livre indica o final da fila formada pelas células copiadas para o semi-espaço destino e é atualizado sempre que ela for incrementada. A partir do início da fila, o ponteiro exame avança à busca de referências em cada célula que alcança. Veja o processo:

(a) A primeira célula referenciada pela raiz no semi-espaço origem é copiada para o semi-espaço destino. Essa referência da raiz é atualizada para indicar a nova localização da célula. O ponteiro exame indica uma posição antes da célula copiada no semi-espaço destino e o ponteiro livre indica a primeira posição após essa célula.

(b) O ponteiro exame avança na fila até encontrar uma célula com alguma referência ou o ponteiro livre.

- Se o ponteiro exame aponta para uma célula, a célula alvo de qualquer referência contida nessa célula será copiada para o semi-espaço destino, caso isto já não tenha sido realizado. Além disso, todas as referências nesta célula devem ser atualizadas para designarem as novas localizações de suas células alvo no semiespaço destino. Caso alguma célula tenha sido copiada no semi-espaço destino o ponteiro-livre é atualizado. Retornar ao passo (b). 
(c) Se houver alguma referência na raiz ainda não verificada pelo coletor, ela será escolhida.

- Se a célula alvo da referência escolhida ainda não foi copiada para o semi-espaço destino, ela o será. Essa referência é atualizada para indicar a localização da célula alvo no semi-espaço destino. Se alguma célula foi copiada, o ponteiro livre é atualizado, o ponteiro exame retrocede uma posição e retorne ao passo (b). Caso contrário retorne ao passo (c).

2. O semi-espaço destino torna-se o semi-espaço corrente. Ou seja, as regras do semi-espaço origem e destino são trocadas entre si.

Quando a célula é copiada para o semi-espaço destino, um ponteiro de redirecionamento, ou seja, uma referência para a nova localização da célula, é inserida na célula antiga. Esta referência indica que a célula foi copiada e sua nova localização. Portanto, se é encontrada uma referência para uma célula no semi-espaço origem que contém o ponteiro de redirecionamento, não é necessário copiar novamente a célula, apenas atualizar a referência para designar a localização da célula no semi-espaço destino. Por outro lado, se o ponteiro de redirecionamento não é encontrado, a célula será copiada e a referência atualizada. O mesmo raciocínio é feito para cópia de células diretamente referenciadas pela raiz.

\section{- Algumas vantagens:}

- Os ciclos de lixo são liberados pelo coletor.

- A organização da heap possibilita uma alocação de memória simples e rápida. Uma requisição de alocação pode ser satisfeita apenas incrementando um ponteiro no bloco livre do semi-espaço origem.

- O coletor realiza a compactação de células livres através da cópia dessas células em posições contíguas. Com isso a cada coleta, elimina-se a fragmentação.

- O custo da coleta de lixo é proporcional ao número de células vivas, não sendo necessário que toda a heap seja sempre percorrida.

\section{- Algumas desvantagens:}

- As células que permanecem vivas são copiadas toda vez que uma coleta de lixo é realizada. 


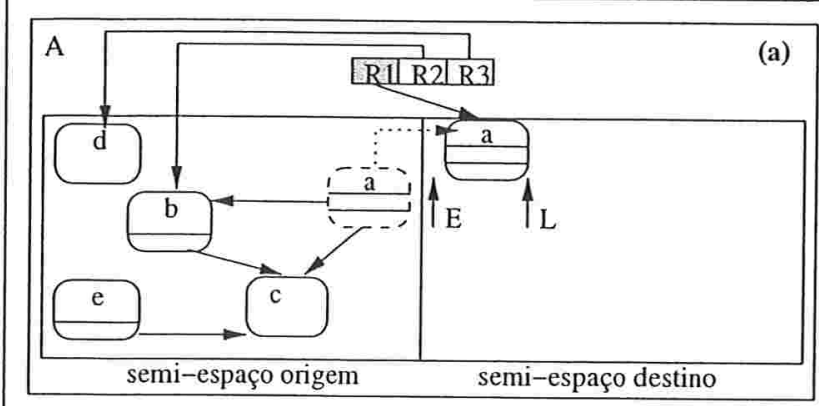

i)Corresponde ao passo (a).

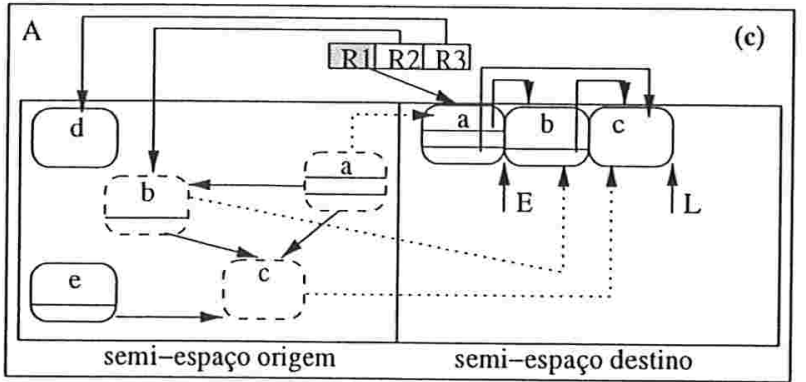

iii) Corresponde ao passo (b).

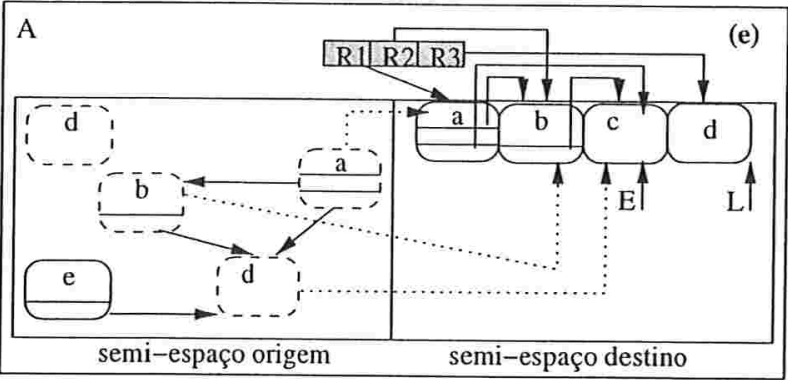

v) Corresponde ao passo (c)

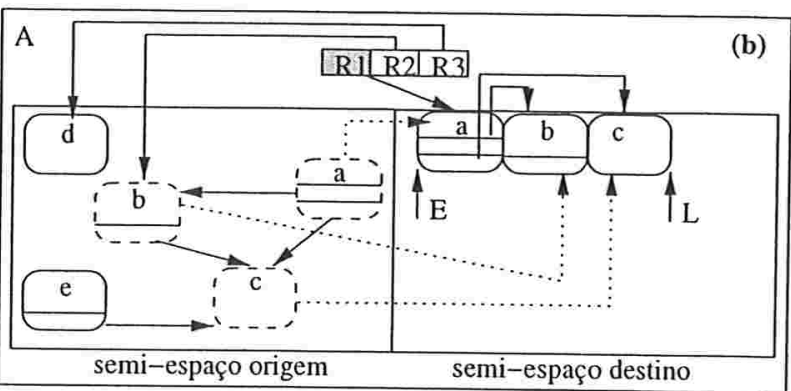

ii) Corresponde ao passo (b).

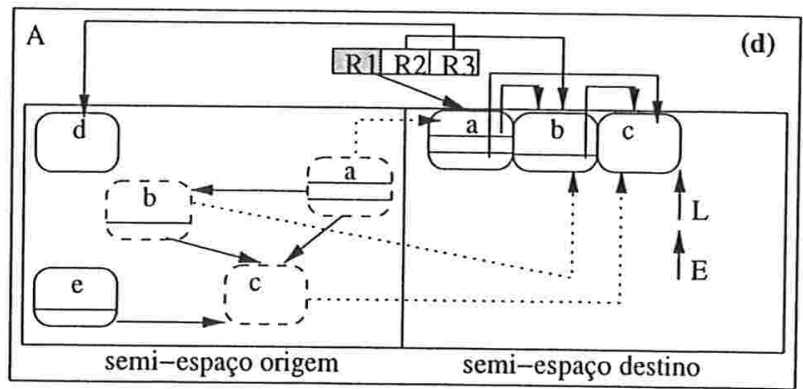

iv) Corresponde ao passo (b).

(b)

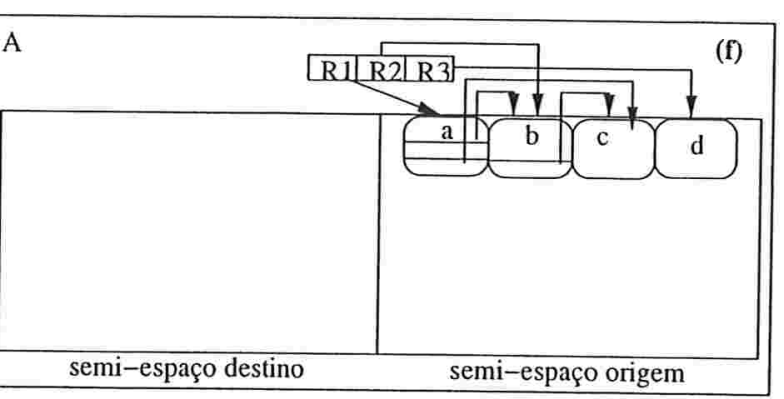

iii) Corresponde ao passo 2.

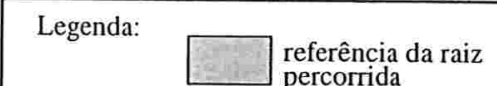
ponteiro de redirecionamento

Figura 2.6: A figura ilustra as células $a, b, c, d$ e $e$ de uma aplicação $A$, em seis momentos da execução do algoritmo semi-espaço não incremental: $(a),(b),(c),(d),(e)$ e $(f)$, nesta ordem de execução. A raiz da aplicação $A$ é composta pelas referências $R 1, R 2$ e R3. As setas na figura indicam as referências existentes entre as células. Os comentários localizados abaixo de cada ilustração referem-se à descrição do algoritmo de semi-espaço não incremental. 
- Custo alto para copiar células grandes.

\subsubsection{Semi-espaço Incremental de Baker}

O algoritmo semi-espaço incremental de Baker [Bak78], como no algoritmo anterior, divide a memória em duas partes: semi-espaço origem e semi-espaço destino. O processo de cópia das células de um semi-espaço para outro é uma adaptação do algoritmo de Cheney [Che70].

A cópia de células pelo coletor é intercalada com a execução do modificador. Considerando a abstração tricolor, as células brancas seriam as células no semi-espaço origem não copiadas para o semi-espaço destino e as células cinzas e pretas seriam as células copiadas no semiespaço destino. As células pretas o ponteiro exame já rastreou, ao contrário das células cinzas. Uma barreira de leitura é utilizada para evitar erros do modificador e do coletor devido a natureza incremental de cópia do coletor de lixo. A barreira é utilizada de modo a propiciar que o modificador acesse apenas células no semi-espaço destino. Assim não será possível que o modificador modifique o grafo de referências de modo que uma célula branca seja referenciada por uma célula preta, pois células brancas não são visíveis ao coletor. Além disso, o modificador não acessará incorretamente uma célula no semi-espaço origem que já foi copiada pelo coletor, pois apenas acessará células no semi-espaço destino.

$\mathrm{Na}$ descrição do algoritmo enfatizaremos apenas as diferenças com o algoritmo anterior. Esse algoritmo é ilustrado na figura 2.7.

\section{- Descrição do algoritmo:}

1. Todas as células referenciadas pela raiz são copiadas para o semi-espaço destino de maneira contígua formando uma fila de células. Apenas o coletor executa.O ponteiro exame indica uma posição antes da primeira célula copiada no semi-espaço destino e o ponteiro livre indica a primeira posição após a última célula copiada. Até este momento somente o coletor executa.

2. O ponteiro exame avança até encontrar uma célula com referência(s) ou o ponteiro livre. Neste passo o modificador poderá intercalar sua execução com o coletor.

- Se o modificador tentar acessar uma célula no semi-espaço origem a barreira de leitura chamará o coletor para que este copie esta célula no semi-espaço destino na posição apontada pelo ponteiro livre. O modificador então acessará na verdade esta 
nova localização da célula ao invés da antiga. Um ponteiro de redirecionamento é também inserido na célula que foi copiada.

- Se o modificador requisitar a alocação de células durante a execução do coletor de lixo, a alocação será feita no semi-espaço destino e estas células serão consideradas por esse ciclo do coletor como células pretas. Baker sugere que essas células sejam alocadas fora da fila de cópia, no outro extremo do semi-espaço destino. Sempre que uma alocação é feita, o coletor deve executar até copiar um certo número de células para o semi-espaço destino, este número aumenta a cada alocação realizada. Isto para evitar que as alocações preencham o semi-espaço destino antes que o coletor termine de copiar todas as células vivas.

- A célula alvo de qualquer referência contida numa célula apontada pelo ponteiro exame será copiada para o semi-espaço destino, caso isto já não tenha sido realizado. Além disso, qualquer referência da célula apontada pelo ponteiro exame deve ser atualizada para designar a nova localização de sua célula alvo no semiespaço destino. Caso alguma célula tenha sido copiada no semi-espaço destino o ponteiro-livre é atualizado. Retornar ao passo 2.

3. O semi-espaço destino torna-se o semi-espaço corrente. Ou seja, as regras do semi-espaço origem e destino são trocadas entre si. Neste passo apenas o coletor executa.

Na descoberta e cópia do conjunto raiz apenas o coletor pode executar porque caso contrário a barreira de leitura não seria utilizada de maneira apropriada. Sendo o conjunto raiz não pertencente ao semi-espaço origem, o modificador poderá acessar a célula alvo apontada por um elemento da raiz. Se esta célula estiver no semi-espaço origem, ela é uma célula branca, contradizendo o princípio deste algoritmo que diz que células brancas não são visíveis ao modificador. Se o elemento da raiz que já foi percorrido pelo coletor, passa a referenciar uma célula branca e esta célula não é referenciada a partir de uma célula cinza, ela não seria mais percorrida pelo coletor e mesmo sendo viva, seria coletada. Deste modo, o coletor poderá executar incorretamente.

\section{- Algumas vantagens:}

- Os ciclos de lixo são liberados pelo coletor. 


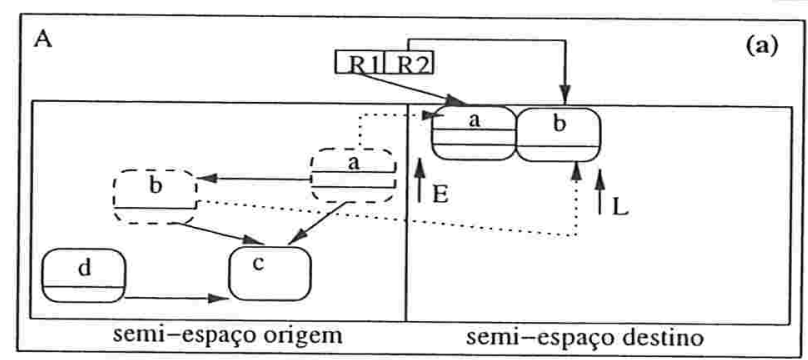

i) Corresponde ao passo 1 .

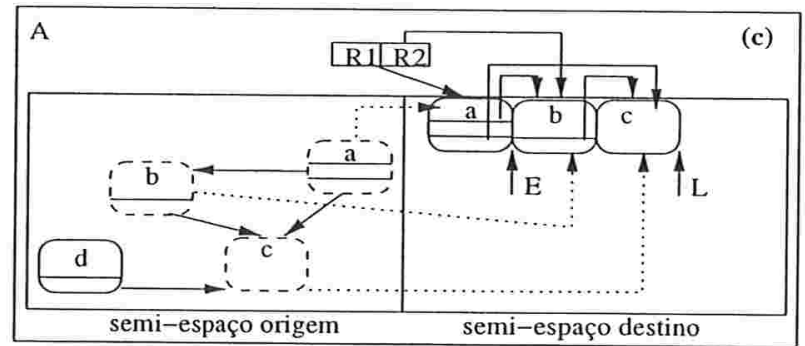

iii) Corresponde ao passo 2 .

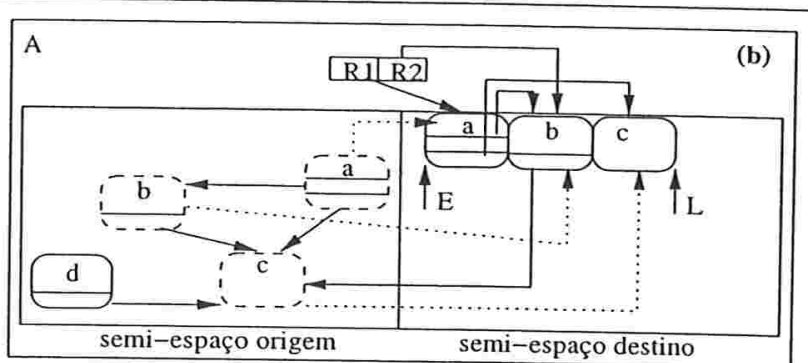

ii) Corresponde ao passo 2 . (b)

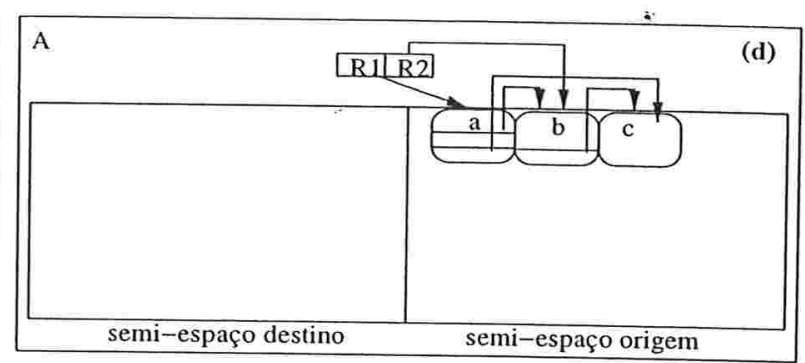

iv) Corresponde ao passo 3.

onteiro de redirecionamento

Figura 2.7: A figura ilustra as células $a, b, c$ e $d$ de uma aplicação $A$, em quatro momentos da execução do algoritmo semi-espaço não incremental: (a), (b), (c) e (d), nesta ordem de execução. A raiz da aplicação $A$ é composta pelas referências $R 1$ e R2. As setas na figura indicam as referências existentes entre as células. Os comentários localizados abaixo de cada ilustração referem-se à descrição do algoritmo de semi-espaço incremental.

- A organização da heap possibilita uma alocação de memória simples e rápida. Uma requisição de alocação pode ser satisfeita apenas atualizando um ponteiro no bloco livre do semi-espaço destino.

- O coletor realiza a compactação de células livres através da cópia dessas células em posições contíguas. Isto contribui para a não fragmentação de memória, assim como, o item anterior.

- O custo da coleta de lixo é proporcional ao número de células vivas, não sendo necessário que toda a heap seja sempre percorrida.

- A coleta, por ser incremental, permite que seja mais adequada em aplicações interativos com o usuário do que o algoritmo anterior. 


\section{- Algumas desvantagens:}

- A barreira de leitura traz um custo adicional ao desempenho do sistema.

- As células que permanecem vivas são copiadas toda vez que uma coleta de lixo é realizada.

- Custo alto para copiar células grandes.

- Coletores de lixo do tipo conservador não podem ser utilizados com esse algoritmo.

\subsubsection{Gerações de semi-espaços}

No algoritmo gerações de semi-espaços, cada geração da heap utiliza o algoritmo de semiespaço. As gerações possuem espaço de memória distintos, sendo que normalmente as gerações mais novas possuem menos espaço que as gerações mais velhas. O número de gerações e o tamanho de cada uma é determinado previamente, com exceção da geração mais velha que pode ter seu espaço aumentado durante a coleta de lixo. As células são sempre alocadas no semi-espaço origem da geração mais nova.

Referências intergerações podem ser criadas quando o modificador atribui uma referência para o campo de uma célula em uma geração distinta de sua célula alvo ou quando uma célula contendo referências é movida para a geração seguinte pelo coletor. As referências intergerações devem fazer parte da raiz da geração que as contêm, portanto, devem ser identificadas pelo coletor. Com este propósito, barreiras de escrita podem ser utilizadas para registrar as referências intergerações criadas pelo modificador. O coletor pode registrar as células movidas por ele mesmo.

O algoritmo de gerações inicia pela geração mais nova. Além disso, o número de ciclos de coleta é maior nesta geração, pois o algoritmo pressupõe que ela possua mais células lixo. A seguir descreveremos o que ocorre durante a coleta de lixo em uma geração qualquer, de um total de $n$ gerações.

\section{- Descrição do algoritmo:}

1. A coleta de lixo de semi-espaço é realizada em uma geração obedecendo as seguintes regras:

(a) As referências intergerações para uma geração devem fazer parte de sua raiz. 
(b) Se uma célula sobrevive a um número pré-determinado de coletas de lixo, há uma tentativa de movê-la para o semi-espaço origem da geração seguinte, ao invés de movê-la para seu semi-espaço destino. Dizemos que esta célula foi promovida. Se a geração em questão for a última, as células não podem ser promovidas. Caso a geração seguinte não possua memória livre suficiente para receber a célula promovida, esta geração é coletada seguindo estas mesmas regras.

2. Se mesmo depois de um ciclo de coleta de lixo em uma geração, não é possível obter a quantidade de memória livre desejada, algumas de suas células mais velhas serão movidas para a geração seguinte, mesmo que suas idades não sejam adequadas. Se a geração em questão for a geração mais velha, as células não poderão ser movidas, mas o tamanho da geração poderá ser aumentado.

\section{- Algumas vantagens:}

- A coleta de lixo pode ser realizada em apenas algumas partes da heap. Neste caso, o tempo despendido com a coleta de lixo é menor.

- Se as células mais novas tornam-se lixo mais rapidamente que células mais velhas, apenas as áreas com mais lixo serão mais freqüentemente coletadas. Desta forma, rapidamente haverá mais blocos livres de memória para serem reutilizadas quando necessário pela aplicação.

\section{- Algumas desvantagens:}

- Custo maior para determinar os elementos que fazem parte da raiz, pois agora além dos que abrangem toda a heap é necessário determinar os específicos de cada geração, ou seja, as referências intergerações.

- Se uma célula é promovida e em seguida torna-se lixo, ela é liberada quando a geração que a recebeu for coletada. Como esta geração não é a mais nova, seu ciclo de coleta poderá tardar e a célula lixo ocupará espaço inutilmente durante mais tempo. O principal problema é que se essa célula possuir referências para outras gerações, essas referências serão consideradas como fazendo parte da raiz dessas gerações e possivelmente serão promovidas, mesmo que sejam células lixo. 


\section{Capítulo 3}

\section{Interface Genérica de Coleta de Lixo}

Um dos problemas de experimentação de coletores de lixo em um sistema de execução de uma linguagem de programação é que este não foi projetado para executar diferentes algoritmos de coleta de lixo. Com uma interface genérica de coleta de lixo, vários algoritmos de liberação automática de memória podem ser facilmente acoplados ao sistema de execução de uma linguagem de programação. Além disso, nenhuma alteração de um algoritmo de coleta de lixo é necessária para que diferentes linguagens o utilizem. Assim, uma interface genérica propicia uma independência entre o coletor de lixo e a linguagem de programação.

A interface genérica de coleta de lixo é composta por duas interfaces: a interface do gerenciador de memória e a interface da linguagem de programação. A primeira interface é implementada pelo gerenciador de memória e utilizada pelo sistema de execução da linguagem de programação. Já a segunda interface é implementada pelo desenvolvedor da linguagem de programação e utilizada pelo coletor de lixo.

A interface da Linguagem de Programação é necessária para que o coletor de lixo delegue à linguagem de programação a implementação de rotinas que envolvem o conhecimento prévio do formato das células. Esse formato é definido na implementação de cada linguagem de programação. Desta forma, a execução do coletor de lixo não se restringirá a um determinado projeto de linguagem de programação.

A interface do gerenciador de memória permite à linguagem de programação requisitar memória de maneira independente do algoritmo de coleta de lixo e permite ao coletor monitorar eventos importantes, como por exemplo, a atualização de uma referência pelo modificador. 
Através dessa interface, as linguagens de programação utilizam-se de rotinas padrão para a interação com o coletor de lixo. Desta forma, o coletor de lixo pode ser alterado, sem que seja necessário alterações na implementação da linguagem de programação. Portanto, a linguagem de programação não precisa saber qual o coletor que está sendo utilizado.

Inicialmente a tese de Durham [Dur97] foi a base de nosso de trabalho. O nosso objetivo era estender a interface definida na tese de Durham e implementá-la em uma linguagem de programação para avaliação de desempenho. Após uma busca bibliográfica mais detalhada, encontramos o trabahho de Uchiyama et al [YUS] que também descreve uma interface genérica muito semelhante à descrita por Durham.

Na primeira seção deste capítulo discorreremos sobre aspectos dos algoritmos de coleta de lixo que justificam a necessidade de algumas rotinas que compõem uma interface genérica de coleta de lixo. Na última seção mostraremos trabalhos relacionados ao tema de nossa dissertação.

\subsection{Interação entre a Linguagem de Programação e o Coletor de Lixo}

Examinando com mais atenção os algoritmos de coleta de lixo descritos no capítulo anterior podemos identificar que alguns pontos dos algoritmos são intrínsecos à implementação da linguagem de programação. É importante que eles sejam identificados para obtermos a independência entre o coletor de lixo e a linguagem de programação. Depois de identificados, esses pontos serão tratados de forma adequada pela interface genérica de coleta de lixo. Essa interface pode, por exemplo, delegar à linguagem de programação a implementação desses pontos ou fornecer ao coletor informações necessárias para que ele os implemente. A seguir descreveremos alguns desses pontos:

\section{- Cópia e liberação de células:}

Uma célula pode ser formada por blocos de memória não contíguos. Por isso, uma célula poderia conter apontadores para suas partes constituintes. A localização desses apontadores é definida pela implementação da linguagem de programação. Quando ocorre a liberação ou a cópia de uma célula é necessário que todas as suas partes 
constituintes sejam liberadas ou copiadas. Portanto, é necessário conhecer as referências internas de uma célula. A interface genérica deve possibilitar ao algoritmo de coleta de lixo liberar ou copiar células sem supor qualquer formato. Outra informação que é necessária é o tamanho da célula ou de suas partes constituintes. Em algoritmos de cópia, esse tamanho é utilizado para determinar se há espaço suficiente para a cópia de uma célula. No caso da liberação de células, o tamanho de cada bloco constituinte da célula indica os limites de cada bloco. A liberação de célula ocorre em qualquer algoritmo de coletá de lixo e a cópia ocorre, por exemplo, no algoritmo semi-espaço.

\section{- Informações do gerenciador de memória inseridos em uma célula:}

Alguns bits da célula podem ser reservados para armazenar informações necessárias ao coletor. Um exemplo é o contador associado a cada célula no algoritmo de contagem de referências. Outro exemplo é o ponteiro de redirecionamento associado a algumas células nos coletores de cópia, como é o caso do algoritmo semi-espaço. Antes que um coletor possa armazenar com segurança informações nas células é necessário que elas disponibilizem bits suficientes para esse propósito. Outra questão é a manipulação dessas informações pelo coletor: o coletor não as acessa diretamente sem conhecer o formato das células. Assim, uma alternativa para manter a independência entre o coletor e a linguagem de programação é permitir apenas ao sistema de execução da linguagem de programação acessar e atualizar esses bits diretamente de acordo com os desígnios do coletor. O valor desses bits pode ser fornecido ao coletor também pelo sistema em execução da linguagem. Se mais de uma informação do coletor estiver inserida nas células, como é o caso dos algoritmos marcar-e-varrer baseados no artigo de Schorr et al [SW67], é necessário que elas sejam identificadas apropriadamente para que sejam corretamente armazenadas nas células e fornecidas ao coletor quando necessário. Observe que essas informações não precisariam obrigatoriamente estar contidas nas células. Se não estivessem, poderiam ser manipuladas diretamente pelo coletor sem prejuízo para a interface genérica. Outro tipo de informação que o coletor pode utilizar são as referências temporariamente alteradas durante a travessia de células pelo coletor, como ocorre nos algoritmos baseadas no artigo de Schorr et al [SW67]. Como apenas a linguagem de programação conhece a localização e o formato de uma referência contida em uma célula, a linguagem de programação deve se encarregar de alterar a referência 
a pedido do coletor de lixo.

- Acesso às células da heap:

O acesso às células da heap pode ser realizado de duas maneiras:

- Através das referências para células:

Em alguns algoritmos, a heap é percorrida seguindo-se as referências para células na heap. Um exemplo disso é a primeira fase do algoritmo marcar-e-varrer. As células da heap são alocadas dinamicamente pelo gerenciador de memória, mas o conteúdo das células não é conhecido por ele. Para um coletor exato percorrer uma célula e descobrir nela referências para outras células, deveria conhecer também o formato dessa célula. Uma alternativa para obtermos independência de linguagem neste caso seria a obtenção dessas referências pelo coletor através do sistema em execução da linguagem de programação.

- Através da disposição das células na heap:

Em alguns algoritmos, toda a heap é percorrida seguindo-se a sequiência de células da heap. Um exemplo disso é a segunda fase do algoritmo marcar-e-varrer, onde células não marcadas são liberadas. Iniciando essa fase do algoritmo do primeiro bloco da heap, teremos:

1. Se for um bloco livre, percorre-se os próximos blocos da heap de forma seqüencial até que seja encontrado um bloco retido. Esse bloco retido pode ser uma célula ou parte dela.

2. O bloco retido é analisado, se ele não faz parte de uma célula marcada será liberado;

3. Caso não se tenha atingido o último bloco da heap, percorrer o próximo bloco. Retornar ao passo 1.

Para localizarmos o próximo bloco a percorrer, o tamanho do bloco acessado correntemente deve ser conhecido. O tamanho dos blocos livres é conhecido pelo gerenciador de memória. O mesmo não ocorre com os blocos retidos. Nesse caso, a informação do tamanho da célula ou de seus blocos constituintes deve ser obtido pelo coletor sem restringi-lo a uma linguagem de programação. Uma alternativa 
seria que o sistema de execução da linguagem de programação fosse capaz de informar o tamanho do bloco retido e a referência para célula que contém esse bloco. Com o tamanho do bloco, o coletor conheceria a localização do próximo bloco a percorrer. Já com a referência para a célula, o coletor de lixo poderia obter informações sobre a célula, como por exemplo, se a mesma está marcada, e liberála se fosse o caso ${ }^{1}$. Entretanto, nem sempre é possível para a linguagem determinar a referência para a célula dado um de seus blocos. Uma solução seria utilizar um mapa de bits durante a fase de marcação, onde*todas as células seriam marcadas, inclusive todos seus blocos. Assim, ao invés de percorrer a heap linearmente, o mapa de bits seria percorrido.

\section{- Descoberta da raiz:}

Todos os algoritmos de coleta de lixo, partem do pressuposto que a raiz de um sistema em execução é conhecido pelo coletor, com exceção dos algoritmos de contagem de referência. É o caso do algoritmo marcar-e-varrer. Nesse algoritmo, as células são percorridas a partir da raiz. O formato da pilha de execução pode ser diferente para cada linguagem de programação. Desta forma, o coletor precisa obter as raízes contidas na pilha de forma a não restringir o coletor a um formato de pilha. Uma alternativa seria que o sistema em execução fornecesse um mapa das referências da pilha a cada execução do coletor. Neste caso porém se uma célula torna-se lixo enquanto o coletor está executando, ela não será liberada nesse ciclo.

\section{- Uso de barreiras de leituras e de escrita}

Essas barreiras permitem que o coletor de lixo execute algumas instruções imediatamente antes de uma célula ser lida ou escrita pelo modificador. Como já foi dito, o formato dos tipos primitivos e das células é definido na implementação da linguagem de programação. Portanto a leitura e a escrita no campo de uma célula deve ser realizado pelo sistema em execução da linguagem. Entretanto, antes que isso ocorra as instruções apropriadas do coletor devem ser executadas. O coletor pode desejar alterar alguma

\footnotetext{
${ }^{1}$ Para o coletor de lixo liberar uma célula sem admitir apenas um formato da célula, é necessário interagir com o sistema em execução da linguagem de programação. O mesmo pode ocorrer quando o coletor deseja conhecer se uma célula foi marcada.
} 
informação das células envolvidas na referência, ou seja, a célula que a contém, ou a sua célula-alvo ou ainda a célula-alvo da nova referência que a substituirá no caso de barreira de escrita.

- Endereço da célula a partir de uma referência:

Às vezes é necessário ao coletor conhecer o real endereço de uma célula. Conhecer apenas a referência de uma célula não implica conhecer o endereço desta. Isto porque o endereço de uma célula pode está codificado na referência ou adicionado de outras informações. O formato de uma referência é definido pela linguagem de programação. Uma solução para a independência do coletor é o sistema de execução da linguagem de programação fornecer o endereço da célula para o coletor. Um coletor de gerações, por exemplo, pode saber a qual geração uma célula pertence através do endereço desta.

\subsection{Trabalhos relacionados}

Nossa busca na literatura encontrou 4 trabalhos publicados sobre a separação modular entre implementação da linguagem de programação e do sistema de alocação e coleta de lixo. Destes, dois trabalhos são abordagens parciais, uma que visa proporcionar uma interface para acoplar vários coletores ao mesmo ambiente de programação[WG98], e outra que visa fornecer um coletor que abstrai a linguagem de programação[HMDW91]. Ambas as interfaces supõe o conhecimento do algoritmo de coleta, ou de detalhes da linguagem. Os outros dois trabalhos apresentam tentativas de modularização completa [Dur97][YUS].

Nesta seção descreveremos as interfaces propostas por Durham e por Uchiyama et al. Cada um destes trabalhos define uma série de rotinas que devem ser implementadas pelo coletor de lixo e pela linguagem de programação.

\subsubsection{Abordagens completas}

\section{Interface genérica proposta por Durham}

\section{Interface da Linguagem de Programação}

- $\operatorname{size}(r e f e r e n c e)$ 
Retorna o tamanho de uma célula indicada por reference.

- copy(reference, new_address)

Copia uma célula indicada por reference para o novo endereço new_address. Essa rotina retorna a nova referência como resultado.

- is_immediate(reference)

Informa se existe uma célula indicada por reference ocupando espaço na heap ou se esta célula é representada na própria reference.

- release(reference)

Armazena na primeira palavra de cada bloco de uma célula indicada por reference o tamanho desse bloco e na última palavra, um ponteiro para o próximo bloco ou zero caso seja o último bloco dessa célula. Essa rotina retorna o endereço do primeiro bloco de memória que compõe a célula.

- process_object(routine_pointer, reference)

Encontra as referências contidas na célula designada por reference e aplica a rotina routine_pointer utilizando cada uma delas como parâmetro. O valor retornado por routine_pointer é usado para atualizar as referências contidas na célula indicada por reference.

- process_object_of_type(routine_pointer, reference, typeId)

Esta rotina é similar a anterior, com a diferença de que o coletor fornece um identificador do tipo da célula typeID como argumento. Desta forma, não será necessário nenhuma checagem de tipo pelo sistema em execução.

- free_bits()

Retorna o número de bits disponíveis para armazenar informações do coletor em qualquer célula, mantendo a integridade da mesma. Isso não se aplica a células que contenham dados com representação imediata.

- available_bits() 
Retorna o número de bits disponíveis para armazenar informações do coletor em qualquer célula, mantendo apenas a integridade dos ponteiros para os blocos que compõem a mesma.

- $\operatorname{mark}(r e f e r e n c e$, value, size_of_value)

Insere a informação value do coletor em uma célula indicada por reference, caso a rotina free_bits() informe que há espaço suficiente para isso.

- read_mark(reference, size_of_value)

Retorna alguma informação do coletor contido na célula indicada por reference que foi armazenada utilizando a rotina anterior.

- store_value(reference, value, size_of_value)

Insere a informação value do coletor em uma célula indicada por reference, caso a rotina available_bits () informe que há espaço suficiente para isso. Observe que neste caso, os dados guardados na célula serão perdidos, com exceção dos ponteiros para seus blocos.

- read_value(reference, size_of_value)

Retorna alguma informação do coletor contido na célula indicada por reference que foi armazenada utilizando a rotina anterior.

- address_of_reference(reference)

Esta rotina retorna o endereço designado por reference. Se houver mais de um bloco de dado associado com o objeto indicado por reference, este método retornará o endereço do bloco de dado que corresponde ao primeiro campo ponteiro na referência.

\section{Interface do Gerenciador de Memória}

- allocate(datatype_id, number_of_blocks, block_size_list)

Liga number_of_blocks blocos, sendo que cada bloco possui pelo menos o tamanho determinado por block_size_list. Esta rotina retorna um ponteiro para o primeiro bloco da lista ligada. Observe que datatype_id é um número de identificação único 
para um tipo de dado em um sistema em execução. Esse número pode ser utilizado na construção de gerenciadores de memória que são personalizados para um sistema de execução específico.

- updateReference (new_reference, old_reference, changing_object, position_in_object, size_of_reference)

Troca a referência old_reference por new_reference, localizado em position_in_object na célula changing_object. O tamanho do campo que será alterado é size_of_reference.

- get_real_reference(reference_pointer)

É chamada em toda operação de leitura quando se deseja implementar uma barreira de leitura. Em coletores de cópia essa rotina é utilizada para que o modificador acesse a nova localização da célula movida através da referência para sua antiga localização reference_pointer.

- new_context_frame(size, reference_array)

Aloca um bloco de memória de tamanho size para uma nova moldura na pilha. O argumento reference_array indica a posição de futuras referências nesta moldura.

- push_reference(a_reference)

Insere a referência a_reference na pilha e retorna a posição dessa alocação. Observe que esta rotina é utilizada para entrada de dados individuais na pilha.

- push_data(data)

Insere o dado data que não é uma referência na pilha e retorna a posição dessa alocação.

Observe que esta rotina é utilizada para entrada de dados individuais na pilha.

- alter_reference(address, new_reference)

Armazena new_reference no endereço address da pilha.

- $\operatorname{pop}()$

Remove a palavra do topo da pilha e retorna-a como resultado. 
- pop_context_frame(size)

Remove o bloco de memória do tamanho size do topo da pilha.

- stack_increase(size_of_update)

Altera o espaço de memória da pilha para o acréscimo de size_of_update.

\section{Interface genérica proposta por Uchiyama et al}

Interface da Linguagem de Programação

- MM_root_scan(traverse)

Encontra as referências contida na raiz e aplica-lhes a função traverse.

- MM_is_reference(field)

Informa se o valor contido no campo field de uma célula é referência ou não.

- MM_dereference(field, object, i)

Informa o endereço do i-ésimo campo de uma célula indicada por object.

- MM_get_size(object)

Informa o tamanho de uma célula indicada por object.

- MM_get_type (object)

Informa o tipo de uma célula indicada por object.

- MM_is_atomic(type)

Retorna se o tipo type contém referências ou não.

- MM_alloc_failure()

Informa que a tentativa de uma alocação falhou.

- MM_encode_header(number)

Codifica um inteiro em um header. 
- MM_decode_header(header)

Decodifica um header em um inteiro.

- MM_make_header(object, size, type, header)

Constrói um header para uma nova célula.

- MM_write_header(object, header)

Escreve um valor header para uma célula.

- MM_read_header (object)

Ler o valor header de uma célula.

- MM_save_state()

Salva o estado do sistema em execução. Esta rotina é usada para rastrear a raiz eficientemente, segundo Uchiyama et al.

- MM_restore_state()

Restaura o estado do sistema em execução.

\section{Interface do Gerenciador de Memória}

- MM_initialize()

Aloca o espaço da heap da memória virtual. Além disso, o coletor realiza as operações iniciais necessárias para sua correta execução. É chamada no início da execução do modificador.

\section{- MM_finalize()}

Realiza operações do coletor necessárias no final da execução do modificador.

- MM_alloc(result, size, type)

Aloca uma célula fornecendo seu tipo type e seu tamanho size. 
- MM_get_field(result, object, i)

Devolve o valor do i-ésimo campo de uma célula indicada por object. Pode ser utilizada para implementar uma barreira de leitura em coletores incrementais de cópia: a atual localização de uma célula será indicado pelo argumento result.

- MM_set_field(object, i, oldval, newval)

Modifica o valor oldval do i-ésimo campo de uma célula indicada por object para o novo valor newval. Pode ser usado pä̀ra implementar a barreira de escrita.

\subsubsection{Abordagens Parciais}

Além do artigo de Uchiyama et al, outros trabalhos visando facilitar a construção de coletores de lixo foram feitos. Entre eles temos a a interface da ExactVM [WG98] e a caixa de ferramentas para coleta de lixo [HMDW91].

A ExactVM é uma Máquina Virtual Java da Sun que disponibiliza uma interface de gerenciamento de memória composta por um conjunto de macros implementadas em C. Através dessa interface é possível implementar vários algoritmos de coleta de lixo. Entretanto, a interface está intrinsecamente ligada à implementação da ExactVM, sendo difícil adaptá-la a outras linguagens de programação. Através dessa interface o coletor de lixo pode, por exemplo, obter o conjunto raiz, suspender e continuar a execução de threads, manipular referências fracas de java. O coletor de lixo conhece detalhes da implementação da ExactVM, por exemplo, ele pode obter um ponteiro para as estruturas que definem o modelo de um objeto e, através desse ponteiro, utilizar macros da ExactVM para obter o mapa de localizacao de referências do objeto. Se o gerenciador de memória possuir um ponteiro para uma classe da ExactVM, ele pode obter, ainda, a superclasse associada com a classe. A implementação desses coletores para outra linguagem de programação não é trivial, pois são dependentes da implementacao da ExactVM, utilizando estrututas específicas desta.

A caixa de ferramentas para coleta de lixo disponibiliza uma biblioteca independente da linguagem para construção de coletores de geração. O gerenciamento de memória implementado com essa biblioteca considera a memória dividida em três áreas: a área coletável, a área percorrível e a área não percorrível. A área coletável é dividida em gerações. Apenas nessa área, o coletor é reponsável por coletar células lixo. A área percorrével pode ser alocada 
e desalocada explicitamente pelo programador. Essa área precisa ser rastreada, pois pode conter referências para a área coletável. A área não percorrível não é examinada pelo coletor. Quanto à linguagem de programação, esta deve implementar um conjunto de rotinas padrão para permitir a utilização da biblioteca. Essas rotinas abstraem a implementação da linguagem, mas foram criadas para um tipo específico de coletor. A linguagem de programação conhece detalhes da implemetação do coletor, por exemplo, é ela quem determina quantas gerações o gerenciador de memória deve possuir. Sendo assim, as rotinas implementadas pela linguagem de programacao não são gerais o süficiente para serem utilizadas por qualquer coletor de lixo. 


\section{Capítulo 4}

\section{Implementação}

A interface genérica de coleta de lixo foi implementada na Jikes $\mathrm{RVM}^{1}$, uma máquina virtual de pesquisa desenvolvida pelo Centro de Pesquisa T.J. Watson da IBM[RVM]. A Jikes RVM foi considerado propícia para a implementação de nossa interface genérica pois:

- possui código fonte aberto e alguma documentação;

- é uma máquina virtual construída para pesquisa principalmente em gerenciamento de memória;

- foi implementado por uma empresa de respaldo, a IBM;

- a Jikes RVM é uma plataforma de pesquisa bem utilizada, servido de base a trabalhos em gerenciamento memória que resultaram em publicações em conferências como Programming Languages Design and Implementation - PLDI, Principles of Programming Languages - POPL e Object-Oriented Systems, Languages and Applications - OOPSLA;

- pode-se obter informações sobre a coleta de lixo durante a execução do Jikes RVM.

Este capítulo ${ }^{2}$ é composto de quatro seções: a primeira descreve a implementação da Jikes RVM relevante para a inclusão de nossa interface genérica de coleta de lixo, a segunda discorre sobre situações não previstas nas interfaces estudadas, a terceira apresenta a nossa

\footnotetext{
${ }^{1}$ RVM é sigla de Research Virtual Machine.

${ }^{2}$ Este capítulo refere-se a versão 2.1.1 da Jikes RVM.
} 
interface genérica de coleta de lixo e a última aborda a implementação dessa interface na Jikes RVM.

\subsection{Jikes RVM}

A Jikes RVM é um sistema complexo com mais de 200 classes e mais de 40.000 linhas de código ${ }^{3}$. Ela é implementada em java, com exceção de uma pequena parte escrita em C. Apesar de ser escrita em Java, a Jikes RVM não executa em cima de outra máquina virtual. Para inclusão de nossa interface genérica na Jikes RVM é necessário entendermos as implicações da implementação em Java da Jikes RVM, sendo que a mesma não executa em cima de uma outra máquina virtual.

Além disso, é necessário analisarmos a parte da implementação da máquina virtual relacionada ao compilador, à definição do modelo de objetos, à localização de referências na pilha de execução, ao início da execução da Jikes RVM e, principalmente, ao gerenciamento de memória.

\subsubsection{Jikes RVM escrita em Java}

\begin{tabular}{|c|}
\hline Aplicaçao \\
\hline Bibliotecas Java \\
\hline Maquina Virtual \\
\hline Bibliotecas Nativas \\
\hline Hardware \\
\hline
\end{tabular}

Figura 4.1: Execução de um programa Java

A execução de um programa Java, normalmente, envolve: o código do usuário compilado para bytecodes executados em uma máquina virtual implementada em cima de um sistema operacional. Veja a figura 4.1. Apesar da Jikes RVM ser escrita em Java, ela não é executada em cima de outra máquina virtual. A própria Jikes RVM é responsável por sua execução. No início da execução da máquina virtual, é necessário que um conjunto de serviços, como o

\footnotetext{
${ }^{3}$ Esses dados foram obtidos analisando o diretório VM_Build que contém as classes da Jikes RVM para uma dada configuração.
} 
compilador, o alocador de objetos e o carregador de classes, já existam para que os demais serviços requeridos para a normal execução da máquina virtual possam ser executados. Esses serviços iniciais, em uma máquina virtual escrita em código nativo ou em uma máquina virtual que executa no topo de uma outra máquina virtual, são disponíveis através de bibliotecas em tempo de execução[AAB+00]. Entretanto, esses serviços, escritos em Java na Jikes RVM, não são disponíveis em bibliotecas em tempo de execução. Para contornar este problema, esses serviços iniciais são fornecidos através de uma imagem de boot executável da Jikes RVM.

A imagem de boot é criada por um programa escrito em Java que é executado em uma máquina virtual Java qualquer, chamada de $J_{V M}^{4}$ de origem. Esse programa é chamado de escritor da imagem de boot. Ele reconhece os métodos e objetos que serão incluídos na imagem de boot, pela chamada especial a métodos init contidos em cada subsistema da máquina virtual. Qualquer classe que seja necessária para executar esse código será carregada dentro do próprio espaço de endereçamento da JVM de origem. Os métodos dessas classes são compilados para código de máquina através do compilador da Jikes RVM e serão incluídos na imagem de boot $\left[\mathrm{AAB}^{+} 00\right]$. O código compilado e os objetos necessários para iniciar a execução da Jikes RVM, como o carregador de classes, o compilador e o alocador de objetos, são copiados para a imagem de boot da Jikes RVM, sendo que esses objetos são convertidos para o formato de objetos da Jikes RVM. A imagem de boot é então armazenada no disco.

Um outro programa, escrito em C, carrega para memória a imagem de boot lida do disco. Além disso, esse programa faz com que a instrução responsável por iniciar a Jikes RVM seja executada. Veja a figura 4.2 .

Depois que sua execução é iniciada, a Jikes RVM pode, dinamicamente, carregar e compilar o restante dela própria, assim como, as classes e métodos da aplicação do usuário.

A Jikes RVM realiza algumas ações que não podem ser escritas em Java. Como, por exemplo, acesso a métodos e dados de uma classe através de um registrador dedicado e, no caso de um coletor de cópia, acesso a uma faixa de memória para copia de objetos. Os compiladores da Jikes RVM possibilitam essas "transgressões" em Java através de uma classe especial chamada VM_Magic ${ }^{5}$. O compilador ignora os bytecodes resultantes desses métodos e insere o código de máquina apropriado no lugar da chamada do método. Além

\footnotetext{
${ }^{4}$ JVM é a sigla para Java Virtual Machine.

${ }^{5}$ Como o gerenciador de memória é escrito em Java e precisa manipular áreas de memória, a utilização dessa classe foi permitida também em nossa implementação para essa finalidade.
} 


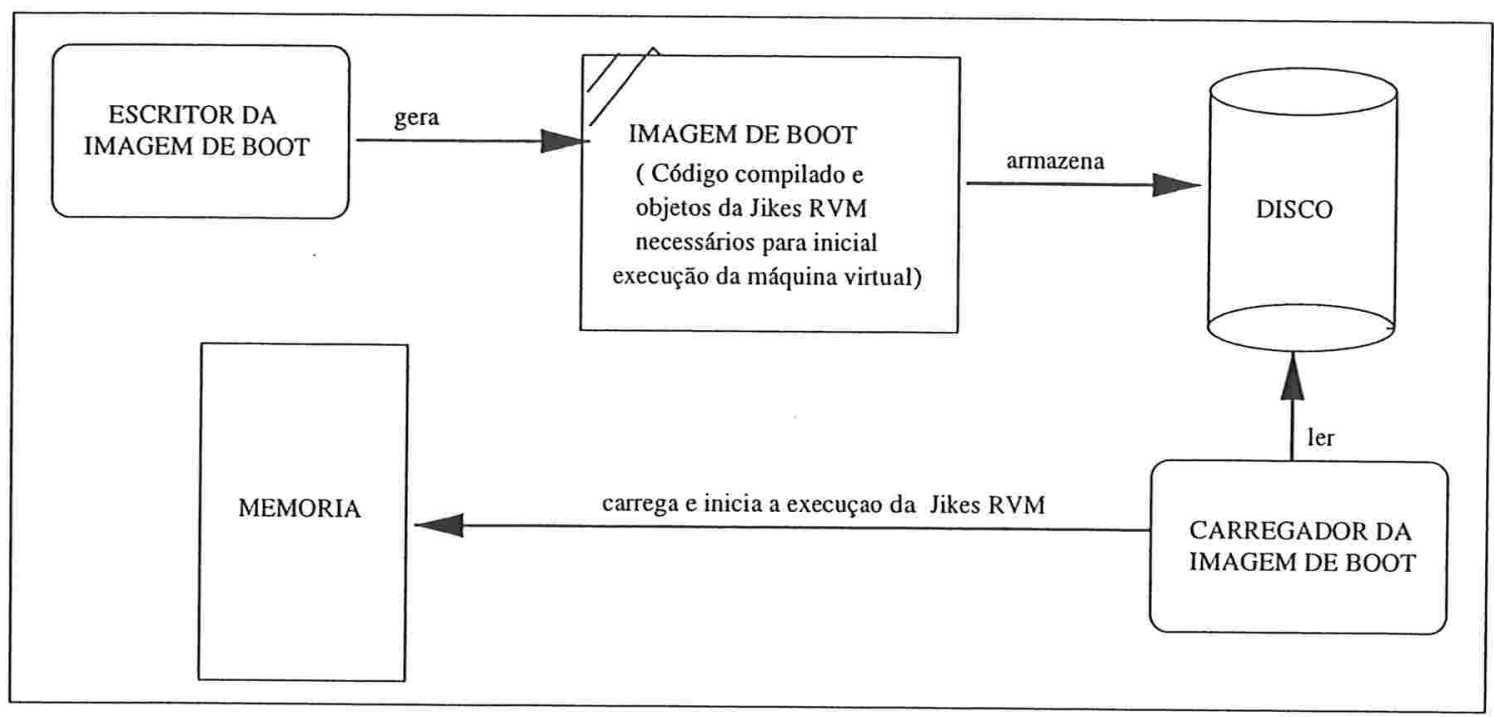

Figura 4.2: Criação e execução da Imagem de Boot da Jikes RVM

da classe VM_Magic, outra classe que é tratada de maneira especial pelo compilador é a classe VM_Address. Essa classe é usada pelo sistema em execução e pelo coletor de lixo para representar endereço de máquina. Os métodos dessa classe podem ser utilizados para aritmética de endereços, tais como, comparação e adição de endereços. Nenhum objeto dessa classe é criado em tempo de execução, ao invés disso, ela é interceptada pelo compilador e convertida dentro do tipo base, de 32 bit ou 64 bit de acordo com a arquitetura da máquina ${ }^{6}$.

\subsubsection{Compiladores}

O Jikes RVM é uma máquina virtual que não interpreta bytecodes, mas os compila para código de máquina e depois os executa. Os compiladores são just-in-time (JIT), ou seja, os bytecodes de um método são compilados para o código de máquina, a primeira vez em que ele é chamado. Esse código de máquina é então armazenado para ser reutilizado nas próximas chamadas a esse método. Na Jikes RVM, o compilador interage com o subsistema de gerenciamento de memória de várias maneiras. O compilador coopera com o coletor para identificar os ponteiros contidos em todos os frames de pilha de cada método na pilha de execução. Ao compilar um bytecode em um método que representa uma alocação de memória, métodos do gerenciador de memória serão invocados. Além disso, para coletores

\footnotetext{
${ }^{6} \mathrm{~A}$ implementação de nossa interface genérica também utiliza essa classe para representar os endereços.
} 
que requerem barreira de escrita, o compilador da Jikes RVM é responsável por inserir ao código compilado, instruções que implementam essa barreira.

Observe que os métodos dos coletores de lixo também são invocados durante a execução de uma aplicação java. Se esses métodos ainda não foram compilados, serão compilados pelo sistema de execução da Jikes RVM. Desta forma, é fácil observar que os diferentes subsistemas da Jikes RVM estão fortemente ligados. O compilador compila o código do coletor de lixo e o coletor de lixo coleta objetos lixo alocados a partir do compilador.

'É possível escolher entre dois tipos de compiladores: baseline e o otimizante. A compilação com o baseline é rápida, porém o código de máquina produzido é ineficiente comparado com o gerado pelo otimizante. Neste trabalho, utilizamos o compilador baseline. Este compilador basicamente troca cada bytecode Java pela equivalente seqüência de instruções de máquina. A principal classe é VM_BaselineCompiler. O corpo do método principal dessa classe invoca para cada bytecode o método apropriado na classe VM_Compiler. Esse método gerará o código assembly do bytecode Java. Em seguida, a classe VM_Assembly gerará o código de máquina binário do código assembly. A classe VM_BaselineCompiler é independente da máquina em que está executando ao contrário das classes VM_Compiler e VM_Assembly. Veja a figura 4.3.

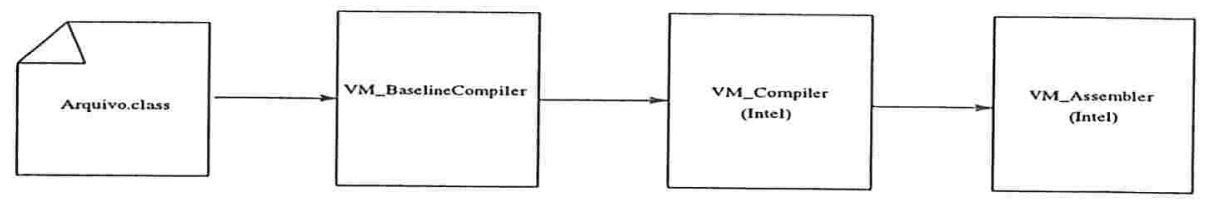

Figura 4.3: Geração de código de máquina na Jikes RVM

\subsubsection{Modelo dos Objetos}

Um objeto é composto conceitualmente por um cabeçalho e campos. Um cabeçalho normalmente contém informações necessárias em tempo de execução à máqụina virtual, como por exemplo, informações que possibilitam a verificação dinâmica de tipos ou a coleta de lixo. Na Jikes RVM, o cabeçalho armazena os seguintes dados sobre cada objeto a ele associado:

- uma referência para a localização de informações de tipo do objeto;

- informações do coletor de lixo sobre o objeto; 
- o estado de bloqueio do objeto, necessário aos processos de sincronização;

- um código hash para identificação do objeto;

As informações de tipo ${ }^{7}$ são armazenada no Type Information Block - TIB, sendo que cada classe do sistema possui um TIB associado. Essas informações são:

- uma referência para a tabela de métodos virtuais;

- uma referência para a descrição do tipo, que inclui a classe do objeto, super-classe, interfaces que ele implementa e deslocamento dos campos que contêm referência;

- referências para estruturas de dados que possibilitam uma checagem de tipo dinâmico e invocação eficiente de interfaces.

Os objetos na Jikes RVM possuem um cabeçalho de duas palavras ${ }^{8}$ : uma palavra armazena uma referência para o TIB e a outra, chamada de estado, informações do gerenciador de memória, código hash e estado de bloqueio.

Os valores em Jikes RVM são tipos primitivos ou referências. Os tipos primitivos incluem int, char, boolean etc., e as referências indicam os objetos alocados na heap. Os tipos primitivos são os tipos imediatos. A referência de um objeto sempre aponta para a terceira palavra a partir do cabeçalho do objeto. Na Jikes RVM os objetos que são vetores crescem na memória em sentido ascendente e os demais objetos, em sentido descendente. Uma referência aponta para o primeiro elemento de um vetor e, para os demais objetos, o local apontado está a um deslocamento negativo de 4 bytes do primeiro campo. Veja a figura 4.4 .

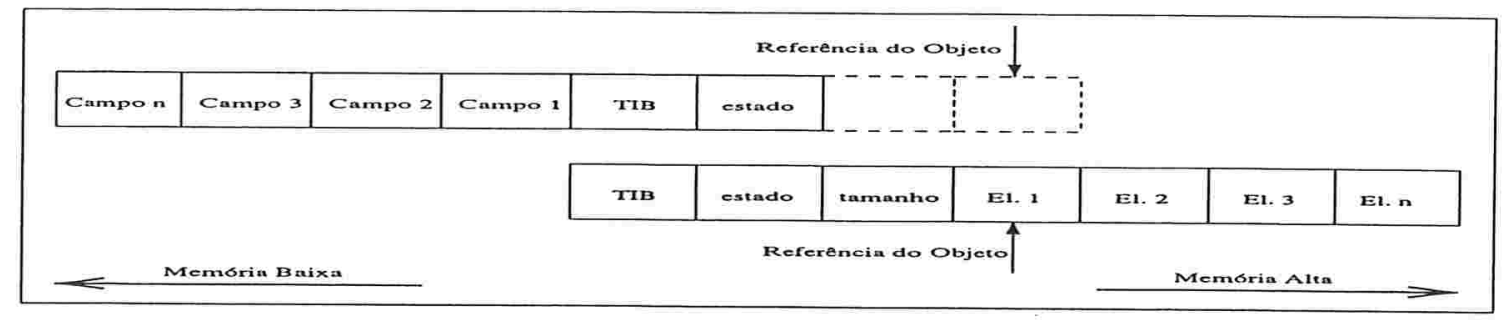

Figura 4.4: Modelo de Objeto na Jikes RVM.

\footnotetext{
${ }^{7}$ Utilizamos aqui a notação original dos autores, porém os TIBs descrevem classes, que, em java, não são todos os tipos.

${ }^{8}$ Existe mais de uma configuração de cabeçalho implementado na Jikes RVM, escolhemos a default.
} 
Outra estrutura de dados importante no modelo do objetos é o JikesRVM Table of Contents - JTOC. Essa estrutura contém:

- referências para campos e métodos estáticos de um objeto;

- literais e referências para constantes de strings;

- referências para o TIB para cada classe do sistema.

\subsubsection{Pilhas de Execução}

A Jikes RVM utiliza threads Java para implementar vários de seus subsistemas, inclusive o coletor de lixo. Cada thread Java possui uma pilha de execução. A pilha de execução contém um registro de ativação para cada invocação de um método, sendo que o compilador otimizante pode omitir os registros para métodos vazios e inline. A pilha é declarada como um vetor de inteiros.

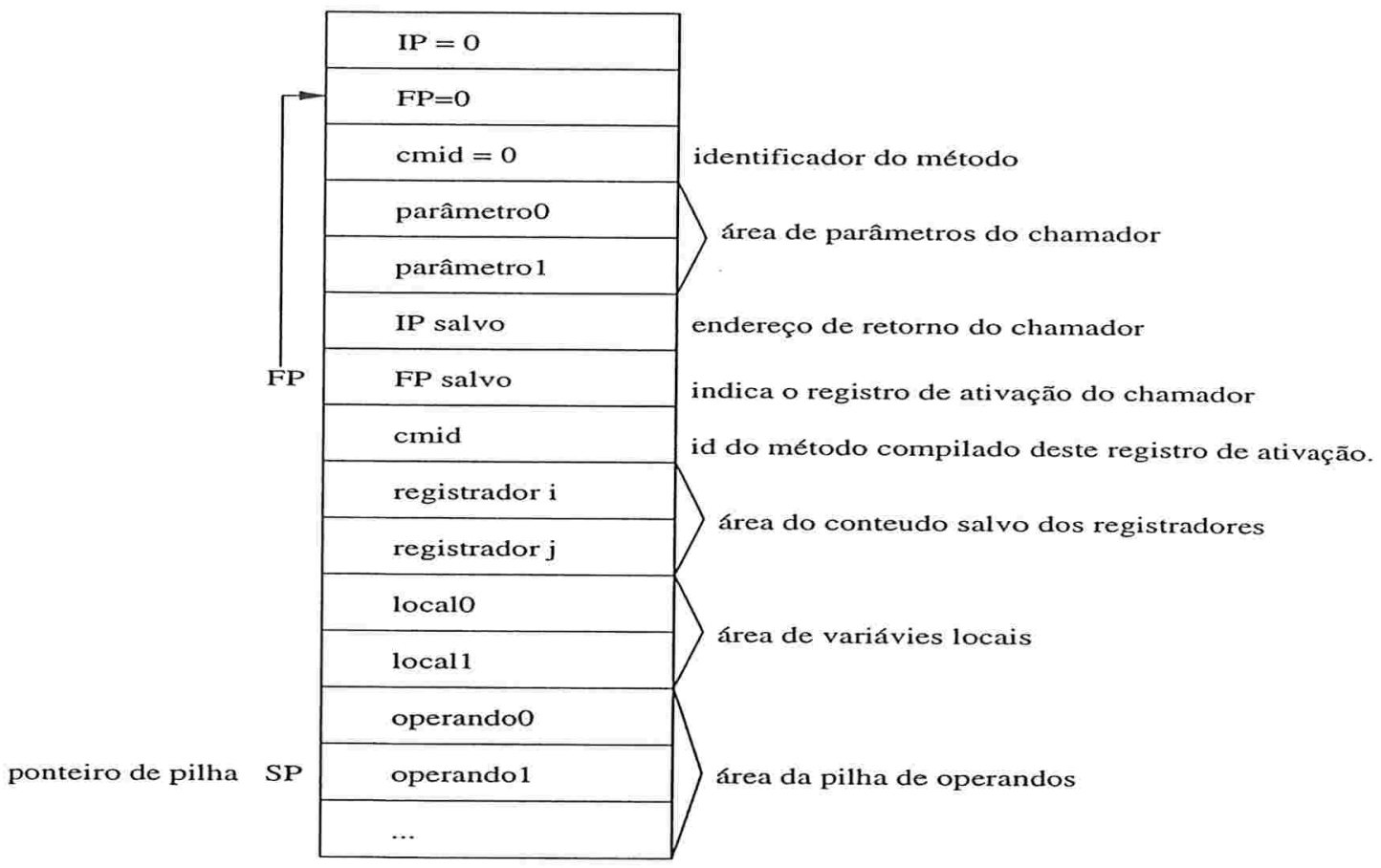

Figura 4.5: Formato da pilha de execução.

Neste trabalho, a Jikes RVM executará no sistema operacional Linux em uma plataforma 
de 32 bit, da intel ${ }^{9}$. A figura 4.5 ilustra as informações contidas em cada registro de ativação de uma pilha de execução ${ }^{10}$ :

- parâmetros utilizados na invocação do método;

- um apontador para o endereço de retorno no método chamador;

- um apontador para o registro de ativação do chamador;

- o identificador do método compilado;

- valores de alguns registradores são armazenados e restaurados após a execução do método;

- variáveis locais;

- área da pilha de operandos utilizados na avaliação de expressões;

Os apontadores FP e SP são utilizados para designar o início e o final do último registro de ativação, respectivamente. Ao término da execução de um método SP recebe o valor contido em FP e FP recebe o valor contido no campo do registro de ativação que designa o registro de ativação do chamador.

As threads Java são as threads da máquina virtual, incluindo as threads do gerenciador de memória, e as da aplicação. O escalonador da Jikes RVM mapeia as threads Java em processadores virtuais que são implementados como pthreads ${ }^{11}$, ao invés de mapeá-las diretamente para o sistema operacional. Cada pthread é mapeada diretamente para uma thread do sistema operacional. Geralmente a Jikes RVM cria um processador virtual para cada processador físico. O sistema operacional é responsável por escalonar suas threads para os processadores disponíveis. As threads Java são escalonadas usando uma fatia do tempo de cada pthread. Nosso trabalho não aborda detalhes de implementação relacionados ao processamento paralelo na Jikes RVM. Para mais detalhes veja $\left[\mathrm{AAB}^{+} 00\right]$. A figura 4.6 ilustra o escalonamento de threads realizado no Jikes RVM ${ }^{12}$.

\footnotetext{
${ }^{9}$ As convenções para este ambiente estão em mudança na Jikes RVM, segundo o The Jikes Research Virtual Machine User's Guide v2.1.1 contido em [RVM].

${ }^{10}$ A figura 4.5 foi adaptada de uma figura existente no código fonte da Jikes RVM.

${ }^{11} \mathrm{O}$ nome pthreads refere-se a POSIX kernel-level threads

${ }^{12} \mathrm{~A}$ figura 4.6 é baseada na figura contida no artigo de [HSHD04]
} 


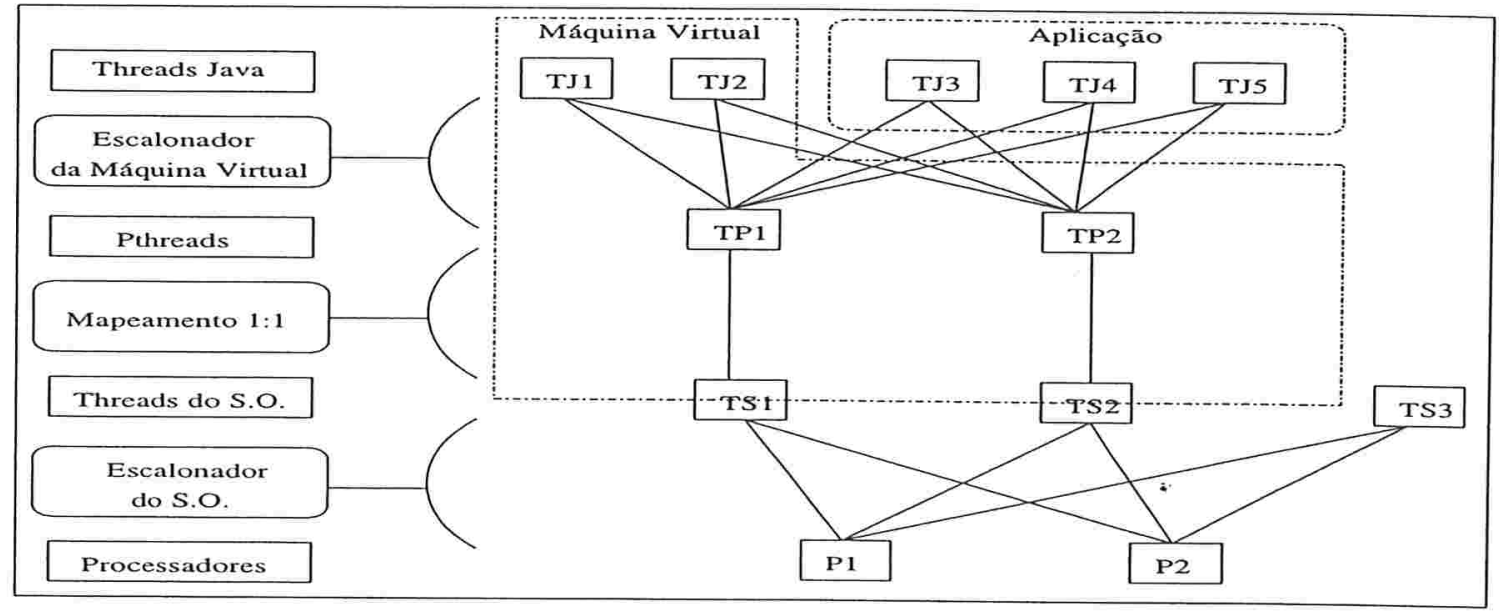

Figura 4.6: Escalonamento de threads na Jikes RVM

As referências para a heap, contidas na pilha de uma thread, são obtidas em alguns pontos de execução da thread, ou seja, nos pontos seguros. Os compiladores da Jikes RVM incluem no código compilado, instruções para que seja possível obter um mapa de localização das referências contidas nas pilhas de execução nesses pontos.

\subsubsection{Gerenciamento de Memória}

A Jikes RVM suporta vários gerenciadores de memória responsáveis pela alocação e liberação automática de objetos na heap. Cada gerenciador de memória pode utilizar um método diferente de alocação e liberação de objetos. A alocação de objetos é concorrente e o coletor de lixo é exato, paralelo e não incremental.

A escolha do gerenciador de memória é definida antes da construção da imagem de boot da Jikes RVM, onde especifica-se qual o compilador que será utilizado para compilar a imagem de boot, o compilador utilizado para compilar as classes carregadas em tempo de execução e o algoritmo de coleta de lixo ${ }^{13}$.

Além dos gerenciadores de memória fornecidos com a Jikes RVM, outros gerenciadores podem ser implementados. É necessário apenas criar um novo diretório para armazenar as classes responsáveis pela coleta e alocação de memória. Esse diretório deve ser especificado

\footnotetext{
${ }^{13} \mathrm{O}$ compilador utilizado para compilar as classes carregadas em tempo de execução da Jikes RVM pode ser especificado como adaptativo. Desta forma, o compilador pode ser especificado na linha de comando, depois de construída a imagem de boot, ou selecionado automaticamente durante a execução de uma aplicação.
} 
em alguns arquivos de configuração da Jikes RVM para que possa ser utilizado na construção de imagem de boot da máquina virtual.

\section{Organização da Heap}

A heap na Jikes RVM é dividida de acordo com a estratégia de gerenciamento de memória utilizada. Em qualquer uma da estratégias implementadas na Jikes RVM, os objetos da aplicação do usuário são alocados em uma das duas heaps: a heap de objetos grandes e a heap de objetos pequenos. A heap de objetos pequenos pode ser divida em mais regiões, dependendo do coletor utilizado. Por exemplo, em um coletor semi-espaço, a heap de objetos pequenos é dividida em duas partes: heap origem e heap destino.

No início da execução da Jikes RVM, uma parte da heap é destinada à armazenar a imagem de boot, a heap de boot. Essa heap contém objetos criados pelo escritor da imagem de boot, diferentemente dos contidos em outras heaps, que são criados durante a execução da Jikes RVM. Os objetos na heap de boot nunca são desalocados, mas podem ser modificados durante a execução da máquina virtual.

Além desses três tipos de heap, existe a heap imortal e a heap de baixo nivel. Na heap imortal, como o próprio nome diz, os objetos não são desalocados durante a execução da Jikes RVM. Essa heap armazena estruturas de dados do gerenciamento de memória. Tanto a heap de boot, como a heap imortal podem referenciar objetos na heap de objetos grandes ou na heap de objetos pequenos, portanto, elas precisam ser percorridas pelo coletor de lixo. A heap de baixo nível está relacionada com as rotinas de apoio à Jikes escritas na linguagem C, e portanto não é percorrida pelo coletor de lixo. Nela objetos são alocados e desalocados com gerenciamento explícito gerenciamento de memória (e.g. rotinas malloc e free de C).

Para cada uma dessas heaps, existe uma classe para representá-la. Nesta classe, além de outras informações, o endereço inicial e final de cada heap é especificado.

\section{Alocação na Heap}

Quando um bytecode referente a um new() na linguagem de programação Java é encontrado pelo compilador, o método de alocação do gerenciador de memória será executado. De acordo com o tamanho do objeto, ele será armazenado na heap de objetos grandes ou na heap de objetos pequenos. 
A alocação de memória na Jikes RVM é realizada em paralelo, sendo que há uma thread responsável pela alocação de memória por processador virtual. Como há um único espaço de endereçamento compartilhado por todas os processadores, o acesso à memória precisa ser sincronizado. Para diminuir a necessidade de sincronização, a alocação na heap de objetos pequenos é realizada através de um ou mais blocos de memória associados a cada processador virtual. Cada um desses blocos é chamado de bloco local do processador. Apenas a thread do processador associado ao bloco, poderá realizar alocações nessa região da memória. Quando uma requisição de memória é obtida, tenta-se alocá-la primeiramente no bloco local do processador. Caso não seja possível, é requisitado mais um bloco de memória da área global. Essa área de memória global é compartilhada por todos os processadores, portanto, requer sincronização. A coleta de lixo é disparada caso não seja possível obter um bloco de memória para o processador quando necessário.

A alocação de um objeto na heap de objetos grandes é feita utilizando-se a técnica de primeiro encaixe. Essa heap é dividida em blocos de tamanhos iguais. O primeiro conjunto de blocos contíguos livres que satisfaçam o tamanho de memória requisitado é utilizado para a alocação.

Depois que uma área de memória para o objeto é criada, ele pode ser inicializado. Nesta fase, o cabeçalho e uma referência para o TIB são criados. Se o objeto for um vetor, o tamanho dele também será armazenado.

\section{Coleta de Lixo}

Existem quatro coletores de lixo paralelos e não incrementais fornecidos com a Jikes RVM: um coletor de semi-espaço, um coletor de gerações com cópia, um coletor marcar-e-varrer e um coletor híbrido de gerações, ondẹ a geração mais nova utiliza o algoritmo de semi-espaço e as outras gerações o de marcar-e-varrer. Uma coleta de lixo pode ser disparada pelo alocador de memória ou, explicitamente, pela aplicação do usuário.

Em sistemas multiprocessados, a coleta de lixo é realizada em paralelo. Desta forma, existe uma thread do coletor para cada processador. Durante a execução do modificador, as threads do coletor não executam. Quando uma coleta de lixo é requisitada, cada thread do modificador executa até que alcance um ponto seguro. Nesses pontos, um mapa de referências da pilha é gerado pelo compilador. As threads do coletor podem então executar. Os coletores 
implementados na Jikes RVM percorrem a heap a partir da raiz. O conjunto raiz é composto pelo mapa de referências de pilha gerado pelo compilador e pelo JTOC. Apenas quando a coleta de lixo termina as threads do modificador são liberadas para executar.

A barreira de escrita, necessária em alguns algoritmos de coleta de lixo, é implementada na Jikes RVM. O compilador insere instruções para implementação da barreira de escrita apenas se esta for requerida pelo coletor.

Na execução da Jikes RVM pode-se obter informações sobre a execução da coleta de lixo, como por exemplo: o número de ciclos de coleta, a média de uma ciclo de coleta e o tempo do maior ciclo. Cada coletor de lixo pode ainda fornecer informações específicas de seu algoritmo de coleta para que sejam disponibilizadas durante a execução de uma aplicação.

\subsection{Situações não previstas nas interfaces estudadas}

O estudo da implementação da Jikes RVM ressaltou problemas não tratados pelas interfaces estudadas até o momento. Apesar de analisarmos um caso específico, a Jikes RVM representa um ambiente de execução real de uma linguagem de programação.

Nesta seção mostraremos as peculiaridades da Jikes RVM que não foram previstas pelas interfaces anteriores.

\subsubsection{Formato de uma referência para um objeto na heap}

Uma referência armazena um endereço pelo qual o sistema de execução da linguagem de programação consegue acessar ou obter informações sobre um objeto na heap. Na Jikes RVM, esse endereço pode apontar para uma região fora da área alocada para o objeto referenciado.

Os coletores podem associar algumas informações dos objetos à região da memória onde eles estão localizados ou determinar a que parte da heap o objeto pertence dado a sua localização (início de um objeto em marcar e varrer, geração em coletores de geracão, etc.). Para isso é necessário obter, a partir de uma referência, a localização do objeto na memória, informação que pode envolver o conhecimento da representação do objeto.

Em coletores de cópia, objetos vivos que referenciam um objeto copiado precisam referenciar sua nova posição na memória. A localização original do objeto, armazena o endereço de sua nova localização para que as referências sejam atualizadas quando necessário. Neste 
caso, esse endereço deve possibilitar ao sistema de execução da linguagem o acesso ao objeto copiado.

O endereço armazenado em uma referência, muitas vezes, devido ao alinhamento requerido na alocação dos objetos, possuem os bits menos significativos iguais a zero. Por exemplo, se o endereço sempre indicar posições múltiplas de 4 bytes, os dois últimos bits do endereço serão sempre zero. Em coletores de cópia, menos bits seriam necessários para armazenar o endereço de um objeto na sua localização original. Por exemplo, a Jikes RVM disponibiliza 30 bits, ao invés de 32 bits para esse endereço.

\subsubsection{Modelos de objetos distintos na heap}

A representação na memória dos objetos vetores diferem dos outros objetos na heap, como podemos perceber através da figura 4.4.

$\mathrm{Na}$ fase de varredura de coletores de lixo como o marcar-e-varrer, os objetos alocados na heap são percorridos sem, a princípio, existir uma referência para cada objeto. Algumas informações do coletor podem ser verificadas durante essa fase para decidir se objeto é lixo ou não. Se essas informações estiverem no próprio objeto, como obtê-las? Se todos os objetos na Jikes RVM, possuíssem o mesmo modelo na memória, o sistema de execução poderia acessar os dados do objeto através de um deslocamento fixo do endereço inicial ou final do objeto, dependendo se eles estivessem organizados de modo ascendente ou descendente na heap. Apesar dos objetos da Jikes RVM serem formados por apenas por um bloco de dados, outra questão foi levantada: a liberação de objetos formados por mais de um bloco. Sem uma referência para o objeto, como o sistema de execução da linguagem de programação saberá quais blocos o constituem?

\subsubsection{Objetos copiados mudam de tamanho}

De acordo com os requerimentos da linguagem Java, todos os objetos devem possuir um código único que não é modificado durante toda a vida do objeto. No modelo de objeto utilizado na Jikes RVM esse código pode ser baseado no endereço do objeto. Se um objeto for copiado, no próprio objeto será armazenado seu endereço original. Desta forma, coletores de lixo de cópia provocam a mudança do tamanho de objeto. 
Neste caso, a linguagem de programação precisa saber quando um objeto será copiado pelo coletor para que possa armazenar o endereço original no local apropriado. Se o objeto terá seu tamanho modificado, o gerenciador de memória precisa conhecer seu novo tamanho para encontrar um espaço suficiente de memória para copiá-lo. Se o gerenciador de memória precisasse do tamanho de um objeto para percorrer os objetos alocados na heap, caso isso fosse possível, o tamanho do objeto não mudaria.

\subsubsection{Objetos "com finalização}

A especificação da linguagem de programação Java diz que antes da memória para um objeto lixo ser reutilizada, a máquina virtual deve invocar o método finalizer() desse objeto. Assim, mesmo que o coletor de lixo considere um objeto como lixo, se esse objeto possuir o método finalizer() não executado, ele e todos os objetos que ele referencia, direto ou indiretamente, precisam permanecer vivos. Para que essa especificação seja satisfeita, o coletor de lixo precisa interagir com o sistema de execução da Jikes RVM.

\subsubsection{Chamadas da biblioteca padrão Java para o gerenciador de memória}

Uma aplicação Java pode chamar alguns métodos definidos pela biblioteca padrão Java que estão relacionadas com o gerenciamento de memória, como os métodos freeMemory() ou gc(). O primeiro retorna quanto de espaço livre existe na heap para alocação, e o segundo dispara a execução de uma coleta de lixo.

Esses métodos precisam ser implementados pelo gerenciador de memória para garantir o correto funcionamento de algumas aplicações.

\subsubsection{Forte ligação entre o Gerenciador de Memória e os outros subsistemas da Jikes RVM}

Mais do que em outras máquina virtuais, diferentes subsistemas que compõem a Jikes RVM são fortemente ligados entre si. O compilador, por exemplo, compila o código do subsistema de gerenciamento de memória da Jikes RVM. Mudanças em um dos subsistemas 
podem alterar o desempenho de outros.

Jikes RVM e o Gerenciador de Memória são escritos em Java e executam dentro da própria Jikes RVM

Como a Jikes RVM e o gerenciador de memória são escritos em Java e executam dentro da própria Jikes RVM temos um impasse: para o gerenciador de memória executar é necessário que a máquina virtual esteja executando e para a Jikes RVM executar precisa que o gerenciador de memória também esteja executando. A Jikes RVM precisa de memória para executar, portanto precisa da execução do gerenciador de memória. O gerenciador de memória para executar precisa, por exemplo, que o carregador de classes e o compilador da Jikes RVM esteja executando.

Threads, paralelismo, estruturas de dados do gerenciador de memória associada ao processador

A Jikes RVM suporta execução paralela, então é possível que múltiplas threads estejam executando ao mesmo tempo. Como o próprio gerenciamento de memória é escrito em java e executa em cima da Jikes RVM, ele precisa ter acesso as threads e aos processadores virtuais da Jikes RVM para implementar sua política de gerenciamento de memória, como por exemplo, execução paralela e "não incremental" do coletor de lixo. Como um único espaço de endereçamento é utilizado, pode ser necessário sincronização para acessar regiões da memória. Algumas estruturas de dados do gerenciamento de memória podem ser associadas a cada processador virtual para diminuir a necessidade de sincronização.

\subsection{Definição da Interface Genérica}

Através dos trabalhos de Durham e de Uchiyama et al, definimos um conjunto de rotinas iniciais para nossa interface genérica. As poucas rotinas definidas por Uchiyama et al necessárias a uma interface genérica de coleta de lixo e não encontradas na tese de Durham foram incorporadas ao nosso trabalho. O mesmo resultado obtido através de algumas rotinas de Uchiyama et al pode ser adquirido pela combinação de outras rotinas contidas na tese Durham ou vice-versa. Outras rotinas foram acrescentados à medida que avançávamos na 
implementação de nossa interface genérica na Jikes RVM. A razão da escolha de cada rotina será apresentada no decorrer desta seção.

\subsubsection{Interface da Linguagem de Programação}

Rotinas relacionadas as informações do coletor

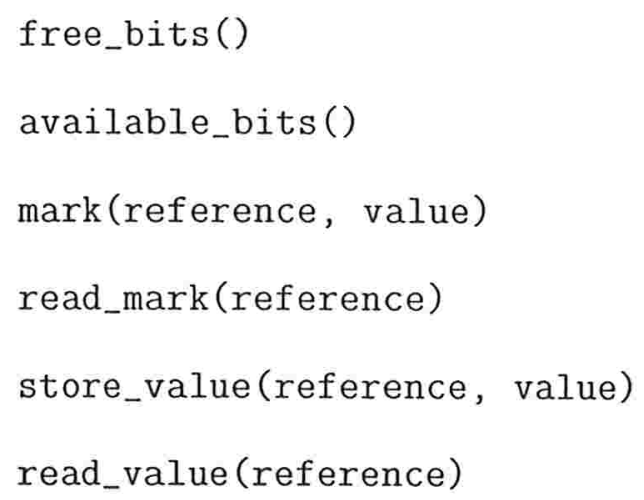

As seis primeiras rotinas estão presentes no trabalho de Durham. Elas foram escolhidas, ao invés das cinco rotinas MM_make_header, MM_decode_header, MM_encode_header, MM_write_header, MM_read_header do trabalho de Uchiyama et al, porque viabilizam uma utilização mais eficiente da memória. Se as rotinas free_bits() ou available_bits() indicarem que não há espaço suficiente nos objetos para as informações do coletor, o gerenciador de memória poderá alocar mais espaço na memória para que essas informações sejam armazenadas. Convencionamos que os bits que devem ser considerados na manipulação dessas rotinas, são os bits mais à direita. Ou seja, se free_bits informa que há dois bits inteiros disponíveis e a rotina mark é utilizada com o argumento value sendo um inteiro, apenas os dois bits mais direita desse inteiro serão considerados pelo sistema de execução da linguagem de programação. O trabalho de Durham, não relata como esse controle é realizado.

\section{Descoberta e processamento da raiz}

root_scan()

A rotina root_scan corresponde a rotina proposta por Uchiyama et al. A diferença é que, em nossa interface genérica, a rotina a ser aplicada a cada referência encontrada na 
raiz não é passada como parâmetro. Ao invés disso, essa rotina é definida na interface do gerenciador de memória e deve ser chamada a partir de root_scan para cada referência encontrada na raiz e seu valor de retorno, utilizado para atualizar o conteúdo das referências. Não escolhemos os métodos de gerenciamento do registro de ativação de Durham porque a forma como os registros de ativação são organizados na memória está muito ligada as características da linguagem. A localização dos registros de ativação podem ser determinadas de maneira estática, como é o caso de FORTRAN, ou dinâmicas e organizadas no formato de uma pilha, como em Pascal ou sem nenhuma organižação definida, como em linguagens em que é possível que o registro de ativação chamado "sobreviva" ao do chamador. O livro do Aho [AVAS86] mostra essas estratégias de alocação do registro de ativação. Além disso, com a rotina root_scan menos mensagens são trocadas entre a linguagem de programação e o gerenciamento de memória.

\section{Processamento das referências em cada objeto}

is_immediate(reference)

process_object(reference, typeId)

A rotina is_immediate de Durham foi escolhida por obter o mesmo resultado da combinação das rotinas MM_get_type e MM_is_atomic de Uchiyama et al. O implementador da linguagem de programação possui mais flexibilidade para descobrir se uma referência é ou não imediata, pois possui todas as informações necessárias para isto.

A rotina process_object foi proposta por Durham. A diferença é que, em nossa interface genérica, a rotina a ser aplicada a cada referência encontrada no objeto não é passado como parâmetro. Ao invés disso, essa rotina é definida na interface do gerenciador de memória e deve ser chamada a partir de process_object para cada referência encontrada no objeto indicado por reference e seu valor de retorno, utilizado para atualizar o conteúdo das referências.

\section{Processamento de objetos com o método finalize}

there_is_garbage() 
Essa rotina foi incluída em nossa interface para tratar o caso dos objetos com o método finalize. Essa rotina é chamada pelo gerenciador de memória para indicar ao sistema de execução da linguagem de programação que há objetos cujo método finalize pode ser executado.

\section{Localização de Objetos}

bottom_address_of_reference(reference)

A rotina bottom_address_of_reference foi incluída na tese de Durham para lidar com os algoritmos de coleta de lixo que decidem a que região um objeto pertence a partir de seu endereço. Entretanto, a rotina de Durham não prevê que o endereço indicado na própria referência pode ser de uma área localizada fora do objeto. Neste caso, é necessário uma exigência para o endereço retornado por esta rotina: o endereço deve fazer parte da área alocada para o objeto. Convencionamos que o endereço retornado é o primeiro do primeiro bloco que compõe o objeto.

\section{Liberação de objetos}

release (reference)

Essa rotina está contida no trabalho de Durham, ela não foi incluída no artigo de Uchiyama et al. Essa rotina retorna o endereço do primeiro bloco de memória que compõe o objeto dado uma referência para o mesmo. Ao implementar essa rotina, algumas informações devem ser inseridas em cada bloco do objeto: a primeira palavra deve armazenar seu tamanho e a última, o endereço do próximo bloco ou zero se o bloco em questão já for o último. Essa rotina evita que o gerenciador de memória controle diretamente quais blocos pertencem a um objeto. No algoritmo de contagem de referência, a referência para o objeto cujo contador tornou-se zero pode ser passado para esta rotina.

Para os coletores de lixo como o marcar-e-varrer que percorrem diretamente os blocos retidos sem utilizar referências para os objetos, outra abordagem deve ser utilizada. O trabalho de Durham não previa que não era possível percorrer os objetos diretamente na memória sem uma referência para eles. O trabalho de Durham considerava que a partir do endereço de início do primeiro bloco do objeto, seria possível encontrar informações sobre o objeto, o 
que não é sempre possível, inclusive na Jikes RVM. Uma solução seria o gerenciador de memória controlar quais blocos são alocados para um mesmo objeto e armazenar as informações relevantes ao coletor fora do objeto, como a marca utilizada no algoritmo marcar-e-varrer. Neste caso, apenas o gerenciador de memória seria responsável por liberar um objeto.

\section{Cópia de objetos}

$$
\text { copy(reference, new_address) }
$$

size_of_object_when_copied(reference)

Assim como a rotina anterior, essa rotina não foi incluída no artigo de Uchiyama et al. Entretanto, essa rotina é necessária para que a cópia seja realizada sem restringir o coletor a um formato de células.

Quanto à rotina size_of_object_when_copied, os dois trabalhos não lidam, explicitamente, com a possível mudança do tamanho de objetos copiados, como acontece com os objetos da Jikes RVM. Essa rotina retorna não o tamanho real do objeto indicado por reference, mas o tamanho que esse objeto teria caso fosse copiado.

\subsubsection{Interface do Gerenciador de Memória}

Rotinas relacionadas ao início e ao final da execução de uma aplicação

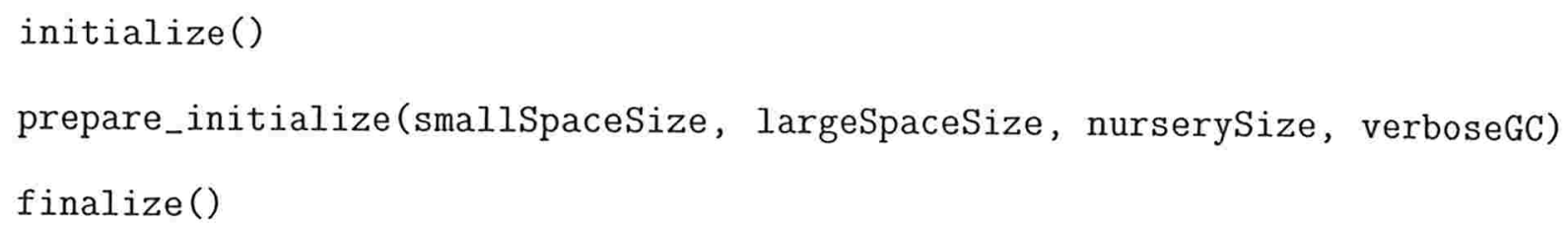

O trabalho de Uchiyama et al. contém as rotinas initialize e finalize para a realização de operações do coletor de lixo quando o sistema em execução inicia e termina, respectivamente. Entretanto, dividimos a rotina initialize em duas outras rotinas: initialize() e prepare_initialize(smallSpaceSize, largeSpaceSize, nurserySize, verboseGC). Essa divisão mostrou-se necessária de vido ao fato da Jikes RVM e o gerenciador de memória serem escritos em Java e executarem dentro da própria Jikes RVM. Alguns métodos do gerenciador de memória, portanto, precisam fazer parte da imagem de boot da Jikes 
RVM. A implementação da rotina initialize() deve alocar os objetos que são necessário para iniciar a execução do gerenciador de memória. Esses objetos são incluídos na imagem de boot, na Jikes RVM. A rotina prepare_initialize inicializa os objetos alocados e realiza as operações necessárias no início da execução da linguagem de programação. Essa rotina possui três parâmetros smallSpaceSize, largeSpaceSize, nurserySize, verboseGC. Os três primeiros parâmetros são um indicativo para gerenciador de memória sobre os tamanho a serem usados para cada tipo de objeto. Dependendo da aplicação, mais objetos grandes ou pequenos são alocados. Por isso, é razoável que essas informações sejam passadas ao gerenciador de memória. SmallSpaceSize, largeSpaceSize e nurserySize referem-se, respectivamente, ao espaço destinado à alocação de objetos pequenos, objetos grandes e objetos da geração mais nova de um coletor de gerações. O quarto parâmetro, verboseGC, indica ao gerenciador de memória se ele pode emitir mensagens para o usuário. As linguagens de programação em que a alocação dos objetos do gerenciador de memória não ocorre em um momento arbitrário podem chamar a rotina prepare_initialize imediatamente depois da initialize.

\section{Informações do gerenciador de memória associada ao processador} setupProcessor (processor)

Apesar de não projetarmos a nossa interface para execução paralela do gerenciador de memória, incluimos a rotina setupProcessor em nossa interface genérica. Essa rotina permite que algumas estruturas de dados do gerenciador de memória sejam associadas a cada processador virtual quando ele é criado pela sistema de execução da linguagem.

\section{Cópia de Objetos}

move_objects ()

Essa rotina retorna true se o gerenciador move objetos na heap e false caso contrário. Essa rotina mostrou-se necessária na implementação da interface na Jikes RVM. Se o código único de cada objeto é baseado em seu endereço, a linguagem de programação precisa conhecer se os objetos são movidos na memória para obter corretamente esse código. 
Barreira de leitura e de escrita

updateReference (new_reference, changing_object)

readReference(reference_pointer)

Os dois trabalhos anteriores possuem rotinas para a criação da barreira de escrita e de leitura. A rotina updateReference é utilizada para implementar a barreira de escrita. Ela deve ser chamada antes do sistema de execução da linguagem de programação atualizar o campo referência do object indicado por changing_object. Já a rotina readReference é utilizada para implementar a barreira de leitura. Ela deve ser chamada antes do sistema de execução da linguagem de programação acessar o object indicado por reference_pointer. Se o objeto foi copiado, essa rotina retorna o endereço apropriado para a sua nova localização.

\section{Alocação de Objetos}

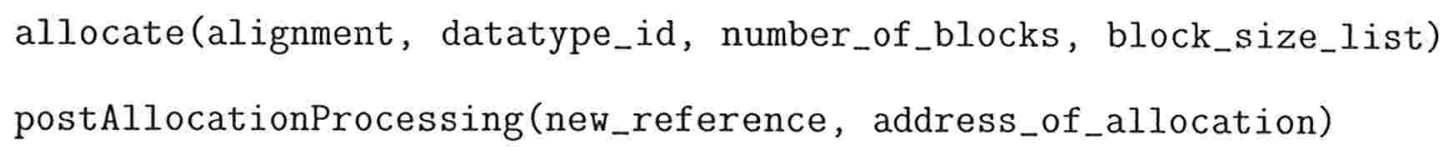

Optamos pela rotina definida no trabalho de Durham por facilitar encontrar memória disponível no conjunto de blocos livres. Esta função solicita um conjunto de blocos de memória ao invés de um único bloco cujo tamanho seja igual a soma dos tamanhos dos blocos anteriores. Observe que rotina de Uchiyama et al obtém o mesmo efeito da rotina anterior, caso fosse chamada number_of_blocks vezes. No entanto, o desempenho de um número menor de chamadas é melhor. Nessa rotina de Durham podemos acrescentar a indicação de uma falha na tentativa de alocação através de um ponteiro especial. Este ponteiro poderia, por exemplo, indicar o endereço 0, sendo que este endereço não poderia ser utilizado com outro propósito. Desta forma, não é necessária a rotina MM_alloc_failure() proposta por Uchiyama et al.

Acrescentamos na rotina allocate o parâmetro alignment. A linguagem de programação pode exigir que os objetos alocados estejam alinhados na memória. Sendo assim, para o gerenciador de memória alocar um objeto na heap, ele precisa conhecer esse alinhamento.

A rotina postAllocationProcessing foi adicionada ao nosso trabalho porque depois que o objeto é criado, informações do gerenciador de memória podem ter que ser inicializadas 
no próprio objeto. Por exemplo, o coletor pode limpar a área de memória destinada a ele no cabeçalho do objeto através dos métodos apropriados da interface da linguagem de programação. Além disso, a referência passada como parâmetro por essa rotina pode ser armazenada pelo gerenciador de memória em alguma posição da memória de maneira que ele possa obtê-la quando necessário. Por exemplo, na fase de varredura de coletores como o marcar-e-varrer, essa referência pode ser utilizada como parâmetro da rotina release. Desta forma, o sistema de execução da linguagem de programação seria responsável pela liberação do objeto. Como parâmentros ela possui uma referência para o objeto e endereço de localização desse objeto na memória.

\section{Processamento de referências}

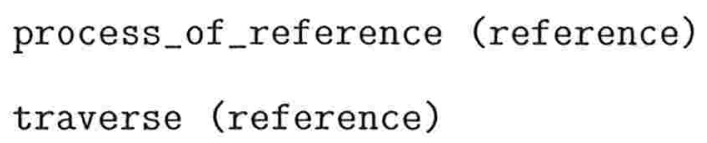

Essas rotinas são chamadas, respectivamente, por process_object (reference, typeId) ou process_object(reference) e root_scan(traverse).

\section{Processamento de objetos com o método finalize()}

block_collection(reference)

get_garbage ()

unblock_collection(reference)

Essas três rotinas foram adicionadas à nossa interface para tratar os objetos que possuem o método finalize. A rotina block_collection fornece ao gerenciador de memória uma referência para o objeto que possui o método finalize. Essa rotina é chamada logo após a alocação do objeto. O gerenciamento de memória pode manter uma lista de todos esses objetos e, caso o coletor de lixo indique que um deles é lixo, não coletá-los, assim como, os objetos referenciados a partir deles. Através da rotina get_garbage(), o sistema de execução da linguagem de programação obtém objetos cujo método finalize pode ser executado. Para avisar que um objeto com o método finalize já pode ser coletado, o método unblock_collection é chamado. 
Conformidade com a biblioteca padrão Java

\author{
gc ( ) \\ freeMemory() \\ totalMemory ()
}

Para atender os requisitos da biblioteca padrão Java essas rotinas foram incluídas na nossa interfface. A primeira dispara a execução de uma coleta de lixo. A segunda, retorna o quantidade de memória livre para alocação. A última, retorna a quantidade total de memória utilizada pela aplicação.

Conhecimento da execução do coletor de lixo gcInProgress ()

Essa rotina foi considerada necessária na implementação da Jikes RVM para informar à linguagem de programação que uma coleta de lixo está sendo executada. Se o coletor de lixo estiver executando, algumas ações da Jikes RVM não devem ser realizadas, como aumentar o tamanho da pilha contida na heap.

\title{
4.4 Implementação da Interface Genérica na Jikes RVM
}

Ao implementarmos a interface genérica de coleta de lixo desejamos que as interações entre a Jikes RVM e o subsistema de gerenciamento de memória sejam realizados através dessa interface. Veja a figura 4.7.

O nosso trabalho procurou modificar o mínimo possível a implementação da Jikes RVM, incluindo o sistema de gerenciamento de memória já existente. Assim, a implementação dos algoritmos de coleta de lixo foram preservados ao máximo, isso porque desejávamos mostrar a possibilidade de implementá-los com a nossa interface genérica, sem a necessidade de conhecer os detalhes de implementação da máquina virtual. Além disso, queríamos avaliar, tanto quanto possível, apenas o que a nossa interface genérica diminui de desempenho a execução das aplicações na Jikes RVM. Se modificássemos o gerenciamento de memória ou a implementação do restante da Jikes RVM de maneira significativa, essa avaliação de desempenho 


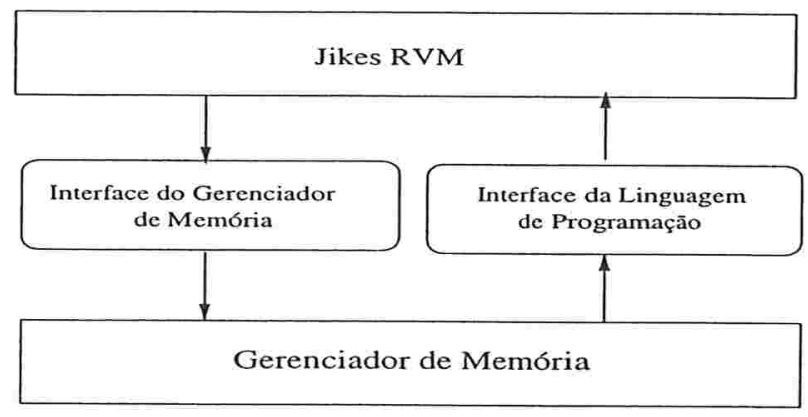

Figura 4.7: Interface entre a mạquina virtual e o gerenciador de memória

seria prejudicada pelo acréscimo dessas mudanças. Uma vantagem dessa metodologia de trabalho é a diminuição da possibilidade de geração de erros durante nossa implementação. Desta forma, concentramo-nos na implementação da nossa interface e não em modificações do código da Jikes RVM ou do gerenciador de memória que iriam além do escopo deste trabalho.

A implementação da interface da linguagem de programação é específica à Jikes RVM. Para essa implementação foi necessário investigarmos como obter da Jikes RVM as informações necessárias à construção de cada método ${ }^{14}$ dessa interface. Além disso, a Jikes RVM era responsável pela chamada de alguns métodos da interface do gerenciador de memória para que este executasse corretamente. O gerenciador de memória, por sua vez, deveria implementar alguns métodos para a correta execução da Jikes RVM, além de respeitar alguns requerimentos da máquina virtual, como o alinhamento dos objetos ao alocá-los na memória e a manipulação correta dos objetos que possuem o método finalize. Alguns métodos de nossa interface já estavam implementados, entretanto, nesses métodos, as classes do gerenciador de memória acessavam diretamente as classes dos outros subsistemas da Jikes RVM e vice-versa ou não eram gerais o suficiente para serem adequadas a todos os gerenciadores de memória.

Foram construídas duas classes para representar cada uma das interfaces: VM_InterfaceLP e VM_InterfaceGM. A primeira classe representa a interface do sistema de execução da linguagem de programação e a segunda, a interface do gerenciamento de memória. Nesta seção abordaremos a implementação dessas classes e a interação entre o gerenciador de memória e os outros subsistemas da Jikes RVM. Agrupamos os métodos dessas classes de acordo com suas funcionalidades.

\footnotetext{
${ }^{14}$ Utilizando a nomenclatura de Java, chamaremos as rotinas de métodos.
} 


\subsubsection{Construção da imagem de boot}

Antes de iniciar a execução da Jikes RVM, a imagem de boot é construída. O método initialize de VM_InterfaceGM é chamado por uma das classes do sistema de execução da linguagem de programação e esta, do escritor da imagem de boot. Todos os objetos chamados à partir do método initialize de VM_InterfaceGM são incluídos na imagem de boot. Veja a figura 4.8 .

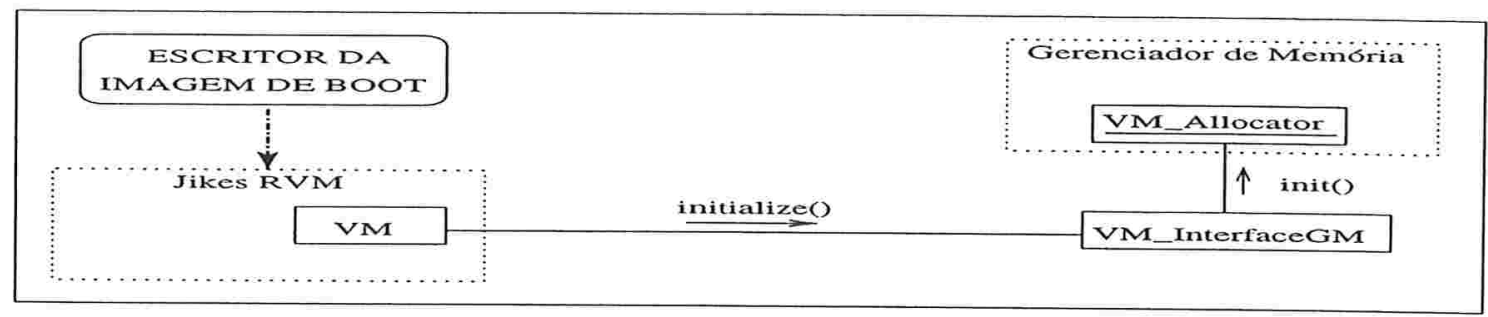

Figura 4.8: Inclusão dos objetos e métodos do gerenciador de memória na imagem de boot.

\subsubsection{Início da execução da máquina virtual}

No início da execução da Jikes RVM, o método prepare_initialize de VM_InterfaceGM é chamado. Neste momento, o gerenciador de memória pode chamar os métodos free_bits, available_bits e reference_free_bits de VM_InterfaceLP. Veja a figura 4.9. Observe que a numeração contida na figura 4.9 e nas demais dessa seção, indicam a ordem em que as mensagens são trocadas.

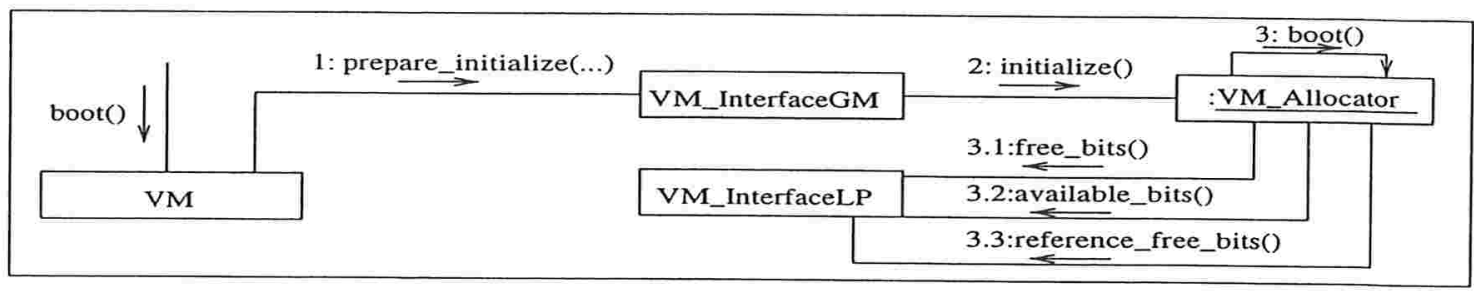

Figura 4.9: Início da execução da máquina virtual. 


\subsubsection{Barreira de leitura e de escrita}

A classe VM_Compiler contém métodos para geração de código referente a escrita no campo de um objeto. Na implementação original da Jikes RVM, em cada um desses métodos havia uma condição de que se a barreira de escrita fosse utilizada pelo coletor de lixo, o código para a barreira seria inserido. Como nossa proposta é que o sistema de execução da linguagem de programação conheça o mínimo possível sobre o coletor de lixo, ao invés dessa condição uma chamada ao método updateReference de VM_InterfaceGM é realizada. Se o coletor não precisar da barreira de escrita, o corpo desse método será vazio. Além disso, esse método é mais flexível já que sua implementação pode ser distinta para cada coletor de lixo. Na implemetação original, apenas um método era chamado. Para a barreira de leitura, que ainda não havia sido inserida nessa versão da Jikes RVM, fizemos o mesmo. Veja a figura 4.10 .

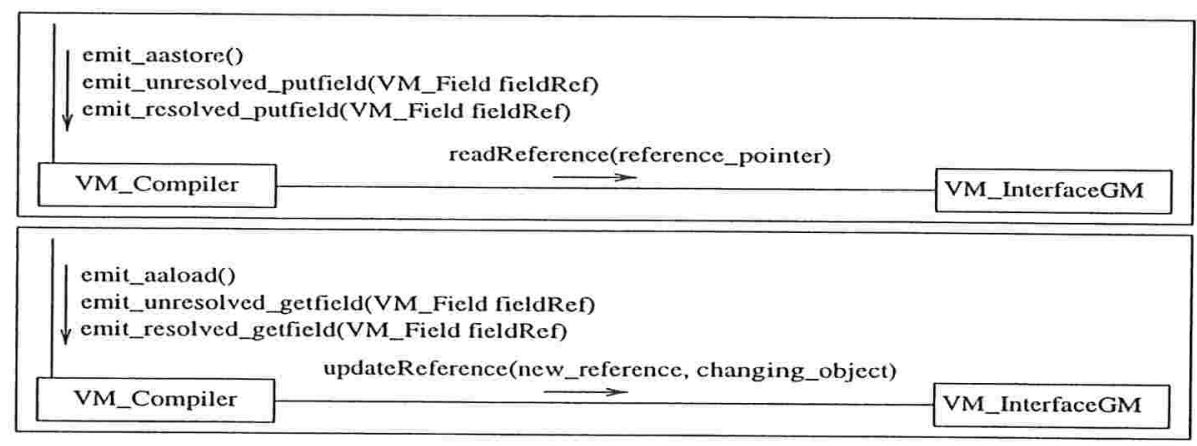

Figura 4.10: Barreira de leitura e de escrita.

\subsubsection{Alocação de objetos na heap}

A geração de código de máquina para o bytecode que representa o método new de Java é associado com o código de alocação de memória. O método allocate de VM_InterfaceGM deverá ser invocado. Durante a tentativa de alocação, a coleta de lixo poderá ser disparada. Com o endereço devolvido por este método, o objeto poderá ser inicializado. Em seguida, o método postAllocationProcessing de VM_InterfaceGM será invocado, para que o gerenciamento de memória tenha oportunidade de inicializar suas informações associadas ao objeto, caso seja necessário. Se o objeto possuir o método finalize, o método block_collection 
de VM_InterfaceGM será chamado.

Veja a figura 4.11 .
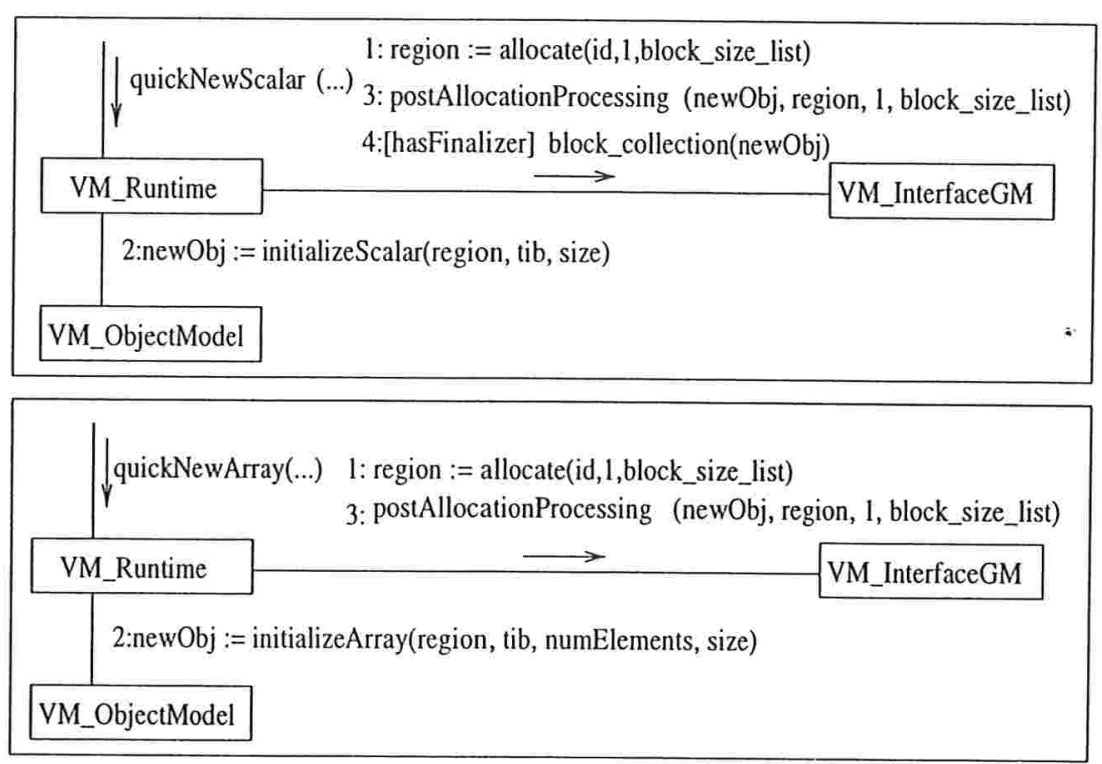

Figura 4.11: Alocação de objetos na heap.

\subsubsection{Execução do coletor de lixo}

A coleta de lixo é disparada pelo gerenciador de memória ou pelo sistema de execução da linguagem de programação. Pelo gerenciador de memória, a coleta de lixo pode ser disparada, por exemplo, na tentativa de alocação de um objeto e pelo sistema de execução, através da chamada do método gc de VM_InterfaceGM. Veja a figura 4.12.

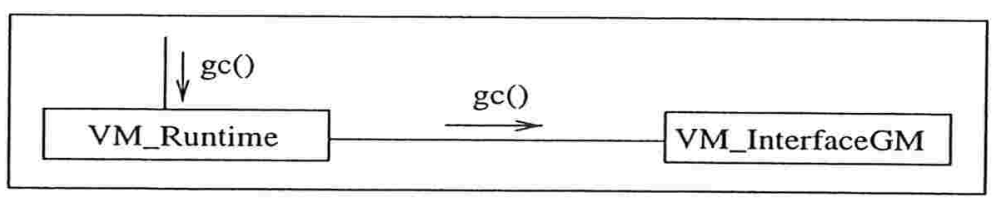

Figura 4.12: Chamada externa para execução do coletor.

Para a descoberta da raiz, o método root_scan da classe VM_InterfaceLP é chamado. $\mathrm{Na}$ Jikes RVM, a raiz é encontrada através do JTOC que contém referência para as informações globais da Jikes RVM. Além dos elementos do JTOC, as referências contidas nas pilhas de 
execução de cada thread da aplicação também fazem parte da raiz. Para cada referência encontrada, o método traverse de VM_InterfaceGM é chamado. Veja a figura 4.13.

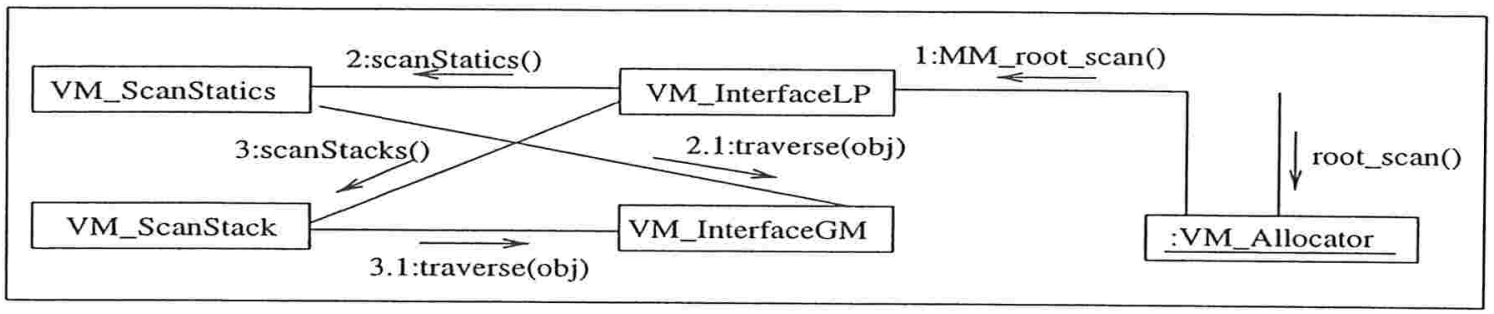

Figura 4.13: Processamento da raiz.

Para encontrar as referências contidas em cada objeto, o coletor de lixo chama um dos métodos process_object de VM_InterfaceLP. Na Jikes RVM, através da referência para um objeto é possível encontrar em seu cabeçalho uma referência para o TIB. Os campos que contém referência podem ser identificados através do TIB. Para cada referência encontrada, o método process_of_reference de VM_InterfaceGM é chamado. Veja a figura 4.14.

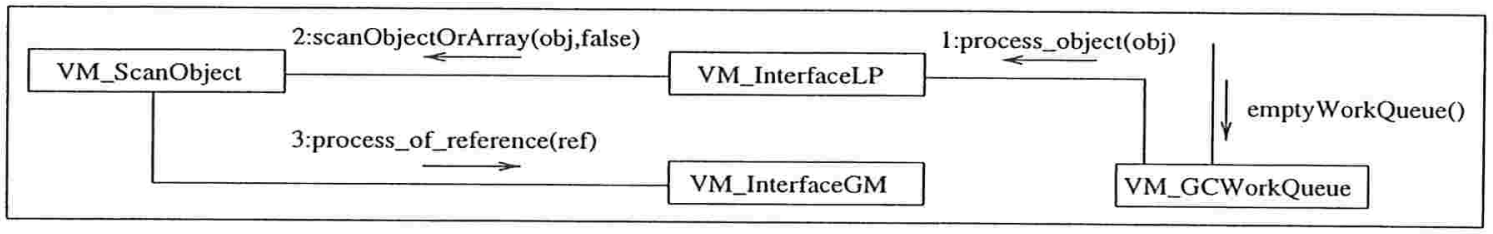

Figura 4.14: Processamento das referências em um objeto.

Nos coletores de cópia, o processamento de uma referência envolve copiar do objeto alvo desta. O método size_of_object_when_copied de VM_InterfaceLP é chamado para que o gerenciador de memória encontre um espaço apropriado para o objeto. O tamanho atual do objeto pode ser encontrado através do TIB. No caso de um objeto vetor, para calcularmos o seu tamanho é necessário identificarmos a quantidade de elementos desse vetor, além do tamanho de cada um deles. Na Jikes RVM, o primeiro campo de um objeto vetor contém a quantidade de seus elementos. Para a cópia do objeto, o coletor de lixo chama o método copy de VM_InterfaceLP. A referência retornada por este método é inserida no espaço antigo do objeto através do método store_value de VM_InterfaceLP. O gerenciador deve chamar o método is_immediate de VM_InterfaceLP, antes de copiar uma referência. Veja a figura 4.15 . 


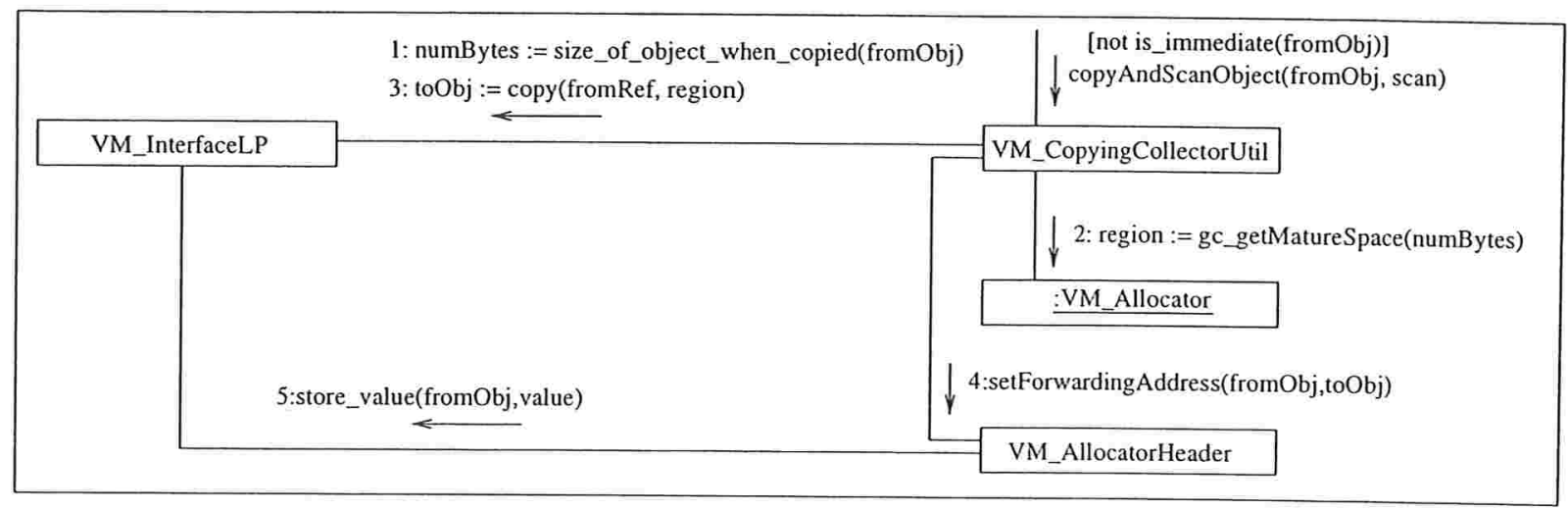

Figura 4.15: Cópia de um objeto.

Durante uma coleta de lixo, informações do coletor podem ser escritas ou lidas em um objeto através dos métodos apropriados da classe VM_InterfaceLP. Veja a figura 4.16.

\begin{tabular}{|c|c|}
\hline \multicolumn{1}{c|}{$\begin{array}{c}\text { 1:barrierBit :=read_mark(obj) } \\
\text { 2:mark(obj,barrierBit2) }\end{array}$} \\
\hline VM_InterfaceLP \\
\hline
\end{tabular}

Figura 4.16: Leitura e escrita de informações do coletor no objeto.

Alguns coletores de lixo precisam obter o endereço do objeto para localizar o espaço de memória a que ele pertence. Para obter essa informação, o coletor de lixo pode chamar o método bottom_address_of_reference de VM_InterfaceLP. Veja a figura 4.17.

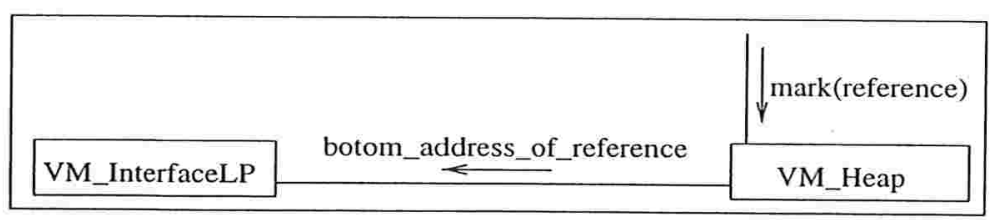

Figura 4.17: Localização do objeto na heap.

\subsubsection{Tratamento de objetos que possuem o método finalize}

Objetos que possuem o método finalize são tratados de maneira especial. Logo após a criação do objeto, o método block_collection de VM_InterfaceGM é chamado pelo sistema 
de execução da linguagem de programação. Durante a coleta de lixo, se houver objetos que poderiam ser liberados, mas não o foram porque ainda o método finalize não foi executado, o coletor de lixo chama o método there_is_garbage de VM_InterfaceLP. Sendo assim, a Jikes RVM pode chamar o método get_garbage de VM_InterfaceGM para obter esses objetos. Para cada objeto que possui o método finalize executado, o método unblock_collection de VM_InterfaceGM é chamado. Deste modo, em um próximo ciclo de coleta esses objetos poderão ser liberados. Veja a figura 4.18.

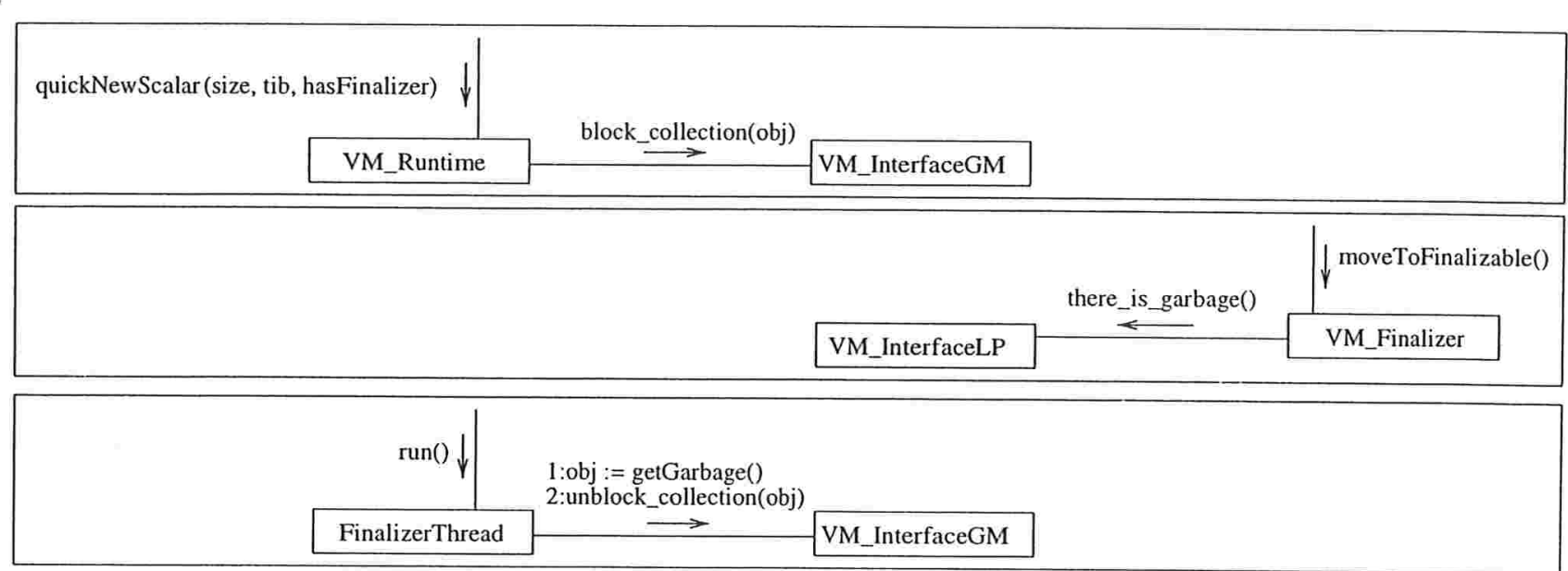

Figura 4.18: Processamento de objetos que possuem o método finalizer.

\subsubsection{Liberação de objetos}

Para liberação de um objeto, o gerenciador de memória pode chamar a rotina release de VM_InterfaceLP, passando como parâmetro a referência para o objeto a ser liberado. Os coletores já implementados na Jikes RVM são responsáveis pela liberação do objeto, portanto, não utilizam esse método. Veja a figura 4.19.

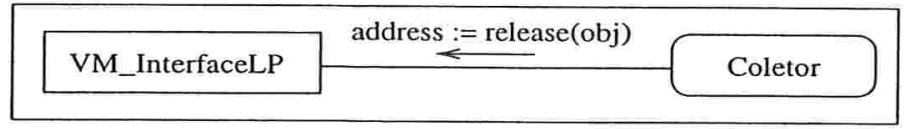

Figura 4.19: Liberação de objetos. 


\subsubsection{Informações sobre o gerenciamento de memória}

A Jikes RVM verifica se o gerenciador de memória move os objetos de lugar, através da chamada ao método move_objects de VM_InterfaceGM, desta forma a máquina virtual pode obter o código único do objeto corretamente, caso este seja baseado no seu endereço. Para saber se uma coleta de lixo está sendo executada, é chamado o método gcInProgress de VM_InterfaceGM. Para saber o tamanho da heap e quantidade de espaço livre, são chamados os métodos totalMemory() e freeMemory de VM_InterfaceGM, respectivamente. Veja a figura Veja a figura 4.20 .

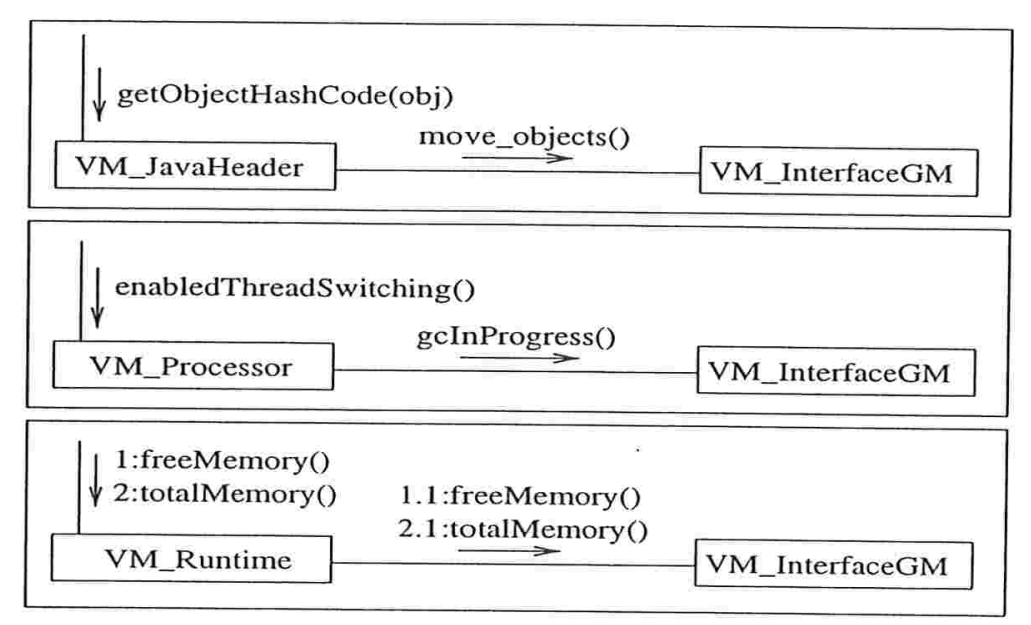

Figura 4.20: Informações relacionadas ao gerenciamento de memória.

\subsubsection{Espaços de memória associadas a cada processador}

Para o processamento paralelo na Jikes RVM, algumas estruturas de dados do gerenciador de memória podem estar associadas a cada processador virtual. Para isso, o sistema de execução da linguagem de programação ao criar cada um desses processadores deve chamar o método setupProcessor de VM_InterfaceGM. Veja a figura 4.21.

\subsubsection{Final da execução da máquina virtual}

O método finalize de VM_InterfaceGM é chamado pela Jikes RVM para que o gerenciador de memória tenha oportunidade de realizar alguma ação antes do final da execução da 


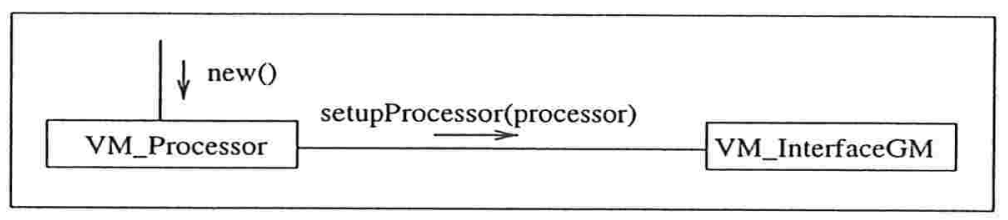

Figura 4.21: Informações do gerenciador de memória associadas ao processador.

Jikes RVM.

finalize de VM_InterfaceGM é chamado. Veja a figura 4.22.

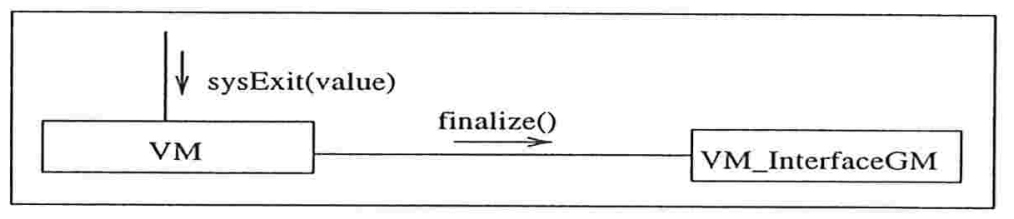

Figura 4.22: finalize no final da execução da Jikes RVM.

\subsection{Implementação dos coletores de lixo}

Modificamos a implementação dos gerenciadores de memória que utilizam o coletor marcare-varrer, o coletor de semi-espaço e o coletor de semi-espaço de gerações. A escolha do coletor de lixo na Jikes RVM é realizada em tempo de construção da imagem de boot. Sendo que para utilizar outro coletor, uma nova imagem de boot deve ser criada. A classe principal de cada gerenciador de memória é chamada de VM_Allocator. Esta classe contém métodos para alocação de memória e para coleta de lixo específicos a cada esquema de gerenciamento de memória. O implementador do coletor de lixo deve implementar uma classe VM_Allocator e colocá-la em um diretório qualquer. O diretório que contém VM_Allocator e um nome para o coletor devem ser indicados, pelo implementador, em um arquivo de configuração da Jikes RVM. Para construir a imagem de boot, o nome dado ao coletor deve ser informado. Desta maneira, a imagem de boot será criada utilizando a classe VM_Allocator apropriada. A maior parte do código de coleta de lixo concentrava-se em apenas um método da classe VM_Allocator, sendo este método bastante extenso. Analisando o código da classe VM_Allocator de cada coletor de lixo, identificamos vários aspectos em comum. Para modularizar o código e facilitar nossa compreensão, incluimos os aspectos em comum a todos os 
coletores em apenas uma classe, VM_CommonAllocator. Veja a figura 4.23.

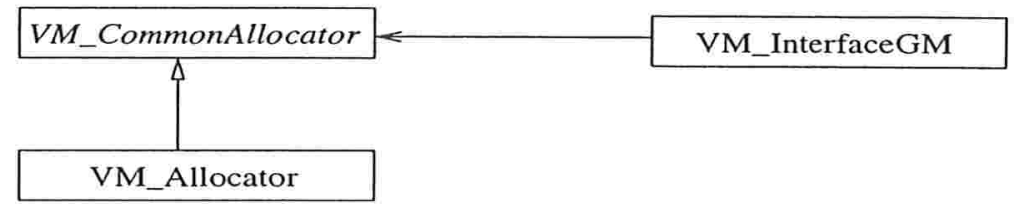

Figura 4.23: VM_CommonAllocator é super-classe de VM_Allocator

Quando uma coleta de lixo é iniciada, o método collect() de VM_Allocator é chamado. Esse método está definido em VM_CommonAllocator. Dividimos esse método em cinco partes principais: inicialização do coletor de lixo, a descoberta da raiz, rastreamento dos objetos na heap a partir da raiz, o processamento dos objetos que possuem o método finalize e a liberação dos objetos lixo. Outro coletor de lixo que defina uma política distinta dessa, deve redefinir esse método em VM_Allocator. Veja a figura 4.24.

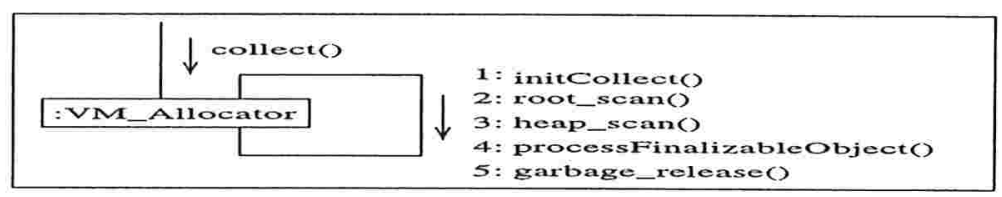

Figura 4.24: Métodos definidos em VM_CommonAllocator e herdados por VM_Allocator

Ao implementamos a interação das classes do gerenciador de memória com as classes da Jikes RVM aplicamos o padrão Facade. As classes do gerenciador de memória que antes precisavam conhecer as classes e métodos da Jikes RVM necessários a sua implementação agora, com o padrão Facade, interagem apenas com uma classe, a VM_InterfaceLP.

$\mathrm{Na}$ implementação original(veja a figura 4.25), as classes do gerenciador de memória conheciam os detalhes de implementação da Jikes RVM, por exemplo, para alocar um objeto, o gerenciador de memória precisava conhecer se o objeto era um vetor ou não, o número de elementos do vetor e, ainda, era responsável por chamar o métodos de inicialização do objeto, passando para esses métodos a referência da classe que armazena informações de tipo. Com a implementação da interface da linguagem de programação, os detalhes de implementação da Jikes RVM não são conhecidas pelo gerenciador de memória, portanto, algumas ações que antes eram destinadas ao gerenciador de memória, passaram a ser apenas atribuídas a Jikes RVM. Com isso, as responsabilidades do gerenciador de memória foram reduzidas, facilitando 


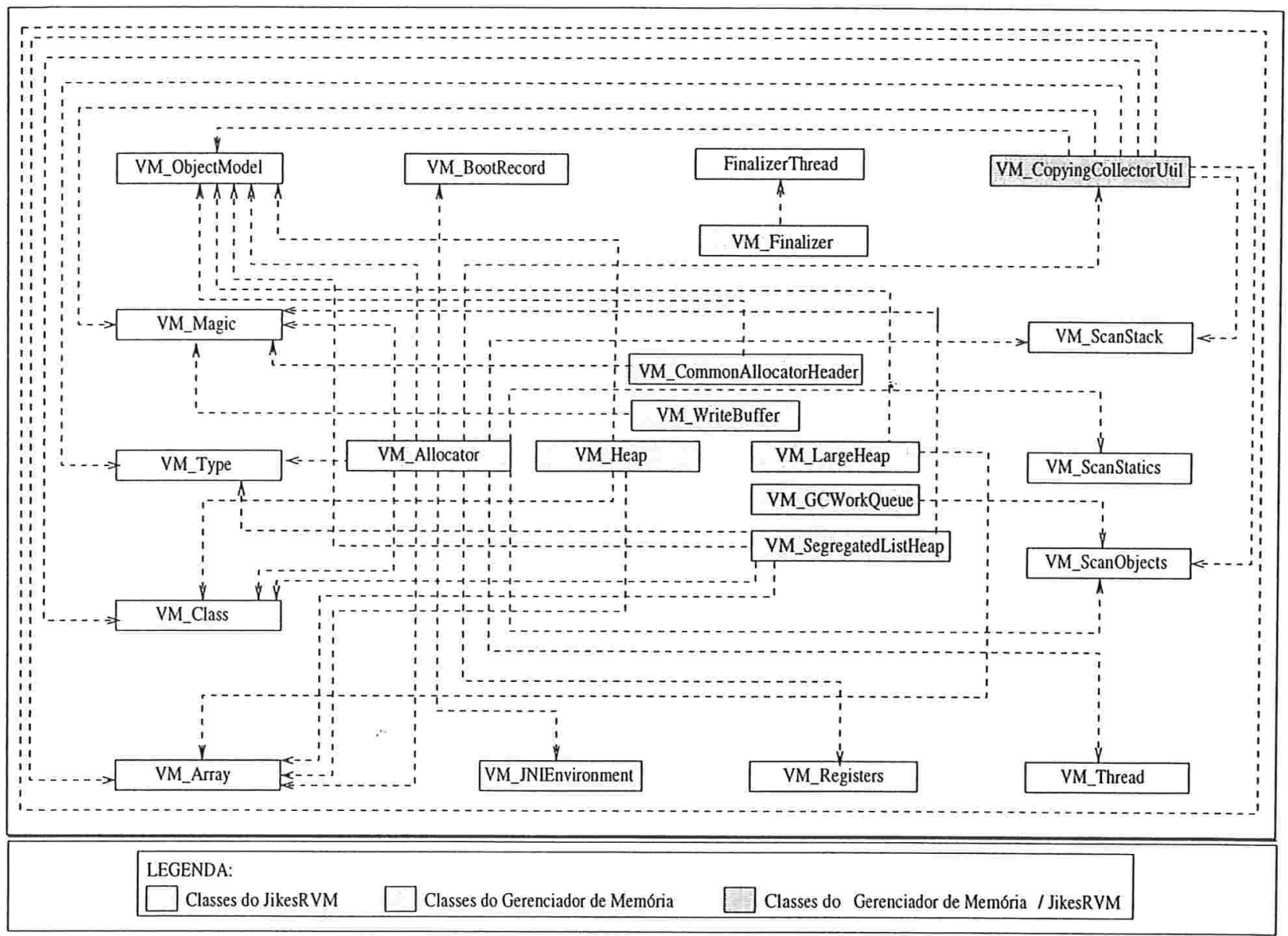

Figura 4.25: Interação do Gerenciador de Memória com as classes da Jikes RVM, antes da aplicação do padrão Facade

sua implementação e reduzindo o número de mensagens trocadas com a Jikes RVM. Utilizando o exemplo da alocação de um objeto, com a nossa interface genérica, o gerenciador de memória precisa essencialmente da quantidade e tamanho de cada bloco requerido para alocação. A inicialização do objeto é realizada apenas pelas Jikes RVM, sem que o gerenciador de memória conheça detalhes à respeito. Apesar de termos acrescentado uma indireção a mais para o gerenciador de memória obter as informações da Jikes RVM com o padrão Facade, é necessário agora um menor número de interações com a Jikes RVM. A classe VM_InterfaceLP implementa as rotinas da interface da linguagem de programação.Veja a figura 4.26.

De maneira análoga, todos os métodos que a Jikes RVM precisa para interagir com o gerenciador de memória foram definidos em apenas uma classe, VM_InterfaceGM. Portanto 


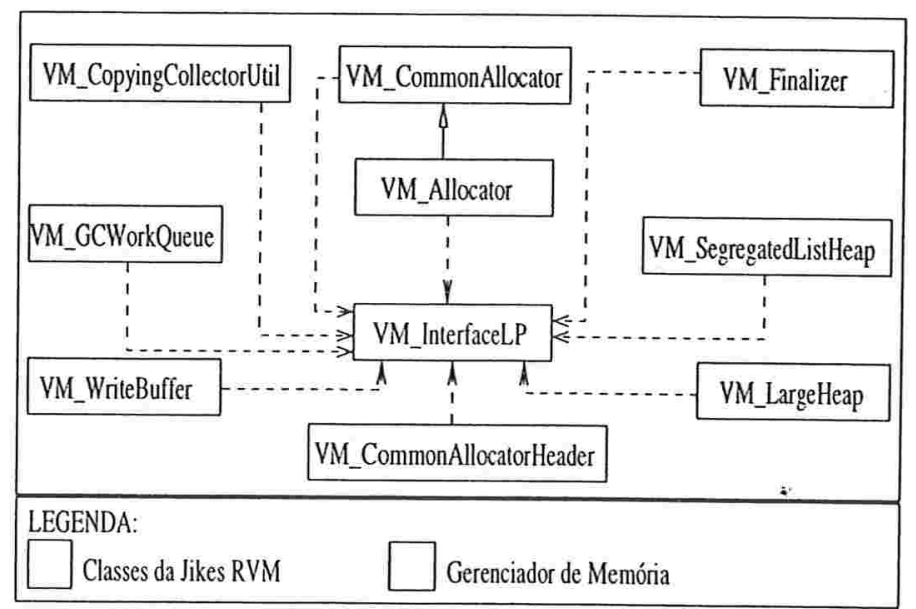

Figura 4.26: Interação do Gerenciador de Memória com as classes da Jikes RVM

para a interação entre a Jikes RVM e o gerenciador de memória, o padrão Facade também foi aplicado. Antes da aplicação desse padrão, a Jikes RVM precisava conhecer as classes do gerenciador de memória para obter deste ações ou informações necessárias a execução da máquina virtual. A Jikes RVM acessava diretamente quatro classes do gerenciador de memória.Veja a figura 4.27.

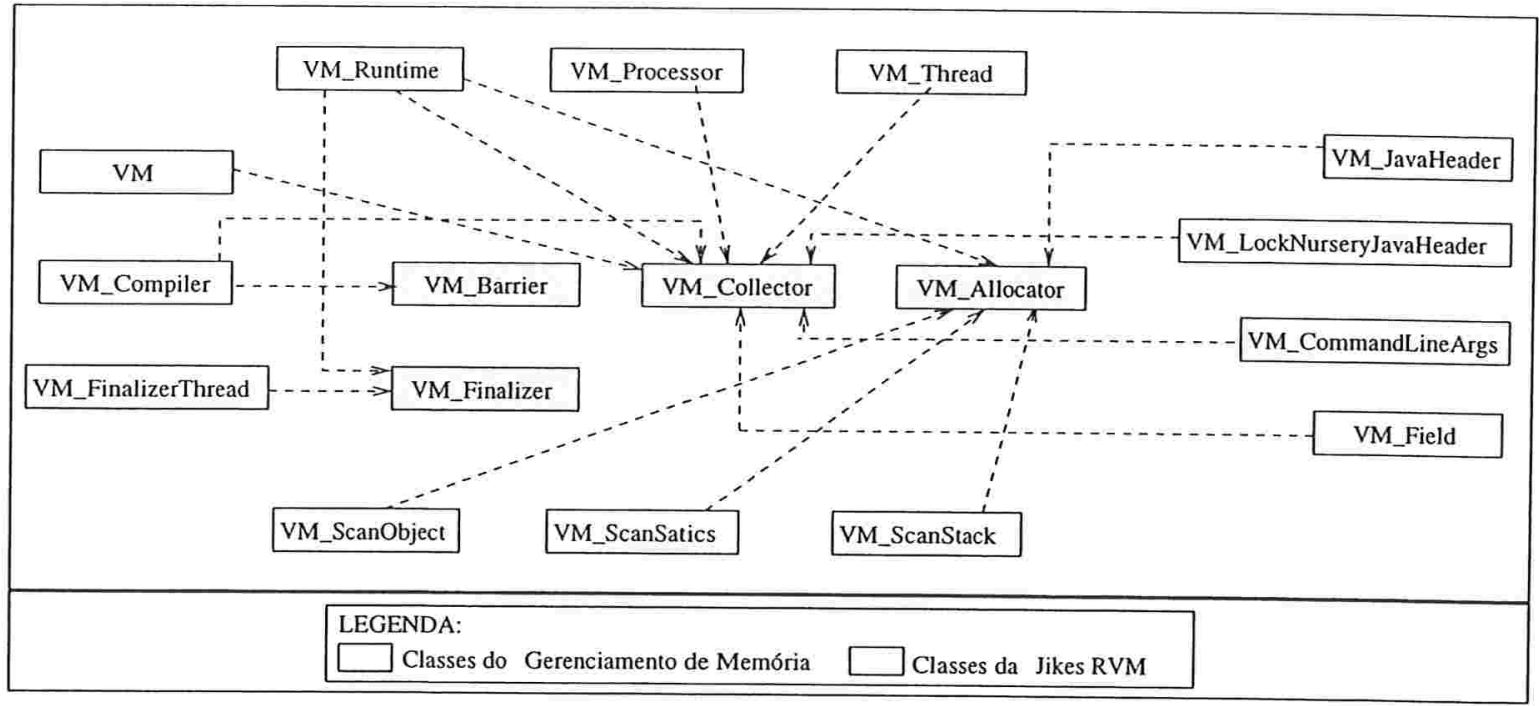

Figura 4.27: Interação das classes da Jikes RVM com o Gerenciador de Memória original

A definição de um conjunto padrão de métodos que são utilizados pela Jikes RVM facilita a implementação do gerenciador de memória. Isto porque, se um gerenciador de memória fosse 
modificado ou um novo fosse implementado na arquitetura original, era necessário conhecer quais classes ou métodos são acessados pela Jikes RVM para não alterá-los inadequadamente ou deixá-los de implementar. Com a nossa interface, o implementador do gerenciador de memória conhece, mais facilmente, todos os métodos que precisam ser implementados para, eventualmente, serem utilizados pela Jikes RVM. Todos esses métodos estão incluídos na classe VM_InterfaceGM. Veja a figura 4.28.

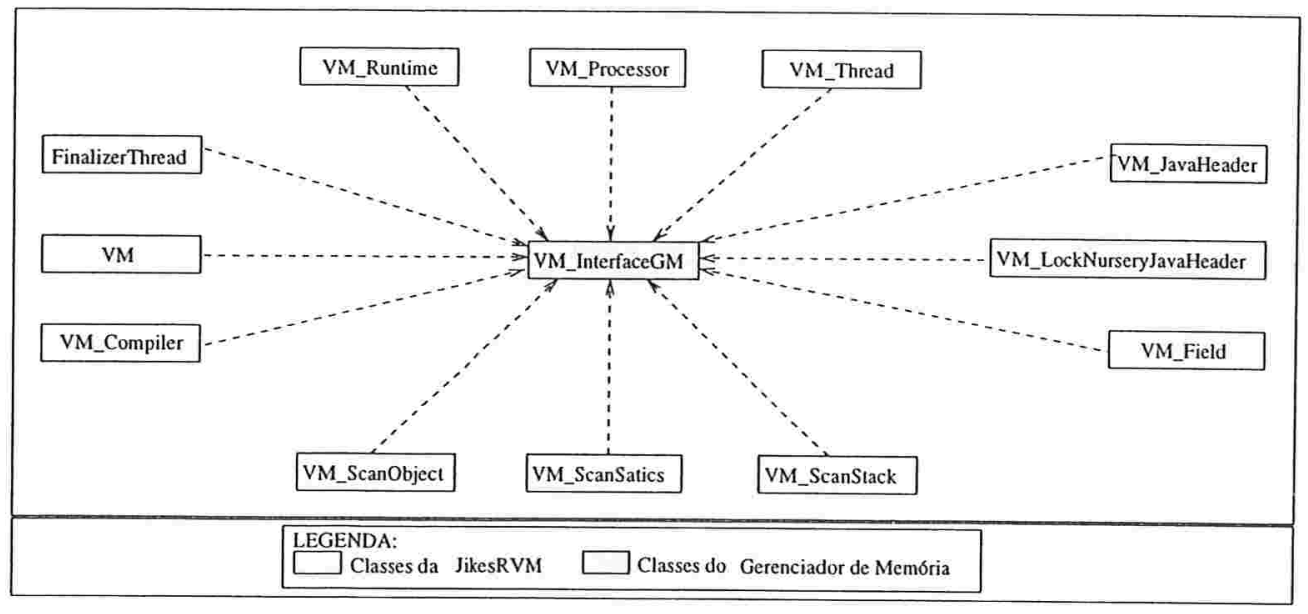

Figura 4.28: Interação das classes da Jikes RVM com o Gerenciador de Memória depois da inclusão da interface do gerenciador de memória

Infelizmente algumas dependências entre a Jikes RVM e o gerenciador de memória continuam existindo. O paralelismo implementado na Jikes RVM, assim como nos coletores de lixo, não foram tratados em nossa interface. Além disso, métodos de classes da Jikes RVM que permitem a manipulação de memória foram utilizadas pelo gerenciador de memória, já que este é escrito em Java e, portanto, não pode acessar diretamente os endereços físicos. Portanto, nem todos os métodos das classes da Jikes RVM são acessadas pelo gerenciador de memória através da interface da linguagem de programação. Não consideramos esses métodos uma violação grave da abstração da linguagem de programação, porque como o gerenciador de memória foi escrito em uma linguagem de alto nível e é necessário que ele se comunique com o sistema operacional de alguma maneira, nós utilizamos as rotinas já fornecidas com a Jikes RVM com esse propósito. As classes da Jikes RVM ainda acessadas diretamente pela Jikes RVM são: VM_Processor, VM_Scheduler, VM_Thread, VM_BootRecord, VM_Magic e VM. As três primeiras classes são relacionadas ao escalonamento de threads em um sistema 
multiprocessado. As classes VM_BootRecord e VM_Magic são relacionadas ao manipulação da memória física ou a comunicação com o sistema operacional. Métodos da classe VM são utilizados para imprimir mensagens do gerenciamento de memória ou parar a execução da máquina virtual caso o gerenciamento de memória queira aborta a execução da máquina virtual, por erros encontrados durante sua execução. A figura 4.29 mostra dependências ainda presentes em nossa implementação.

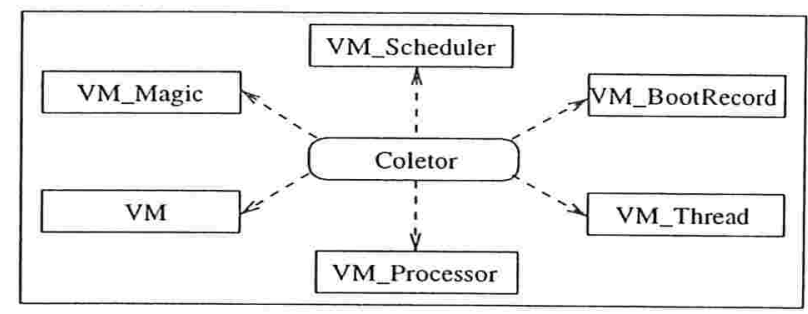

Figura 4.29: Dependências ainda existentes entre o Gerenciador de Memória e a Jikes RVM 


\section{Capítulo 5}

\section{Avaliação de Resultados}

A implementação do Jikes RVM com a inserção da interface genérica de coleta de lixo foi avaliada tendo como base a implementação original dessa máquina virtual. Essa avaliação foi realizada através de duas medidas: o número de linhas de código, sem os comentários, da implementação do gerenciador de memória e o tempo de execução da máquina virtual para cada coletor de lixo implementado.

\subsubsection{Análise do código}

Verificamos o número de linhas em cada esquema de gerenciamento de memória para a Jikes RVM modificada e a Jikes RVM original. Veja a tabela abaixo:

\begin{tabular}{|c|c|c|c|}
\hline Coletor de lixo & Jikes Original & Jikes Modificada & Diferença \\
\hline \hline Marcar-e-varrer & 4656 & 4043 & 613 \\
\hline Semi-espaço & 4077 & 3436 & 641 \\
\hline Semi-espaço de Gerações & 4432 & 3863 & 569 \\
\hline
\end{tabular}

Os dados mostram que o número de linhas em nossa implementação para o gerenciamento de memória é significativamente menor que na implementação original. Isso porque a Jikes RVM original considera algumas classes pertencentes ao gerenciamento de memória que em nossa implementação, por serem específicas da linguagem de programação, pertencem à Jikes RVM: VM_ScanObjects, VM_ScanStatics, VM_ScanStack. Essas classes são responsáveis por encontrar referências em um objeto e na raiz. Além disso, as classes VM_Collector e VM_Barriers não foram incluídas em nossa implementação. A primeira porque era apenas 
uma indireção entre classes da Jikes RVM e o gerenciamento de memória, e a segunda porque era utilizada, pelo compilador da Jikes RVM para invocar uma mesma implementação de ação do coletor mediante uma barreira de escrita. Com a nossa interface genérica a implementação do coletor para a barreira de escrita é mais flexível, pois o coletor implementa a ação que desejar caso a barreira de escrita seja utilizada. Outro fator importante que contribuiu para um menor número de linhas em nossa implementação foi a exclusão de linhas relacionadas a detalhes de implementação da linguagem de programação.

Verificamos o. número de linhas do código das classes principais de coleta de lixo para cada implementação do coletor na Jikes RVM modificada e na Jikes RVM original. Para as duas máquinas virtuais as principais classes do coletor de semi-espaço e de semi-espaço de gerações são VM_Allocator e VM_CopyingCollectorUtil e para o coletor marcar-e-varrer é VM_Allocator. Apenas a implementação de VM_Allocator difere para todos os coletores. A implementação de VM_CopyingCollectorUtil difere para cada máquina virtual. Veja a tabela abaixo:

\begin{tabular}{|c|c|c|c|}
\hline Coletor de Lixo & Jikes Original & Jikes Modificada & Diferença \\
\hline \hline Marcar-e-varrer & 342 & 204 & 138 \\
\hline Semi-espaço & 518 & 324 & 194 \\
\hline Semi-espaço de Gerações & 768 & 646 & 122 \\
\hline
\end{tabular}

Os dados mostram que a implementação das principais classes do coletor de lixo é menor para a nossa implementação. Isto porque o implementador de VM_Allocator pode herdar os métodos da classe VM_CommonAllocator diminuindo assim sua carga de trabalho. Além disso, na classe VM_CopyingCollectorUtil dos coletores de cópia retiramos todas as linhas de código que acessavam diretamente a Jikes RVM para copiar um objeto.

\subsubsection{Análise de desempenho}

Para compararmos o desempenho da Jikes RVM implementada com a nossa interface em relação a implementação original utilizamos 9 benchmarks do JOlden Benchmark Suite[CM01]: Health, TreeAdd, MST, Voronoi, BiSort, Em3d, Perimeter, TSP e BH. Os testes foram realizados em uma máquina Athlon XP 1700+1.4Ghz, 512 MB, sistema operacional Debian GNU Kernel 2.4.20. Foram realizados, dez execuções de cada benchmark para cada configurações de coleta de lixo em cada máquina virtual. Os parâmetros de um mesmo benchmark 
foram os mesmos para todas as execuções sendo escolhidos de maneira que a Jikes RVM pudesse executar por mais tempo. Nos testes realizados as saídas dos coletores de lixo foram as mesmas para as duas versões da máquina virtual, a original e a descrita neste trabalho. Os coletores utilizados foram: marcar-e-varrer, semi-espaço e semi-espaço de gerações. As duas máquinas virtuais executaram com o compilador baseline.

Foram feitos dois cálculos para comparar a performance. Inicialmente comparamos o tempo médio de execução de cada benchmark para cada algoritmo de coleta em cada uma das máquinas virtuais. Em seguida consolidamos os dados medindo quanto, em média, os benchmarks ficaram mais lentos para cada um dos algoritmos de coleta.

Os dados mostram que, como esperado, a Jikes RVM modificada possui pior desempenho do que a Jikes RVM original na execução de todos os benchmarks. A perda de performance era esperada pela aplicação do padrão Facade, pois ao inserimos duas indireções em nossa implementação: a Jikes RVM comunica-se com o coletor através da classe VM_InterfaceGM e esta chama os métodos adequados do gerenciamento de memória, por outro lado o gerenciador de memória comunica-se com a classe VM_InterfaceLP e esta chama os métodos adequados da Jikes RVM. Além disso, a inserção de herança na implementação de VM_Allocator, com a criação da classe VM_CommonAllocator, devido à resolução dinâmica de nomes em java, deve também ocasionar perda de performance.

Para um dado coletor de lixo calculamos a diferença percentual de cada benchmark entre as duas máquinas virtuais. Tiramos a média dessas diferenças e obtivemos o quanto, em média, é menor o desempenho de nossa máquina virtual para cada coletor de lixo implementado. Raciocínio análogo foi aplicado para o desvio padrão. A perda de desempenho para o coletor de semi-espaço em nossa implementação é muito elevada. O mesmo não acontece com os coletores marcar-e-varrer e semi-espaço de gerações. Até o presente momento não detectamos a causa da diferença obtida pelo coletor de semi-espaço em nossa implementação. 


\begin{tabular}{|c|c|c|c|c|c|}
\hline Coletor & Benchmark & $\begin{array}{c}\text { Tempo Médio } \\
\text { Jikes Original }\end{array}$ & $\begin{array}{c}\text { Desvio Padrão } \\
\text { Jikes Original }\end{array}$ & $\begin{array}{c}\text { Tempo Médio } \\
\text { Jikes Modificada }\end{array}$ & $\begin{array}{c}\text { Desvio Padrão } \\
\text { Jikes Modificada }\end{array}$ \\
\hline MV & BH & 1,25 & 0,06 & 1,65 & 0,03 \\
\hline MV & BiSort & 1,01 & 0,03 & 1,33 & 0,02 \\
\hline MV & Em & 0,67 & 0,02 & 0,88 & 0,20 \\
\hline MV & Health & 1,97 & 0,03 & 2,92 & 1,27 \\
\hline MV & MST & 0,64 & 0,00 & 0,80 & 0,01 \\
\hline MV & Perimeter & 0,60 & 0,02 & 0,72 & 0,01 \\
\hline MV & TreeAdd & 0,57 & 0,01 & 0,72 & 0,02 \\
\hline MV & TSP & 5,93 & 0,08 & 6,18 & 0,10 \\
\hline MV & Voronoi & 0,65 & 0,01 & 0,81 & 0,01 \\
\hline \hline SE & BH & 4,43 & 0,34 & 9,97 & 0,16 \\
\hline SE & BiSort & 1,37 & 0,30 & 2,92 & 0,04 \\
\hline SE & Em & 1,29 & 0,07 & 2,39 & 0,09 \\
\hline SE & Health & 9,69 & 0,18 & 29,26 & 3,25 \\
\hline SE & MST & 1,44 & 0,38 & 2,41 & 0,02 \\
\hline SE & Perimeter & 0,86 & 0,01 & 1,47 & 0,07 \\
\hline SE & TreeAdd & 0,86 & 0,05 & 2,30 & 0,02 \\
\hline SE & TSP & 7,16 & 0,05 & 9,58 & 0,75 \\
\hline SE & Voronoi & 1,28 & 0,04 & 2,34 & 0,02 \\
\hline \hline SEG & BH & 1,35 & 0,03 & 1,70 & 0,04 \\
\hline SEG & BiSort & 1,19 & 0,09 & 1,44 & 0,10 \\
\hline SEG & Em & 0,73 & 0,01 & 0,85 & 0,01 \\
\hline SEG & Health & 2,66 & 1,58 & 2,68 & 0,08 \\
\hline SEG & MST & 0,72 & 0,01 & 0,86 & 0,01 \\
\hline SEG & Perimeter & 0,67 & 0,01 & 0,80 & 0,08 \\
\hline SEG & TreeAdd & 0,66 & 0,01 & 0,77 & 0,01 \\
\hline SEG & TSP & 6,04 & 0,05 & 6,25 & 0,12 \\
\hline SEG & Voronoi & 0,75 & 0,05 & 0,87 & \\
\hline Lend & VVMarcar & $-v a r$ & \\
\hline
\end{tabular}

Legenda: $\mathrm{MV}=$ Marcar-e-varrer $\mathrm{SE}=$ Semi-espaço $\mathrm{SEG}=$ Semi-espaço de gerações

\begin{tabular}{|c|c|c|}
\hline Coletor de Lixo & Tempo Médio & Desvio Padrão \\
\hline \hline Semi-espaço de Gerações & 14,07 & 7,69 \\
\hline Marcar-e-Varrer & 27,11 & 11,78 \\
\hline Semi-espaço & 114,56 & 52,69 \\
\hline
\end{tabular}




\section{Capítulo 6}

\section{Conclusão}

Apesar das dependências ainda existentes reduzimos significantemente o nível de detalhes que o implementador do gerenciamento de memória precisa conhecer sobre o sistema de execução da linguagem de programação. As dependências remanescentes se devem, principalmente, à interação direta do gerenciador de memória com o subsistema de sincronização e threads da Jikes RVM. Isto porque nossa interface genérica foi projetada para sistemas uniprocessados e a Jikes RVM foi implementada para executar de modo paralelo em máquinas multiprocessadas, assim como os coletores de lixo. Desta maneira, permitimos que as estruturas de dados relacionadas ao processamento paralelo implementado na Jikes RVM fossem acessadas diretamente pelas classes do gerenciador de memória.

A implementação na Jikes RVM contribuiu para o enriquecimento da definição de nossa interface, desde que nos deparamos com situações que até então não havíamos previsto, por exemplo, uma característica da Jikes RVM é que ela e o gerenciador de memória executam dentro dela própria sendo que o gerenciador de memória serve tanto à aplicação como a Jikes RVM. Em particular podemos citar a separação da inicialização do coletor em duas fases distintas:: a fase de construção das estruturas de dados que precisam estar na memória para iniciar sua execução em algum momento arbitrário e a fase de inicialização dessas estruturas no início da execução do sistema da linguagem de programação. Essa divisão é geral o suficiente para atender os requerimentos da Jikes RVM, sem restringir a nossa interface apenas a essa máquina virtual. Para sistemas de execução da linguagem de programação que não necessitam dessa distinção, a segunda fase é chamada imediatamente depois da primeira não prejudicando a execução da linguagem. 
A implementação na Jikes RVM não apenas contribuiu com o acréscimo de rotinas ou melhor definição destas, mas também mostrou-nos limitações ainda persistentes em nossa interface. Como por exemplo o gerenciador de memória acessa diretamente a Jikes RVM para conhecer o início e o fim da área de memória reservada para a imagem de boot. Futuramente pensamos em incluir em nossa interface uma rotina para que seja especificado uma área de memória onde os objetos não devem ser coletados, sendo que esta área pode conter uma região já ocupada. No caso da Jikes RVM, essa área ocupada conteria a imagem de boot.

Em relação à implementação dos coletores de lixo concluimos que a interface genérica de coleta de lixo possibilitou uma abstração dos detalhes de implementação da linguagem de programação, salvo as considerações anteriores. Com um conjunto de rotinas padrão de interação com a linguagem de programação, reduzimos o tempo gasto para a implementação do coletor de lixo, sendo ainda possível uma maior clareza para determinarmos quais eram os aspectos comuns a todos os coletores. Sendo assim, o número de linhas em nossa implementação decresceu em relação a implementação original. Para implementarmos a classe principal de coleta de lixo marcar-e-varrer diminuimos em torno de $40 \%$ o número de linhas de código, por exemplo. Além disso, como a interface do gerenciamento de memória comunica-se diretamente com a classe VM_CommonAllocator, poderíamos, futuramente, modificar a maneira como o coletor de lixo é adicionado a Jikes RVM, não sendo mais necessário restringir o nome da classe principal de coleta de lixo a VM_Allocator e nem indicar o diretório que a contém no arquivo de configuração da Jikes RVM.

O desempenho da execução da Jikes RVM com a inclusão de nossa interface foi pior que a execução da Jikes RVM original. Este era o resultado esperado tendo em vista que o padrão facade foi empregado, ou seja, adicionamos uma indireção a mais para a chamada dos métodos do gerenciamento de memória pela Jikes RVM e vice-versa. Entretanto a queda de desempenho do coletor de semi-espaço em nossa implementação foi além do que esperávamos, sendo que a causa desse acréscimo ainda não foi detectada.

Através de nossa interface, é possível mais facilmente incluir diferentes coletores de lixo em uma mesma implementação da linguagem de programação. Isso porque o implementador do coletor não se preocupará com os detalhes de implementação da linguagem. Além disso, a mesma implementação da interface da linguagem de programação pode ser utilizada para todos os coletores de lixo, sem que diferentes implementações interfiram nos possíveis testes de desempenho que possam ser realizados entre os coletores. Por outro lado, o mesmo coletor de lixo poderá ser facilmente incluído em diferentes implementações do sistema de execução 
da linguagem que contenham nossa interface, sendo possível testar o mesmo coletor de lixo para diferentes linguagens de programação sem alterações signficativa.

Como trabalhos futuros podemos citar a implementação de outros coletores como o marcar-e-compactar e o de contagem de referências, a criação de uma interface específica para coletores implementados em linguagens de alto nível, incluindo os problemas relacionados a multiprocessamento e regiões da memória utilizados por outros sistemas e, principalmente, uma reescrita dos algoritmos de coleta já utilizados visando melhorar sua performance. 


\section{Referências Bibliográficas}

$\left[\mathrm{AAB}^{+} 00\right]$ Bowen Alpern, Dick Attanasio, John J. Barton, M. G. Burke, P. Cheng, J.D. Choi, Anthony Cocchi, Stephen J. Fink, David Grove, Michael Hind, Susan Flynn Hummel, D. Lieber, V. Litvinov, Mark Mergen, Ton Ngo, J. R. Russell, Vivek Sarkar, Manuel J. Serrano, Janice Shepherd, S. Smith, V. C. Sreedhar, H. Srinivasan, and J. Whaley. The Jalapeño virtual machine. IBM System Journal, 39(1), February 2000.

[AAC $\left.{ }^{+} 99\right]$ Bowen Alpern, C. R. Attanasio, Anthony Cocchi, Derek Lieber, Stephen Smith, Ton Ngo, John J. Barton, Susan Flynn Hummel, Janice C. Sheperd, and Mark Mergen. Implementing Jalapeño in Java. In OOPSLA'gg ACM Conference on Object-Oriented Systems, Languages and Applications, volume 34(10) of ACM SIGPLAN Notices, pages 314-324, Denver, CO, October 1999. ACM Press.

[ABCS01] Clement R. Attanasio, David F. Bacon, Anthony Cocchi, and Stephen Smith. A comparative evaluation of parallel garbage collectors. In H. G. Dietz, editor, Proceedings of the Fourteenth Annual Workshop on Languages and Compilers for Parallel Computing, volume 2624 of Lecture Notes in Computer Science, pages 177-192, Cumberland Falls, Kentucky, August 2001. Springer-Verlag.

[AEL88] Andrew W. Appel, John R. Ellis, and Kai Li. Real-time concurrent collection on stock multiprocessors. ACM SIGPLAN Notices, 23(7):11-20, 1988.

[AP87] Santosh Abraham and J. Patel. Parallel garbage collection on a virtual memory system. In E. Chiricozzi and A. D'Amato, editors, International Conference on Parallel Processing and Applications, pages 243-246, L'Aquila, Italy, September 1987. Elsevier-North Holland. 
[AP03] Hezi Azatchi and Erez Petrank. Integrating generations with advanced reference counting garbage collectors. In 12th International Conference on Compiler Construction, CC 2003, volume 2622 of Lecture Notes in Computer Science, pages 185-199, Warsaw, Poland, May 2003. Springer-Verlag Heidelberg.

[App91] Andrew W. Appel. Garbage collection. In Peter Lee, editor, Topics in Advanced Language Implementation, pages 89-100. MIT Press, 1991.

[AR98] Saleh E. Abdullahi and Graem A. Ringwood. Garbage collecting the Internet: a survey of distributed garbage collection. ACM Computing Surveys, 30(3):330373, September 1998.

[AVAS86] Jeffrey D. Ullman Alfred V. Aho and Ravi Sethi. Compilers: Principles, Techniques, Tools. Addison-Wesley, 1986.

[Bak78] Henry G. Baker. List processing in real-time on a serial computer. Communications of the ACM, 21(4):280-94, 1978.

[Bar88] Joel F. Bartlett. Compacting garbage collection with ambiguous roots. Technical Report 88/2, DEC Western Research Laboratory, Palo Alto, CA, February 1988. Also in Lisp Pointers 1, 6 (April-June 1988), 2-12.

[BCM04a] Stephen M. Blackburn, Perry Cheng, and Kathryn S. McKinley. Myths and reality: The performance impact of garbage collection. In Sigmetrics - Performance 2004, Joint International Conference on Measurement and Modeling of Computer Systems, New York, NY, June 2004.

[BCM04b] Stephen M. Blackburn, Perry Cheng, and Kathryn S. McKinley. Oil and water? high performance garbage collection in Java with MMTk. In ICSE 2004, 26th International Conference on Software Engineering, Edinburgh, May 2004.

[BOP03] Katherine Barabash, Yoav Ossia, and Erez Petrank. Mostly concurrent garbage collection revisited. In OOPSLA'03 ACM Conference on Object-Oriented Systems, Languages and Applications, ACM SIGPLAN Notices, Anaheim, CA, November 2003. ACM Press. 
[BW88] Hans-Juergen Boehm and Mark Weiser. Garbage collection in an uncooperative environment. Software Practice and Experience, 18(9):807-820, 1988.

[Che70] C. J. Cheney. A non-recursive list compacting algorithm. Communications of the ACM, 13(11):677-8, November 1970.

[CM01] Brendon Cahoon and Kathryn S. McKinley. Data flow analysis for software prefetching linked data structures in java. In PACT '01: Proceedings of the 2001 International Conference on Parallel Architectures and Compilation Techniques, pages 280-291. IEEE Computer Society, 2001.

$\left[\mathrm{DLM}^{+} 76\right]$ Edsgar W. Dijkstra, Leslie Lamport, A. J. Martin, C. S. Scholten, and E. F. M. Steffens. On-the-fly garbage collection: An exercise in cooperation. In Lecture Notes in Computer Science, volume 46. Springer-Verlag, New York, 1976.

[Dur97] Alan Michell Durham. Implementing Run-Time System in a Compiler. PhD dissertation, University of Illinois, Urbana-Champaign, 1997.

[GGU72] M. R. Garey, R. L. Graham, and Jeffrey D. Ullman. Worst-case analysis of memory allocation algorithms. In Fourth Annual ACM Symposium on the Theory of Computing. ACM Press, 1972.

[GJ87] Carlo Ghezzi and Mehdi Jazayeri. Programming Language Concepts. John Wiley \& Sons, 1987.

[GR83] Adele Goldberg and D. Robson. Smalltalk-80: The Language and its Implementation. Addison-Wesley, 1983.

$\left[\mathrm{HBM}^{+}\right.$04] Xianlong Huang, Stephen M. Blackburn, Kathryn S. McKinley, J. Eliot B. Moss, Z. Wang, and Perry Cheng. The garbage collection advantage: Improving program locality. In OOPSLA'O4 ACM Conference on Object-Oriented Systems, Languages and Applications, ACM SIGPLAN Notices, Vancouver, October 2004. ACM Press.

[HDH03] Martin Hirzel, Amer Diwan, and Matthew Hertz. Connectivity-based garbage collection. In OOPSLA'03 ACM Conference on Object-Oriented Systems, Languages and Applications, ACM SIGPLAN Notices, Anaheim, CA, November 2003. ACM Press. 
[HMDW91] Richard L. Hudson, J. Eliot B. Moss, Amer Diwan, and Christopher F. Weight. A language-independent garbage collector toolkit. Technical Report COINS 91-47, University of Massachusetts at Amherst, Department of Computer and Information Science, September 1991.

[HSHD04] Matthias Hauswirth, Peter F. Sweeney, Michael Hind, and Amer Diwan. Vertical profiling: Understanding the behavior of object-oriented applications. In OOPSLA'O4 ACM Conference on Object-Oriented Systems, Languages and Applications, ACM SIGPLAN Notices, Vancouver, October 2004. ACM Press.

[Nee96] Michael S. Neely. An analysis of the effects of memory allocation policy on storage fragmentation. Master's thesis, University of Texas at Austin, 1996.

[Pir98] Pekka P. Pirinen. Barrier techniques for incremental tracing. In Richard Jones, editor, ISMM'98 Proceedings of the First International Symposium on Memory Management, volume 34(3) of ACM SIGPLAN Notices, pages 20-25, Vancouver, October 1998. ACM Press.

[PJ02] Tony Printezis and Richard Jones. GCspy: An adaptable heap visualisation framework. In OOPSLA'02 ACM Conference on Object-Oriented Systems, Languages and Applications, SIGPLAN Notices, Seattle, WA., November 2002. ACM Press.

[RVM] Jikes ${ }^{\text {TM }}$ RVM Home Page. http://www-124.ibm.com/developerworks/oss/ jikesrvm/.

[SKB04] Sunil Soman, Chandra Krintz, and David Bacon. Dynamic selection of application-specific garbage collectors. Technical Report 2004-09, UCSB, January 2004.

[Ste75] Guy L. Steele. Multiprocessing compactifying garbage collection. Communications of the ACM, 18(9):495-508, September 1975.

[Ste99] Darko Stefanović. Properties of Age-Based Automatic Memory Reclamation Algorithms. PhD dissertation, University of Massachusetts, 1999. 
[SW67] H. Schorr and W. Waite. An efficient machine independent procedure for garbage collection in various list structures. Communications of the ACM, 10(8):501-506, August 1967.

[TS85] Jean-Paulo Tremblay and Paul G. Sorenson. The Theory and Practice of Compiler Writing. McGraw-Hill, 1985.

[Wat89] David A. Watt. Programming Language Concepts and Paradigms. Prentice Hall, 1989.

[WG98] Derek White and Alex Garthwaite. The GC interface in the EVM. Technical Report SML TR-98-67, Sun Microsystems Laboratories, December 1998.

[Wil94] Paul R. Wilson. Uniprocessor garbage collection techniques. Technical report, University of Texas, January 1994.

[WJNB95] Paul R. Wilson, Mark S. Johnstone, Michael Neely, and David Boles. Dynamic storage allocation: A survey and critical review. In Henry Baker, editor, Proceedings of International Workshop on Memory Management, volume 986 of Lecture Notes in Computer Science, Kinross, Scotland, September 1995. Springer-Verlag.

[YUS] Ken Wakita Yuji Uchiyama and Masataka Sassa. Modular integration of memory management in programming language system. http://www.is.titech.ac.jp/ 〜wakita/lab/papers/cc2002.pdf, Submitted for publication.

[Zor89] Benjamin G. Zorn. Comparative Performance Evaluation of Garbage Collection Algorithms. PhD thesis, University of California, Berkeley, March 1989. 